Aus der Arbeitsgruppe Cellular Neuroscience

(Prof. Dr. M. Simons)

des Max-Planck-Instituts für Experimentelle

Medizin in Göttingen

\title{
Die Rolle der $\beta$-Sekretase bei der Myelinisierung im Zentralen Nervensystem
}

\author{
INAUGURAL - DISSERTATION \\ zur Erlangung des Doktorgrades \\ der Medizinischen Fakultät \\ der Georg-August-Universität zu Göttingen
}

vorgelegt von

Hannes Frederik Treiber

aus Heidelberg

Göttingen 2013 
Dekan: Prof. Dr. rer. nat. H. K. Kroemer

I. Berichterstatter: Prof. Dr. med. M. Simons

II. Berichterstatter: Prof. Dr. rer. nat. Th. Bayer

III. Berichterstatterin: Prof. Dr. rer. nat. P. Virsik-Köpp

Tag der mündlichen Prüfung: 23.04.2014 


\section{Inhaltsverzeichnis}

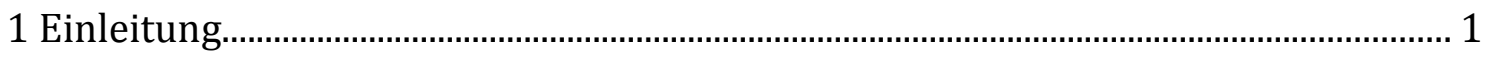

1.1 Überblick Demenz...................................................................................................... 1

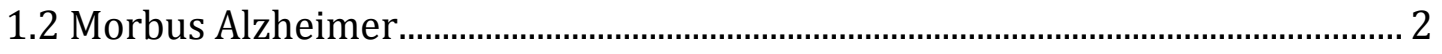

1.3 Histopathologie der Alzheimer-Demenz: Amyloid-Plaques aus A $\beta$ und neurofibrilläre Tangles aus hyperphosphoryliertem Tau...................................... 6

1.4 Schlüsselenzym der A $\beta$-Synthese: BACE1, die $\beta$-Sekretase...................................11

1.5 Physiologische Funktion von BACE1 ....................................................................... 14

1.6 Myelin: Struktur und Funktion.............................................................................. 14

1.7 Die Rolle von BACE1 in der Myelinisierung............................................................ 17

1.8 De- und Remyelinisierung im Tiermodell................................................................... 21

1.9 Fragestellung und Zielsetzung der Arbeit................................................................24

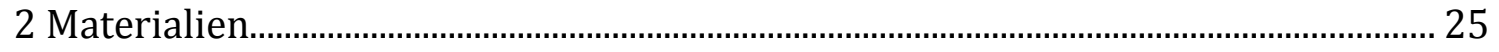

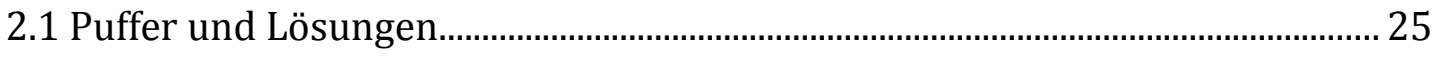

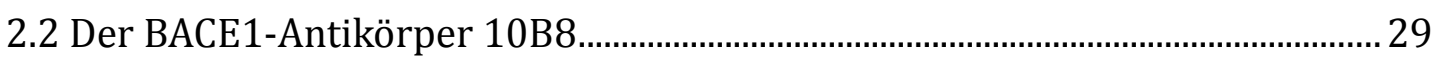

2.3 Weitere verwendete Antikörper................................................................................ 30

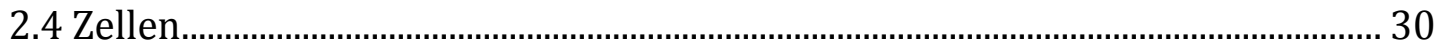

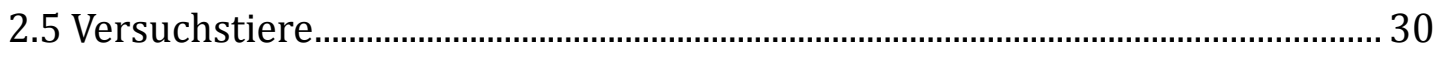

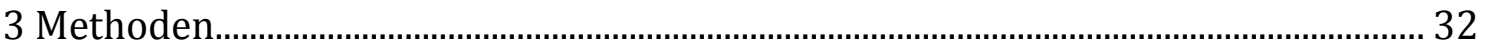

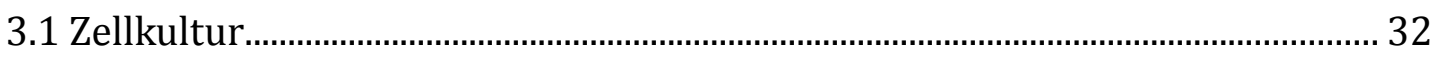

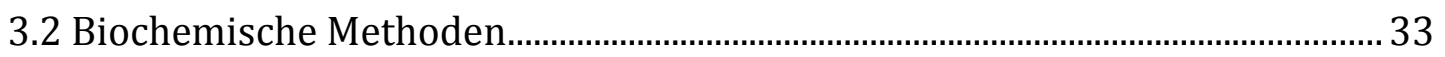

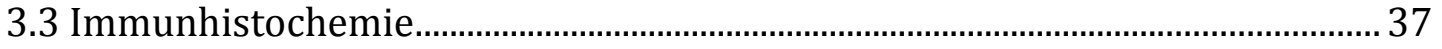

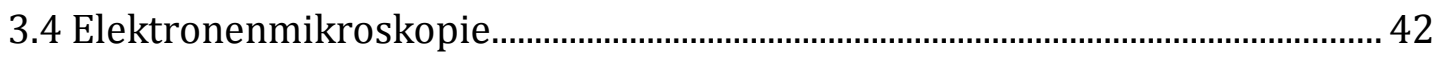

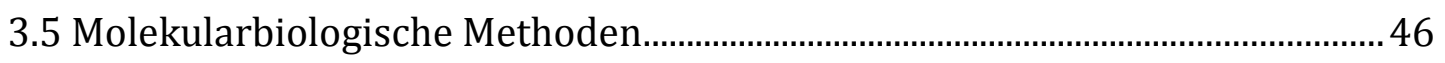

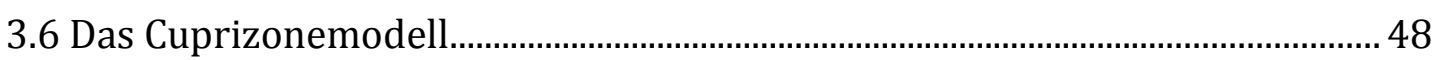

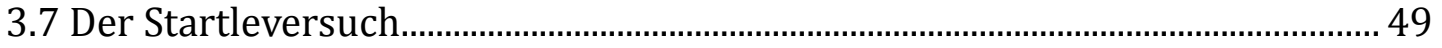

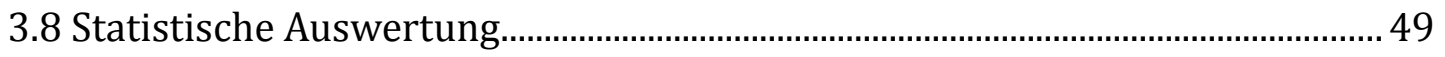

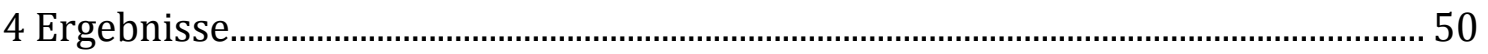

4.1 Die BACE1-Expression in Modellen der Demyelinisierung.................................50

4.2 Der BACE1-Antikörper 10B8 in der Immunfluoreszenz......................................56

4.3 Die Remyelinisierung im ZNS von BACE1-ko-Mäusen nach

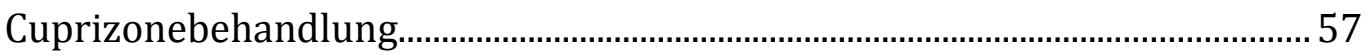




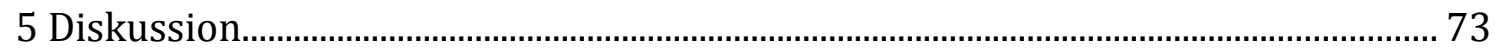

5.1 Die BACE1-Expression in Modellen der Demyelinisierung..................................73

5.2 Das Cuprizonemodell in BACE1-ko-Mäusen..........................................................76

5.3 BACE1 wird in allen Zelltypen des Gehirns exprimiert.........................................83

5.4 Der Einfluss von Inflammation auf die BACE1-Expression....................................86

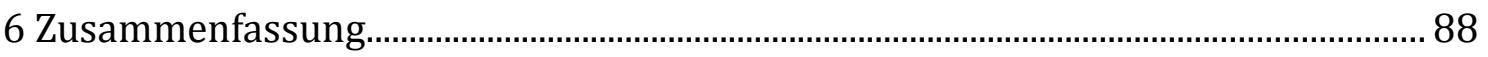

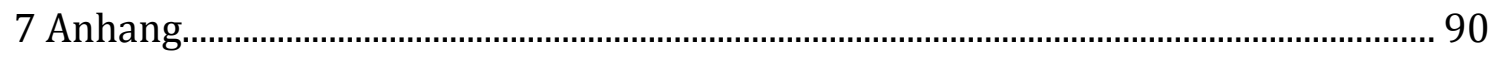

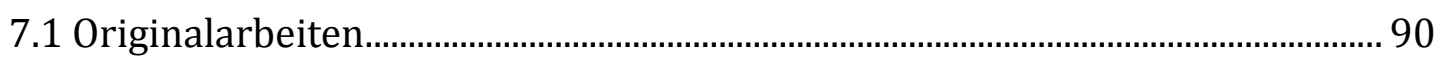

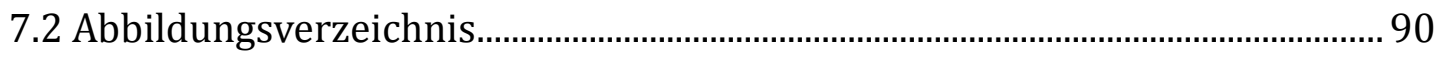

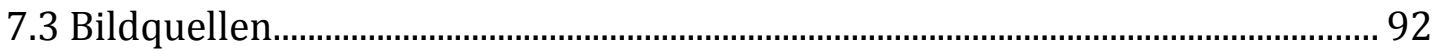

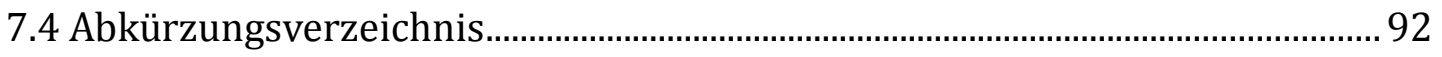

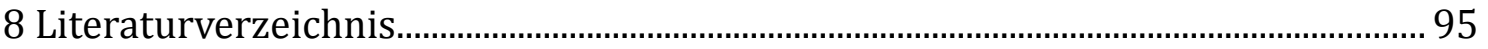




\section{Einleitung}

\section{1 Überblick Demenz}

Die Demenz ist eines der häufigsten psychiatrisch-neurologischen Syndrome. Umgangssprachlich versteht man darunter zumeist das Nachlassen der Gedächtnisleistung. Gerade im Alter wurde in der Vergangenheit ein gewisses Maß an Desorientierung und Verwirrtheit als normal dargestellt und akzeptiert. Heute jedoch kann man die Demenz als durch spezifische Erkrankungen des Gehirns verursacht erfassen und verschiedene Formen voneinander abgrenzen. So ist das schwindende Gedächtnis zwar weiterhin ein Hauptmerkmal der Demenz, aber bei Weitem nicht das einzige. Auch weitere kognitive Funktionen wie das Denk- oder das Planungsvermögen können abnehmen. Ferner kann es zu Störungen der Impulskontrolle und des Affektes kommen. Das Sozialverhalten kann ebenfalls betroffen sein. Solche Symptome können jedoch auch im Rahmen anderer Erkrankungen, etwa eines Delirs oder einer Depression, auftreten. Um von einem demenziellen Syndrom zu sprechen, müssen Gedächtnisstörung und Abnahme der kognitiven Leistungen daher für mehr als sechs Monate bestehen (Dilling und Freyberger 2012). Diese Kriterien werden in der Internationalen statistischen Klassifikation der Krankheiten und verwandten Gesundheitsprobleme (ICD-10) der Weltgesundheitsorganisation formuliert und sind heute in der klinischen Praxis und in der Wissenschaft anerkannt. Auch die „Leitlinie Demenz“ der Deutschen Gesellschaft für Psychiatrie, Psychotherapie und Nervenheilkunde und der Deutschen Gesellschaft für Neurolo-

gie basiert auf dieser Definition (Diener 2012). In den Vereinigten Staaten von Amerika ist die Definition nach dem Diagnostic and Statistical Manual of Mental Disorders (DSM-IV) verbreitet. Wie in der ICD-10 werden darin ebenfalls weitere Merkmale der Demenz neben der Gedächtnisstörung genannt, auch eine Abgrenzung von ähnlich imponierenden Bewusstseinsstörungen wie dem Delir wird gefordert. Betont wird darin jedoch besonders die Einschränkung der sozialen und 
beruflichen Fähigkeiten (Frances und Ross 2001) - einer der wesentlichen Gründe, weshalb die Demenz von Betroffenen und Angehörigen so gefürchtet wird. Durch ihren auch heute noch oft unaufhaltsam fortschreitenden Verlauf, der bis hin zur Pflegebedürftigkeit und völligen Abhängigkeit von Dritten führen kann, stellt sie eine große Belastung für alle Beteiligten dar.

Auch sozioökonomisch haben Demenzerkrankungen durch ihre Häufigkeit und die mit ihnen verbundenen Einschränkungen einen hohen Stellenwert. Eine Studie aus dem Jahr 2005 (Ferri et al. 2005) ermittelte mittels des Delphi-Konsensusverfahrens weltweit etwa 24,3 Millionen Demenzkranke zum Zeitpunkt der Untersuchung und 4,3 Millionen Neuerkrankungen pro Jahr. Alle 20 Jahre verdoppele sich diese Anzahl; 81,1 Millionen Menschen seien 2040 betroffen. Aktuell leben bereits 60 \% der Erkrankten in Entwicklungsländern, eine Quote, die nach den Berechnungen noch weiter steigen wird. Die Demenz ist eine Erkrankung des alternden Menschen: Mit steigendem Lebensalter nimmt auch die Prävalenz der Demenz deutlich zu (Ferri et al. 2005). Die wirtschaftliche Belastung durch Demenzerkrankungen wird beim allgemeinen Trend zu immer höherem Lebensalter weiter zunehmen: In England betrugen die Ausgaben für die Langzeitbetreuung Demenzkranker 2002 etwa 0,6\% des Bruttoinlandsproduktes, nämlich 5,4 Milliarden Pfund. Projektionen für 2031 erwarten dort einen weiteren Anstieg der Ausgaben auf bis zu annähernd $1 \%$ des Bruttoinlandsproduktes (Comas-Herrera et al. 2011).

Heute unterscheidet man anhand der Ätiologie verschiedene Formen der Demenz. Als primäre Demenzerkrankungen werden in den aktuellen Leitlinien der Morbus Alzheimer (oder Alzheimer-Demenz, AD), die vaskuläre Demenz, die gemischte Demenz, die frontotemporale Demenz, die Demenz bei primärem Parkinson-Syndrom und die Demenz mit Lewy-Körperchen genannt (Diener 2012). Sekundäre Demenzen treten bei Schäden des Gehirns infolge von anderen Erkrankungen auf. Mit ungefähr 50-60 \% ist die AD für den Großteil der Demenzerkrankungen verantwortlich (Blennow et al. 2006).

\subsection{Morbus Alzheimer}

\subsubsection{Historischer Abriss}

Trotz ihrer immensen Häufigkeit ist die AD eine relativ junge Erkrankung. Zuerst beschrieben wurde sie von Alois Alzheimer, der 1906 auf einem Kongress in Tübin- 
gen Folgendes über eine Patientin berichtete, die in keine der damals geläufigen Diagnosen zu passen schien: Sie litt unter einer progredienten Gedächtnisstörung, zeigte Eifersüchteleien gegen ihren Ehemann, versteckte oder verlegte Gegenstände und vermutete zeitweise, dass man ihr nach dem Leben trachtete. Den Arzt hielt sie mal für einen Besucher, mal für einen ihr übelwollenden Mediziner, mal für jemanden, der sich ihr unsittlich nähere. Immer wieder verfiel sie in langdauernde Schreiattacken. Das sinnvolle Lesen war ihr nicht mehr möglich, ihr vorgelegte Gegenstände

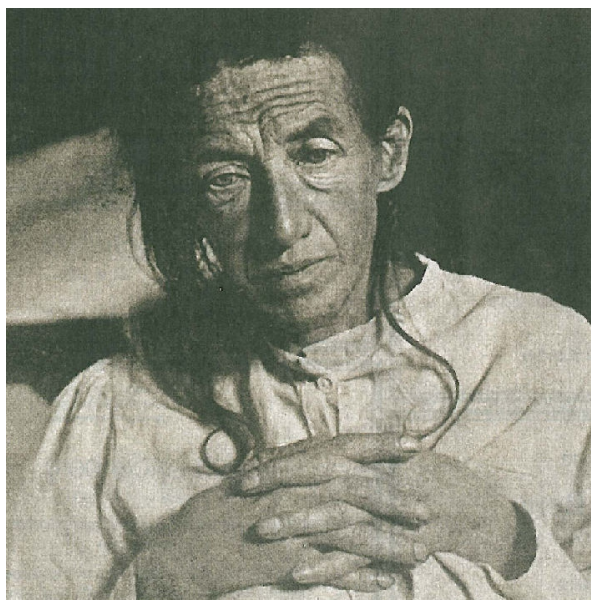

Abbildung 1.1: Auguste Deter, der erste berichtete Fall einer Alzheimer-Demenz (aus Wikimedia commons) konnten nicht konstant korrekt benannt oder sinnvoll verwendet werden. Sie paraphrasierte. In scharfem Kontrast zu diesen ausgeprägten kognitiven Einschränkungen stand der körperliche Befund, der nach heutigen Maßstäben altersentsprechend war. Viereinhalb Jahre später verstarb die Patientin im Alter von 55 Jahren, zuletzt war sie völlig antriebslos (Alzheimer 1907). Ihr Name war Auguste Deter (Cipriani et al. 2011).

Der Fall war deshalb so bedeutend, weil Alzheimer nicht nur die Symptome beschrieb, sondern nach ihrem Tod zusätzlich das Gehirn makro- und mikroskopisch untersuchte. Alzheimer beschrieb ein „gleichmäßig atrophiertes Gehirn ohne makroskopische Herde" (Alzheimer 1907). In der Histologie fand er mittels der bis heute verwendeten Silberimprägnierung nach Bielschowsky (Bielschowsky 1902) Veränderungen der intrazellulären Neurofibrillen, die er auch in untergehenden Neuronen nachweisen konnte und die offensichtlich diesen Zelltod überdauerten. Zusätzlich beschrieb er zahlreiche im Kortex gelegene Herde, die bereits ohne Färbung zu erkennen seien. Damit referierte Alzheimer einen exemplarischen klinischen Fall und die Pathologie, die bis heute als Kennzeichen der AD anerkannt wird. Eine erneute Untersuchung des Falles und der wiederentdeckten Proben im Jahr 1999 bestätigte, dass auch nach aktuellen Maßstäben die Diagnose AD korrekt gewesen wäre (Graeber und Mehraein 1999). Somit zeigte bereits der erste Bericht über die Erkrankung anschaulich eine mögliche Klinik und deren Verlauf. 


\subsubsection{Diagnosestellung}

Zur Diagnose werden heute gerade in der Wissenschaft die Kriterien des National Institute of Neurological Disorders and Stroke und der Alzheimer's Disease and Related Disorders Association (NINCDS-ADRDA) verwendet. Diese sind gegenüber der ICD-10 detaillierter und ermöglichen so eine bessere Abgrenzung zu Gesunden oder andersartig Erkrankten. Sie erschienen erstmals 1984 als Reaktion auf die Tatsache, dass bei jeder fünften klinischen Diagnose in der Autopsie andere Krankheiten als ursächlich erkannt wurden (McKhann et al. 1984) und erfuhren 2011 eine Anpassung an den aktuellen Stand der Wissenschaft (McKhann et al. 2011). In den NINCDS-ADRDA-Kriterien wird zwischen wahrscheinlicher, möglicher und definitiver AD unterschieden. Wichtig ist, dass analog zur Definition der Demenz als Syndrom im ICD-10 hier die AD als primär klinische Diagnose aufgefasst wird, die durch apparative Befunde nur unterstützt werden kann. Nur für die Diagnose einer definitiven $\mathrm{AD}$ werden histopathologische Untersuchungen gefordert. Als eine einfache Möglichkeit, die Demenz zu quantifizieren, wird hier etwa der Mini Mental Status Test (MMST; Folstein et al. 1975) vorgeschlagen. In den deutschen DemenzLeitlinen von 2012 findet sich dieser Test zur Einschätzung des Schweregrades wieder. Unterteilt werden leichte, moderate oder mittelschwere sowie schwere AD. Werden im MMST alle Fragen korrekt beantwortet, entspricht dies der Höchstpunktzahl von 30. Bei 26 bis 20 erreichten Punkten liegt eine leichte, bei 19 bis 10 eine moderate und bei weniger als 10 schließlich eine schwere AD vor. Diese Einteilung ist eine wichtige Richtschnur bei der Festlegung der Therapie.

\subsubsection{Aktueller Stand der Therapie}

Für die AD stehen eine Reihe von unterstützenden Verfahren zur Verfügung, die in der Demenz-Leitlinie von 2012 empfohlen werden. Diese werden als psychosoziale Interventionen zusammengefasst und beinhalten etwa die Ergotherapie, die Musiktherapie und Strukturierung von Tagesaktivitäten. Auch Begleiterscheinungen der AD wie Angst, Agitiertheit, Depression oder Schlafstörungen können auf vielfältige Weise behandelt werden. Die etablierte Pharmakotherapie der AD selbst ist jedoch bei Weitem nicht so vielgestaltig. Zum Einsatz kommt entweder Memantin, ein NMDA-Rezeptor-Antagonist, oder eine Substanz aus der Gruppe der zentralen Acetylcholinesteraseinhibitoren. Den Medikamenten ist gemein, dass sie weder eine Heilung bieten noch das Fortschreiten der Erkrankung verhindern können. Daher 
wird beständig nach neuen pharmakologischen Angriffspunkten auf der Basis des immer tiefer reichenden Verständnisses der Pathophysiologie der AD gesucht.

\subsubsection{Genetik}

Anhand des Alters der Patienten werden früh und spät beginnende AD unterschieden. Als Unterscheidungspunkt wurde das Lebensalter von 65 Jahren definiert. Vom Standpunkt der Genetik jedoch werden sporadische und familiäre AD unterschieden. Beide Formen bezeichnen jeweils dieselbe Krankheit, die in Verlauf und Schwere unterschiedlich verlaufen kann. Die familiäre AD (FAD) ist besonders häufig bei Patienten mit früh beginnender AD zu finden (Cruts et al. 1998). Die überwiegende Anzahl der AD-Patienten leidet jedoch an der sporadischen Form. Weniger als 0,1 \% der Fälle können der FAD zugerechnet werden (Harvey et al. 2003). Sie wird in einem autosomal-dominanten Modus vererbt. Aktuell sind drei Gene bekannt, die AD auslösen können. Dabei handelt es sich um das Amyloid-VorläuferProtein (Amyloid-Precursor-Protein, APP) sowie Presenilin 1 und 2 (PSEN1 und PSEN2). Diese Gene beeinflussen sämtlich den Amyloid-Stoffwechsel im Gehirn. APP war das erste Gen, das man mit der FAD in Verbindung bringen konnte (Goate et al. 1991). Es liegt auf Chromosom 21, was erklärt, warum Patienten mit Trisomie 21 häufiger unter AD leiden: Es handelt sich um einen Gendosiseffekt (Podlisny et al. 1987). Deutliche Unterstützung bekam diese Hypothese durch den Fall einer Patientin, die aufgrund einer partiellen Trisomie 21 unter dem Down-Syndrom litt, jedoch nur zwei Kopien des APP-Gens besaß. Neuropsychologisch, kernspintomografisch und neuropathologisch ließ sich bei ihr im hohem Alter keine AD nachweisen (Prasher et al. 1998). Presenilin wurde erst später entdeckt, ist jedoch als Ursache der FAD insgesamt häufiger (Lleó et al. 2002; Janssen et al. 2003). PSEN1 liegt auf Chromosom 14 (Sherrington et al. 1995), PSEN2 auf Chromosom 1 (LevyLahad et al. 1995).

Auch bei der sporadischen AD (SAD) gibt es genetische Faktoren, die bisher nur zum Teil verstanden werden. Ein deutlicher Beleg dafür ist jedoch der Umstand, dass das Ausmaß der Erblichkeit von AD in einer großen Studie an Zwillingen beinahe 80 \% betrug (Gatz et al. 2006). Sowohl Männer als auch Frauen waren betroffen. Am häufigsten verantwortlich dafür ist mit großer Wahrscheinlichkeit das Apolipoprotein-E-(ApoE)- $\varepsilon 4-A l l e l$ (Raber et al. 2004). Die Assoziation zwischen ApoE-ع4 und AD wurde 1993 zuerst beschrieben (Corder et al. 1993; Poirier et al. 1993). Es handelt sich um einen Gendosiseffekt, wobei eine erhöhte Allelanzahl mit 
einem jüngeren Erkrankungsalter einhergeht: Im Schnitt verringert jede Allelkopie das Erkrankungsalter um etwa zehn Jahre (Poirier et al. 1993). Metaanalysen ergaben für heterozygote Anlageträger ein dreifach erhöhtes Risiko, an AD zu erkranken, für homozygote Träger sogar ein fünfzehnfaches (Farrer et al. 1997). Es wurde nach weiteren Risikogenen gesucht, jedoch konnte bisher keines mit einer ähnlichen Bedeutung wie ApoE gefunden werden (Blomqvist et al. 2006).

\subsection{Histopathologie der Alzheimer-Demenz: Amyloid-Plaques aus $A \beta$ und neurofibrilläre Tangles aus hyperphosphoryliertem Tau}

Schon in seinem ursprünglichen Fallbericht beschrieb Alzheimer zwei histopathologische Veränderungen des Gehirns: veränderte Neurofibrillen und viele kortikal gelegene Herde. Diese beiden Befunde charakterisieren bis heute die AlzheimerErkrankung und grenzen sie von allen anderen Demenzformen ab (Robles 2009). In aktueller Terminologie spricht man von senilen Plaques und neurofibrillären Tangles (Bündeln).

\subsubsection{Neurofibrilläre Tangles, das Tau-Protein und die Tauopathien}

Erst 1986 konnte die Zusammensetzung der lange bekannten neurofibrillären Tangles aufgeklärt werden. Sie setzen sich aus Tau zusammen (Grundke-Iqbal et al. 1986; Nukina und Ihara 1986), einem Protein, das physiologischerweise in den Axonen der Neurone des ZNS vorkommt. Dort bindet es an Tubulin und erleichtert damit die Polymerisierung der Tubulin-Dimere zu stabilen Mikrotubuli (Weingarten et al. 1975). Diese Aufgabe wird jedoch nicht ausschließlich von Tau übernommen, wie auch der Befund, dass Mäuse, die, quasi als Maximalform der Inhibition, kein Tau mehr exprimieren (sogenanntes „knock-out”, im Folgenden: ko), ein immunhistologisch im Wesentlichen unbeeinträchtigtes ZNS besitzen, nahelegt (Harada et al. 1994). Vielmehr gibt es eine ganze Reihe weiterer sogenannter Mikrotubuli-assoziierter Proteine (MAP), die ähnliche Aufgaben erfüllen (Borisy et al. 1975; Bloom et al. 1984). Tau wird im Rahmen dieser Nomenklatur wie sein Genlokus auch als Mikrotubuli-assoziiertes Protein Tau (MAP-T) bezeichnet (Goedert et al. 1988). Durch alternatives Spleißen entstehen mehrere Isoformen (Goedert et al. 1989). Tau kann an einer Vielzahl von Serin- und Threoninresten phosphoryliert 
werden (Billingsley und Kincaid 1997). Diese Phosphorylierung wird durch eine Reihe von Kinasen reguliert. In der Ontogenese ändert sich dabei das Ausmaß der Phosphorylierung: Mit steigendem Alter werden alle Tau-Isoformen weniger stark phosphoryliert (Kanemaru et al. 1992; Mawal-Dewan et al. 1994). Eine der für die Phosphorylierung verantwortlichen Kinasen ist die Proteinkinase N (PKN; Mukai et al. 1994; Mukai und Ono 1994). Durch diese Phosphorylierung kann Tau schlechter an Mikrotubli binden. So kommt es zu einer Störung des Mikrotubuliaufbaus (Taniguchi et al. 2001).

Bei der $\mathrm{AD}$ als bedeutender Erkrankung mit Auftreten von neurofibrillären Tangles wird Tau nicht de-, sondern hyperphosphoryliert. Dadurch lagert es sich $\mathrm{zu}$ paarigen schraubenförmigen Filamenten zusammen (paired helical filaments, PHF). Aus diesen wiederum setzen sich die neurofibrillären Tangles zusammen (Grundke-Iqbal et al. 1986; Nukina und Ihara 1986). Dieser Befund korreliert mit der Beobachtung, dass PKN mit den neurofibrillären Tangles kolokalisiert ist (Kawamata et al. 1998). Die Ausbreitung der neurofibrillären Veränderungen im
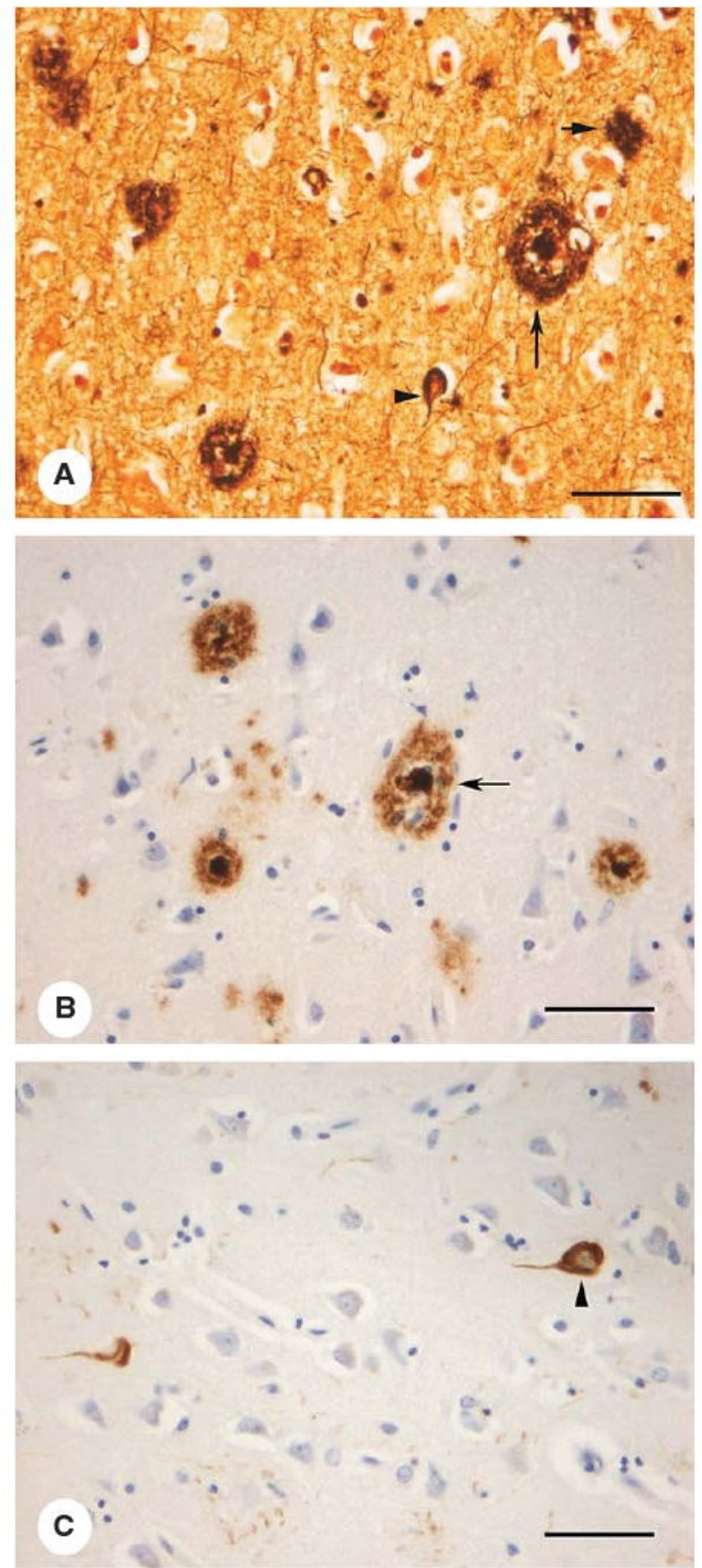

Abbildung 1.2: AD-Pathologie in Gehirnschnitten des Neokortex (aus Purohit et al. 2011). In der modifizierten Bielschwosky-Silberimprägnation (A) kommen senile Plaques (großer Pfeil) und neurofibrilläre Tangles (kleiner Pfeil) zur Darstellung. (B) und (C) zeigen immunohistochemische Nachweise der senilen Plaques und neurofibrillären Tangles. Maßeinheit $=150 \mu \mathrm{m}$

Gehirn von AD-Patienten wurde in einer großen topologischen Studie beschrieben (Braak und Braak 1991). Dabei ließ sich eine stadienhafte Ausbreitung von trans- 
entorhinal - die Übergangszone vom entorhinalen Kortex zum angrenzenden temporalen Kortex - über das limbische System bis auf den gesamten durch sechs histologische Schichten gebildeten Isokortex nachweisen (Braak und Braak 1991).

Zusammenfassend lässt sich feststellen, dass ein Fehlen von Tau anscheinend gut kompensiert werden kann, während Fehler im Aufbau von Tau-Proteinen bei Weitem nicht so problemlos toleriert werden. So spielt verändertes Tau nicht nur bei der AD, sondern bei einer Reihe von weiteren Krankheiten eine entscheidende Rolle. Diese fasst man unter dem Oberbegriff der Tauopathien zusammen (Iqbal et al. 2010). Zu dieser großen Gruppe von Erkrankungen gehören etwa die sporadische kortikobasale Degeneration, die progressive supranukleäre Blickparese (progressive supranuclear palsy, PSP), der Morbus Pick sowie die erbliche frontotemporale Demenz mit Parkinsonismus des Chromosoms 17 (FTDP-17; Lee et al. 2001).

\subsubsection{Senile Plaques und Amyloid}

Senile Plaques sind die für die AD charakteristische Läsion des Gehirns. Zuerst beschrieben wurden sie im ausgehenden 19. Jahrhundert von Blocq und Marinesco (Blocq und Marinesco 1892). Typischerweise findet man sie im Kortex, besonders im Isokortex (Braak und Braak 1991). Zunächst lassen sich Ablagerungen in den basalen Anteilen des Isokortex finden (Braak-Stadium A), die dann auf den Assoziationskortex übergreifen (Braak-Stadium B). Im Braak-Stadium C ist schließlich auch der primäre motorische und sensorische Kortex betroffen (Braak und Braak 1991). Sie sind jedoch nicht spezifisch für die Erkrankung; vielmehr treten sie auch bei klinisch gesunden Probanden auf (Blessed et al. 1968). Doch die Anzahl der Plaques korreliert mit dem Ausmaß der Demenz (Blessed et al. 1968). Dies legt nahe, dass sie in der Pathogenese der AD eine Schlüsselrolle spielen. Daher war die Aufreinigung und Sequenzierung des Hauptbestandteils der Plaques, A $\beta$ (zunächst aufgrund seines Molekulargewichts von $4 \mathrm{kDa}$ A4 genannt), ein großer Fortschritt für die Alzheimer-Forschung (Masters et al. 1985). Kurz zuvor war diese Sequenzierung auch aus zerebrovaskulären Amyloid-Ablagerungen gelungen, die ebenfalls für die $\mathrm{AD}$ typisch sind (Glenner und Wong 1984). A $\beta$ entsprach keinem damals bekannten Protein. Der nun mögliche Abgleich mit Bibliotheken komplementärer DNA (deoxyribonucleic acid) erlaubte jedoch, das APP-Gen als Vorläufer zu identifizieren (Kang et al. 1987; Tanzi et al. 1987). Es folgte die Beobachtung, dass die Produktion von $A \beta$ keineswegs ein Krankheitszeichen ist, sondern auch unter physiologischen Bedingungen stattfindet (Haass et al. 1992). Damit erschienen immense 
Möglichkeiten für die Therapie der AD denkbar. Wäre es möglich, die Synthese von $\mathrm{A} \beta \mathrm{zu}$ kontrollieren, könnte man vielleicht dem Fortschreiten der AD Einhalt gebieten oder sogar Neuerkrankungen verhindern. Dazu war es erforderlich, den Mechanismus der $\mathrm{A} \beta$-Synthese näher zu charakterisieren.

\subsubsection{Herkunft von Amyloid: Metabolismus von APP und A $\beta$-Synthese}

Der Ausgangsstoff der Amyloidablagerungen, das APP, war bereits bekannt, und auch ihr Hauptbestandteil, $A \beta$, war im Detail analysiert worden. $A \beta$ ist ein Proteinfragment, das aus APP freigesetzt wird. A $\beta$ ist ein zentrales Peptid von APP. Folglich müssen für seine Bildung zwei Spaltungen notwendig sein. Möglicherweise sind also zwei Enzyme gemeinsam für die Entstehung von $A \beta$ verantwortlich. Die postulierten Enzyme wurden als $\beta$ - und $\gamma$-Sekretase bezeichnet. Die Eigenschaften der postulierten Sekretasen konnten teilweise aufgrund der bekannten Daten vorhergesagt werden, für die $\beta$-Sekretase etwa anhand möglicher Substratcharakteristika (Citron et al. 1995). So war es möglich, ein gutes Bild des Amyloid-Stoffwechsels zu zeichnen. In dessen Zentrum steht APP als Ausgangsstoff, der auf zwei Arten prozessiert werden kann: amyloidogen oder nicht-amyloidogen. Nur beim amyloidogenen Stoffwechselweg kommt es zur Bildung von $A \beta$, während am Ende des nichtamyloidogenen Stoffwechsels Produkte ohne Aggregierungstendenz entstehen. Amyloidogener Stoffwechsel konnte in Neuronen des Hippokampus von Ratten nachgewiesen werden, die humanes APP exprimieren (Simons et al. 1996). Neurone sind besonders von der AD betroffen (Simons et al. 1996).

APP ist ein großes Transmembranprotein, das durch alternatives Spleißen in mehreren Isoformen vorliegt. Diese werden nach Anzahl der Aminosäuren bezeichnet (Überblick in Sandbrink et al. 1994). Der Großteil des Proteins ist extrazellulär, das kurze carboxyterminale Ende intrazellulär lokalisiert. Die A $\beta$-Sequenz umfasst einen Teil der Transmembran- sowie einen Teil der extrazellulären Domäne. Im amyloidogenen Stoffwechsel wird zuerst durch die $\beta$-Sekretase das extrazelluläre aminoterminale Ende abgespalten. Das entstehende Fragment bezeichnet man als lösliches APP- $\beta$ (soluble APP- $\beta$, sAPP- $\beta$ ). Der membrangebundene Rest besteht aus 99 Aminosäuren und wird daher C99 genannt. Er kann nun von der $\gamma$ Sekretase gespalten werden. Dies führt zur Freisetzung des problematischen A $\beta$ Peptids. Ein kleiner intrazellulärer Rest bleibt zurück, die intrazelluläre Domäne von APP (APP intracelullar domain, AICD). Beim nicht-amyloidogenen Stoffwechsel hingegen wird APP direkt durch die $\alpha$-Sekretase gespalten. Die Schnittstelle liegt 


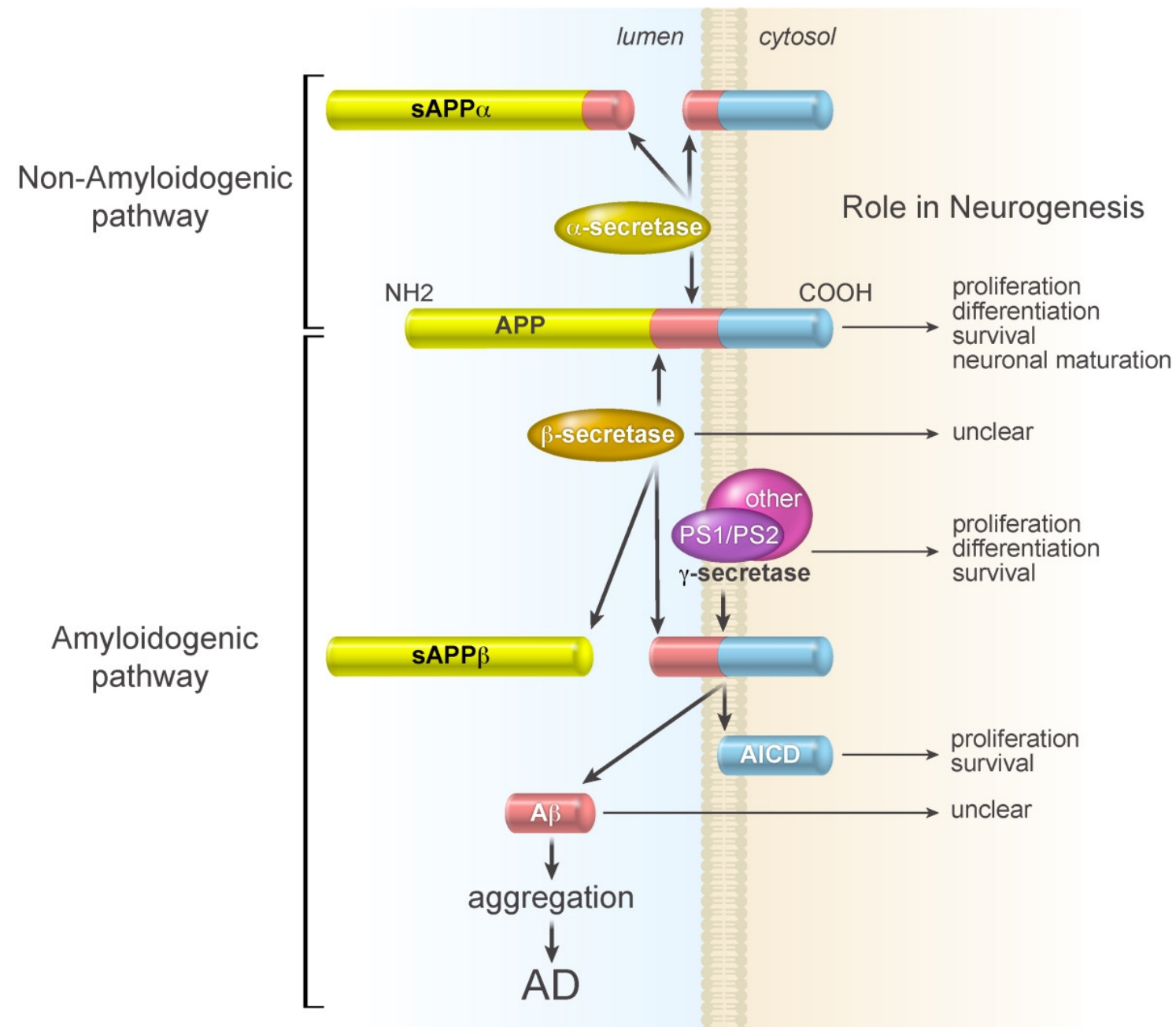

Abbildung 1.3: Stoffwechsel des Amyloid-Precursor-Proteins (aus Mu und Gage 2011). Im nicht-amyloidogenen Stoffwechsel verhindert die $\alpha$-Sekretase das Entstehen von A $\beta$. Im amyloidogenen Stoffwechsel entsteht dieses durch sequenzielle Spaltung von APP durch die $\beta$ - und die $\gamma$-Sekretase. A $\beta$ aggregiert zu Amyloid-Ablagerungen, die typisch für die AD sind. PS1/PS2 = Presenilin 1/Presenilin 2.

zentral in der $A \beta$-Sequenz, wodurch dessen Bildung verhindert wird. Es entsteht lösliches APP- $\alpha$ (soluble APP- $\alpha$, sAPP- $\alpha$ ) und ein kürzeres membrangebundenes Fragment, genannt C83. Die Schnittstelle der $\gamma$-Sekretase ist noch intakt. Sie spaltet ein kurzes extrazelluläres Peptid ab, genannt p3. Die entstehende AICD wird intrazellulär weiter metabolisiert. Der Stoffwechsel von APP hin zur Entstehung von A $\beta$ ist essenzielle Grundlage des heutigen Verständnisses der Pathophysiologie der AD. Eine ausführliche Übersicht findet sich in Blennow et al. 2006; Cole und Vassar 2008; Zhang et al. 2012.

Es gelang schließlich mehreren Gruppen, in kurzer Folge zwei Enzyme zu identifizieren, welche Eigenschaften der vorhergesagten $\beta$-Sekretase zeigten. Zuerst be- 
schrieben wurde das $\beta$-site APP-cleaving enzyme 1, BACE1 (Hussain et al. 1999; Saunders et al. 1999; Sinha et al. 1999; Vassar et al. 1999; Yan et al. 1999; Lin et al. 2000). Kurz darauf wurde ein homologes Protein beschrieben, welches ebenfalls APP an der fraglichen Stelle schnitt: BACE2 (Saunders et al. 1999; Acquati et al. 2000; Bennett et al. 2000a; Hussain et al. 2000; Solans et al. 2000).

Auch die Suche nach der $\gamma$-Sekretase war erfolgreich. Es konnte gezeigt werden, dass sie entweder mit PSEN1 identisch ist oder zumindest von PSEN1 als Kofaktor abhängt (De Strooper 1998). Damit konnte mechanistisch erklärt werden, wie $\mathrm{Mu}$ tationen in PSEN1 zu FAD (Sherrington et al. 1995) führen: Es handelt sich um gain-of-function-Mutationen (De Strooper et al. 1998). Heute ist klar, dass die $\gamma$ Sekretase ein Komplex aus mehreren Proteinen ist. Das aktive Zentrum wird durch PSEN1 oder PSEN2 gebildet (Wolfe 2012). Damit würde sie ein attraktives Ziel für die Pharmakotherapie der AD darstellen. Während es bei der $\beta$-Sekretase eine große Herausforderung ist, Inhibitoren zu entwickeln, die klein genug sind, um die Blut-Hirn-Schranke zu überwinden, gelang dies im Falle der $\gamma$-Sekretase (Hardy und Selkoe 2002). Doch es zeigte sich, dass PSEN1 für die Funktion des notchSignalwegs unverzichtbar ist und eine Inhibierung mit schweren Nebenwirkungen wie Immunschwäche und Anämie einhergehen könnte (De Strooper et al. 1999). Daraufhin wurde ein $\gamma$-Sekretase-Inhibitor beschrieben, der nicht mit der Prozessierung von notch interagiert, aber die Produktion von $A \beta$ verhindert (Petit et al. 2001). Entgegen des initial berichteten Erfolges konnte später jedoch gezeigt werden, dass diese Inhibitoren die $\gamma$-Sekretase nicht direkt beeinflussen (Esler et al. 2002). Aktuell sind keine Substanzen verfügbar oder offiziell in Entwicklung, die einerseits die $A \beta$-Produktion verhindern und andererseits keine oder nur geringe Nebenwirkungen durch Inhibierung des notch-Signalweges aufweisen (Wolfe 2012). Damit ist die $\gamma$-Sekretase als pharmakologisches Ziel in den Hintergrund gerückt. Da BACE1 mutmaßlich das geschwindigkeitsbestimmende Enzym im amyloidogenen Stoffwechsel ist (Cole und Vassar 2008), bleibt die Inhibition der $\beta$-Sekretase folglich weiterhin ein wichtiges Ziel der AD-Forschung, um direkt die Entstehung von $A \beta$ zu verhindern.

\subsection{Schlüsselenzym der Aß-Synthese: BACE1, die $\beta$-Sekretase}

Seit ihrer Postulierung ist die $\beta$-Sekretase Gegenstand zahlloser Untersuchungen gewesen. Heute geht man davon aus, das BACE1 tatsächlich die gesuchte $\beta$-Sekreta- 
se ist. Einen exzellenten Überblick über die Vorhersagen zur $\beta$-Sekretase und deren Abgleich mit den Eigenschaften von BACE1 liefern Kandalepas und Vassar 2012. Im Folgenden soll die Biologie von BACE1 näher beschrieben werden. Die Protease BACE1 konnte zuerst 1999 kloniert werden. Ihre Überexpression ging mit einer erhöhten Anzahl der fraglichen APP-Spaltprodukte einher (Sinha et al. 1999; Vassar et al. 1999). Die schwedische Mutation von APP, ein bekannter Auslöser der FAD, der mit einer erhöhten A $\beta$-Produktion einhergeht (Citron et al. 1992; Mullan et al. 1992), wird von BACE1 deutlich besser gespalten als der Wildtyp: Von einer zehn(Yan et al. 1999) bis sogar einer sechzigfachen (Lin et al. 2000) Erhöhung der katalytischen Effizienz wurde berichtet. Demgegenüber verhinderte eine Mutation im aktiven Zentrum von BACE1 die Entstehung von A $\beta$ (Hussain et al. 1999).

Das Gen von BACE1 liegt auf Chromosom 11q23.3 (Saunders et al. 1999). Das ursprüngliche BACE1-Protein besteht aus 501 Aminosäuren. Aminoterminal beginnt es mit einem 21 Aminosäuren langen Signalpeptid, gefolgt von einem Propeptid von 24 Aminosäuren Länge. Das eigentliche luminale Ende erstreckt sich von Aminosäure 46 bis 460, der sich eine Transmembrandomäne von 17 Aminosäuren anschließt. Das kurze intrazelluläre carboxyterminale Ende wird von 24 Aminosäuren gebildet (Vassar et al. 1999). In der Sequenz finden sich zwei Motive aktiver Zentren an den Aminosäuren 93-96 und 289-292. Beide enthalten das hochkonservierte Muster D T/S G T/S, welches Aspartatproteasen charakterisiert (Vassar et al. 1999). Zusammengefasst handelt es sich bei BACE1 also um ein Transmembranprotein vom Typ 1 mit einer einzelnen Transmembrandomäne, das zwei extrazellulär gelegene aktive Zentren besitzt (Vassar et al. 1999). BACE1mRNA wird in den meisten Geweben gering exprimiert, nur in Pankreas und Gehirn fanden sich größere Mengen (Vassar et al. 1999). Mittels In-situ-Hybridisierung konnte die mRNA in Gehirnschnitten von Mäusen insbesondere in Hippokampus, Kortex und Zerebellum nachgewiesen werden. Auf zellulärer Ebene wurde die Expression vor allem in Neuronen festgestellt, während sie in Gliazellen gering war (Vassar et al. 1999). BACE1 lässt sich mittels Immunopräzipitation als etwa 70 kDa großes Protein nachweisen. Erwartet wurde eine Größe von 51 kDa. Dieser Unterschied kommt durch Glykosilierung von Asparaginsäure (N-Glykosilierung) zustande (Vassar et al. 1999). BACE1 ist in der Zelle in den Kompartimenten des sekretorischen Stoffwechsels vorhanden, darunter im Golgi-Apparat, im TransGolgi-Netzwerk, in sekretorischen Vesikeln und in Endosomen (Vassar et al. 1999). Auf seinem Weg durch den Golgi-Apparat wird durch Furin und andere Konvertasen nach der charakteristischen Sequenz RLPR das Propeptid abgespalten. Eine 


\section{BACE}

signal peptide cleavage site

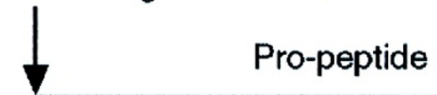

1 MAQALPWLLLWMGAGVLPAHGTQHGIRLPLRSGLGGAPLGLRLPRETDEE

51 PEEPGRRGSFVEMVDNLRGKSGQGYYVEMTVGSPPQTLNILVDTGSSNEA

101 VGAAPHPFLHRYYQRQLSSTYRDLRKGVYVPYTQGKWEGELGTDLVS I PH

151 GPNVTVRANIAAITESDKFFIN $\stackrel{\star}{*}$ GSNWEGILGLAYAEIARPDDSLEPFFDS

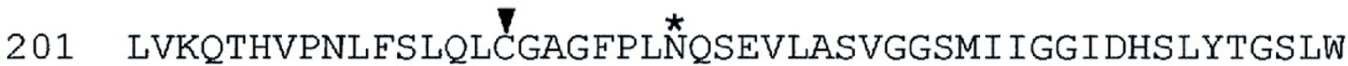

251 YTPIRREWYYEVI IVRVE INGQDLKMDCKEYNYDKS IVDSGTTNLRLPKK

301 VFEAAVKSIKAASSTEKFPDGFWLGEQLVCWQAGTTPWNI FPVISLYLMG

351 EVTNّ̂QSFRITILPQQYLRPVEDVATSQDDCYKFAISQSSTGTVMGAVIME

401 GFYVVFDRARKRIGFAVSACHVHDEFRTAAVEGPFVTLDMEDCGYNIPQT

451 DESTLMT IAYVMAAICALFMLPLCLMVCQWRCLRCLRQQHDDFADDISLL $501 \mathrm{~K}$ transmembrane domain

Abbildung 1.4: Sequenz von BACE1 (aus Vassar et al. 1999). Signal- und Propeptid werden bei der Maturation abgespalten. Die aktiven Zentren (DTGS und DSGT) und die Transmembrandomäne sind markiert.

Autokatalyse findet nicht statt (Bennett et al. 2000b; Pinnix et al. 2001). Experimentelle Befunde zeigen allerdings, dass auch Pro-BACE1 $\beta$-Sekretase-Aktivität entfaltet. Daher wäre eine Inhibierung dieses Maturationsschrittes kein erfolgsversprechendes therapeutisches Ziel zur Behandlung der AD (Creemers et al. 2001).

Die Frage, ob BACE1 selbst ein lohnendes Ziel zur AD-Behandlung ist, kann nicht alleine mit seiner Bedeutung für die Entstehung von Amyloid beantwortet werden. Zwar besagte die Amyloid-Kaskaden-Hypothese, das Amyloid der Auslöser der AD ist (Hardy und Allsop 1991; Hardy und Selkoe 2002), doch war zunächst völlig unklar, ob BACE1 nicht weitere, möglicherweise lebenswichtige, Funktionen im Organismus hat. Um diese Frage möglichst umfassend beantworten zu können, war die Generierung von BACE1-ko-Mäusen das nächste große Ziel der AD-Forschung. Wären diese Tiere lebensfähig und gesund, stünde einer möglichst weitgehenden Inhi- 
bition von BACE1 zumindest aus der Sicht von potenziellen Nebenwirkungen nichts mehr im Wege. Zwei Gruppen gelang es schließlich unabhängig voneinander, BACE1-ko-Mäuse zu etablieren. Beide berichteten, dass die Tiere lebensfähig, normal entwickelt, gesund und phänotypisch nicht von Wildtypmäusen zu unterscheiden seien. Eine $\beta$-Sekretase-Aktivität im Gehirn ließ sich nicht nachweisen (Luo et al. 2001; Roberds et al. 2001). Damit schien BACE1 endgültig als das pharmakologische Ziel zur Behandlung der AD etabliert.

\subsection{Physiologische Funktion von BACE1}

Während die pathophysiologische Relevanz von BACE1 also gut erforscht wurde, war bisher über physiologische Funktionen der $\beta$-Sekretase nur wenig bekannt. Zunächst wurden nur wenige weitere Substrate gefunden: ST6Gal I, eine Sialyltransferase (Kitazume et al. 2001, 2003), P-selectin glycoprotein ligand-1 (Lichtenthaler et al. 2003), Amyloid-Precursor-like-Protein (Li und Südhof 2004) sowie die $\beta$-Untereinheit der spannungsabhängigen Natriumkanäle (Wong et al. 2005). Diesen Arbeiten ist gemeinsam, dass sie keine Verbindung zwischen den neuen Substraten und etwaigen klinischen Folgen der BACE1-Inhibiton auf Phänotypebene herstellen können. Im Jahr 2006 erschienen jedoch zwei große Arbeiten, die BACE1 eine Rolle bei der Ausbildung der Myelinscheiden zuschrieben (Hu et al. 2006; Willem et al. 2006). Beide Arbeiten untersuchten die Myelinisierung im PNS, die Gruppe von Hu et al. erweiterte diesen Ansatz auch auf das ZNS.

\subsection{Myelin: Struktur und Funktion}

Der Name Myelin wurde von Virchow geprägt (Virchow 1854). Es handelt sich dabei um eine Hüllstruktur um Axone, deren wesentliche Funktion es ist, die saltatorische Erregungsleitung im Nervensystem von Vertebraten zu ermöglichen. Es findet sich auch im PNS. Dort wird es von den Schwann-Zellen gebildet, im ZNS von den Oligodendrozyten (Simons und Trotter 2007). Im PNS umhüllt eine SchwannZelle immer nur ein Axon, während im ZNS ein Oligodendrozyt mehrere Axone mit einer Myelinscheide versehen kann. Da in der vorliegenden Arbeit die Myelinisierung im ZNS untersucht wurde, sollen Unterschiede zwischen PNS und ZNS im Fol- 
genden zugunsten der Darstellung der spezifischen Charakteristika des Myelins im ZNS ausgespart werden.

Die Myelinscheide selbst besteht aus spiraligen Wicklungen von Erweiterungen der Plasmamembran der Oligodendrozyten (Baumann und Pham-Dinh 2001). Sie ist daher die häufigste Membranstruktur im ZNS (Baumann und Pham-Dinh 2001). Myelin ist regelmäßig aufgebaut, in der Elektronenmikroskopie zeigt sich eine periodische Struktur aus elektronendichten major dense lines und dazwischenliegenden double intraperiodic lines (Baumann und Pham-Dinh 2001). Die major dense line wird gebildet durch die aneinander anliegenden („kompaktierten“) intrazellulären Seiten der Zellmembran des Oligodendrozyts (Baumann und Pham-Dinh 2001). Die intraperiodic lines (auch minor lines genannt) werden jeweils durch die extrazellulären Reste der Membranproteine gebildet (Baumann und Pham-Dinh 2001). Sie verschmelzen nicht miteinander, daher sind in höchsten Vergrößerungen zwei $\mathrm{zu}$ erkennen (,double") (Baumann und Pham-Dinh 2001). Eine Lamelle misst jeweils 12 Nanometer (Baumann und Pham-Dinh 2001). Bis zu 150 Lamellen werden dabei pro Internodium gebildet (Fields 2008). Als Internodium wird der durch eine myelinisierende Zelle ausgebildete Myelinabschnitt entlang eines Axons bezeichnet. Die von den Oligodendrozyten ausgebildeten Internodien sind 150-200 Mi-

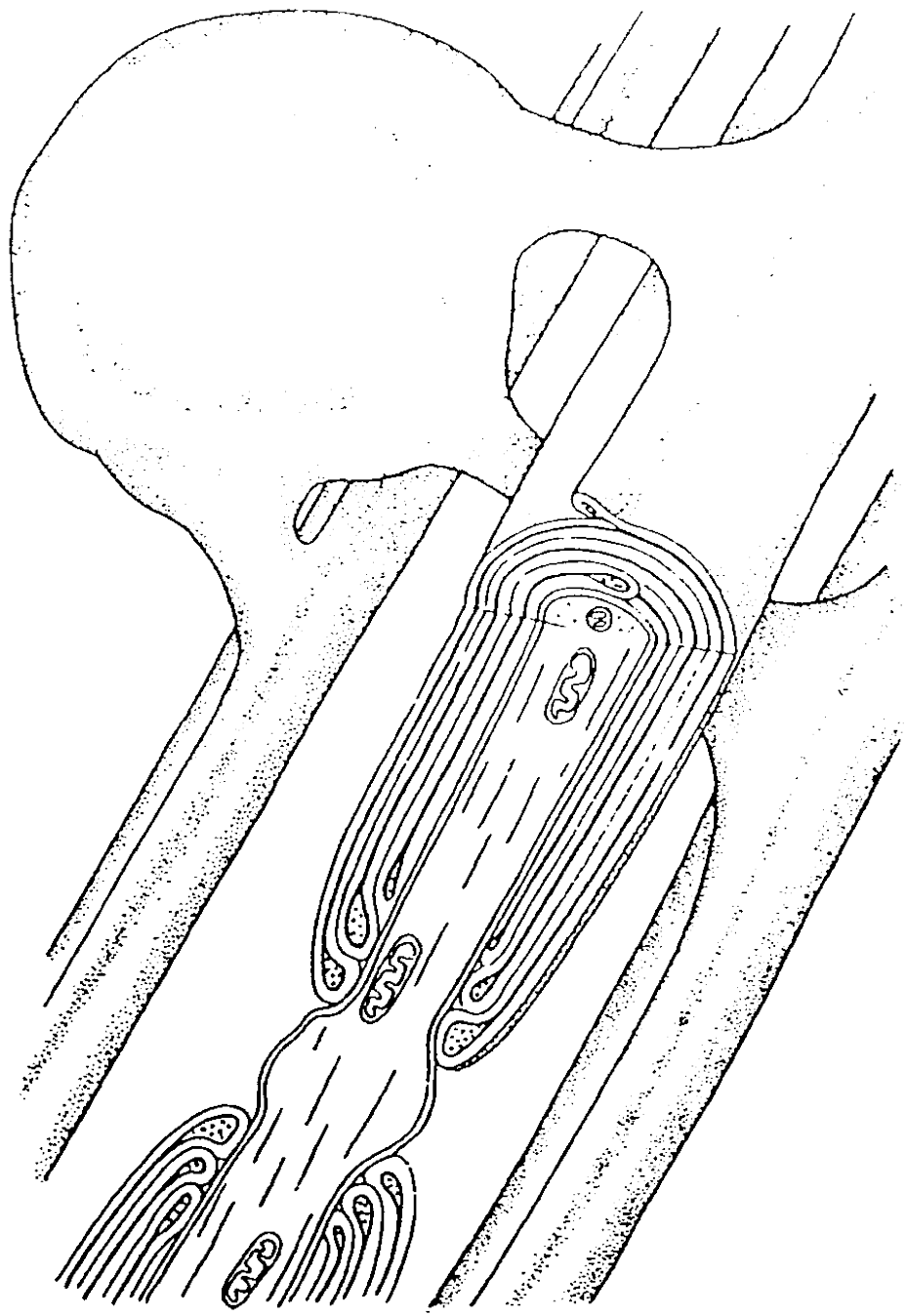

Abbildung 1.5: Schematische Darstellung eines Oligodendrozyten, der mehrere Axone ummantelt. Die spiralig um das Axon gewickelte Myelinscheide endet an einem Ranvierschen Schnürring. Im Axon sind Mitochondrien zu erkennen. Modifiziert nach Baumann und Pham-Dinh 2001. 
krometer lang (Butt und Ransom 1989). Von einem Oligodendrozyt werden durchschnittlich 20-30 Axone myelinisiert (Butt und Ransom 1989). Zwischen den Internodien befinden sich die Ranvierschen Schnürringe. Hier fehlt die isolierende Myelinschicht und die Zellmembran des Axons grenzt direkt an die extrazelluläre Matrix (Baumann und Pham-Dinh 2001). Des Weiteren finden sich spannungsabhängige Natriumkanäle in großer Anzahl (ffrench-Constant et al. 2004).

Myelin enthält deutlich weniger Wasser als die graue Substanz im Gehirn. Dort liegt der Wassergehalt bei knapp 80 \%, während Myelin etwa 40 \% Wasser enthält (Baumann und Pham-Dinh 2001). Auch die Relation von Lipiden zu Proteinen in der Myelinscheide ist charakteristisch, mit etwa $70 \%$ zu $30 \%$ kehrt sie die Verhältnisse in anderen Zellmembranen nahezu um (Baumann und Pham-Dinh 2001). Diese Eigenschaften tragen wesentlich zur elektrischen Isolation der Axone durch die Myelinscheide bei. Myelin wird durch charakteristische Proteine gekennzeichnet. Im ZNS sind das basische Myelinprotein (Myelin basic protein, MBP) sowie das Proteolipid-Protein (PLP) die häufigsten Proteine. Nach klassischer Sicht machen sie gemeinsam bereits $80 \%$ der Gesamtproteine des Myelins aus (Baumann und Pham-Dinh 2001). Dieser Einschätzung ist jüngst widersprochen worden: Es handele sich dabei um eine methodisch bedingte Überschätzung ihres Gesamtanteils (Jahn et al. 2009). MBP und PLP sind Proteine mit geringem Molekulargewicht (Baumann und Pham-Dinh 2001). PLP ist besonders empfindlich. Schon kleinste Veränderungen der Aminosäuren, etwa durch Punktmutationen, können zur Peilzaeus-Merzbacher-Erkrankung führen, die durch motorische und kognitive Defizite gekennzeichnet ist und bei der sich eine diffuse Hypomyelinisierung nachweisen lässt (Hobson und Garbern 2012). Weiterhin enthält Myelin Glykoproteine. Hier sind besonders das Myelin-assoziierte Glykoprotein (MAG) und das MyelinOligodendrozyten-Glykoprotein (MOG) hervorzuheben. MOG als Mittel zur Induktion einer Experimentellen Autoimmunen Enzephalomyelitis (EAE) hat eine besondere Bedeutung in der Erforschung von demyelinisierenden Erkrankungen erhalten. Diese Methode wird in Kapitel 1.8.2 detaillierter erläutert.

Die zugrundeliegende Biologie unterscheidet sich zwischen dem Myelin des ZNS und des PNS, nicht jedoch die Funktion. Eine der wesentlichen Funktionen des Myelins ist die elektrische Isolation des Axons. Dadurch wird die so genannte saltatorische Erregungsleitung möglich. Damit können nervale Impulse deutlich schneller weitergeleitet werden. Das Aktionspotential „springt“ zwischen den Internodien und wird an den Ranvierschen Schnürringen verstärkt. Dies ermöglicht deutlich höhere Fortleitungsgeschwindigkeiten im Nervensystem von Vertebraten als die 
kontinuierliche Weiterleitung entlang nicht myelinisierter Axone. Die Unterschiede sind dabei beträchtlich: In den sogenannten C-Fasern, das sind Axone, die nicht myelinisiert werden, beträgt die Fortleitungsgeschwindigkeit 0,6 bis 2 Meter pro Sekunde (Gasser 1941). Die dicken, myelinisierten A $\alpha$-Nervenfasern bringen es dagegen auf mehr als 100 Meter pro Sekunde (Gasser 1941). Darüber hinaus ist auch das Axon von der regelrechten Zusammensetzung der Myelinscheide abhängig: Das Fehlen der Myelinproteine PLP und seiner Spleiß-Isoform DM20 führte bei Mäusen zunächst zu Schwellungen von Axonen und im höheren Alter auch zum Untergang der Axone (Griffiths et al. 1998). Auch das Ersetzen von PLP im ZNS von Mäusen durch seinen phylogenetischen Vorläufer, das Protein P0, das häufigste Protein im PNS von Säugetieren (Patzig et al. 2011), führte zu axonaler Degeneration, schwerer neurologischer Beeinträchtigung und verkürzter Lebensspanne der Versuchstiere (Yin et al. 2006). Ebenso führte das Fehlen von 2',-3'-Cyclic-nucleotide-3'phosphodiesterase (CNP), ebenfalls ein von Oligodendrozyten exprimiertes Myelinprotein, zu frühzeitig nachweisbarer axonaler Degeneration (Edgar et al. 2009).

Die Myelinisierung ist also ein kritischer Prozess in der Entwicklung und fortgesetzten Funktion des Nervensystems. Schädigung der Myelinscheide können zu schwersten Krankheitsbildern führen. Die häufigste Erkrankung dieser Gruppe und wahrscheinlich gleichzeitig auch die häufigste neurologische Erkrankung des jungen Erwachsenenalters mit chronischem Verlauf ist die Multiple Sklerose (Compston und Coles 2002). Ein Zusammenhang zwischen BACE1 und der Myelinisierung könnte daher einerseits das Ende des vielversprechendsten kausalen Ansatzes zur Therapie der AD sein, andererseits aber auch ein Schlüssel zum Verständnis und damit auch zu neuen Therapiemöglichkeiten von demyelinisierenden Erkrankungen wie der Multiplen Sklerose.

\subsection{Die Rolle von BACE1 in der Myelinisierung}

Bekannt war bereits, dass BACE1 vor allem von Neuronen exprimiert wird. Der initiale Befund, der zur Vermutung führte, dass BACE1 eine Rolle bei der Myelinisierung spielen könnte, war die zeitliche Korrelation der BACE1-Expression im Gehirn von Mäusen und der Beginn der Myelinisierung. BACE1 wird nach der Geburt am stärksten exprimiert, dann innerhalb der ersten beiden Lebenswochen deutlich vermindert, um schließlich im Gehirn erwachsener Mäuse den niedrigsten Expres- 
sionsgrad zu erreichen (Willem et al. 2006). Die Myelinisierung im PNS beginnt ebenfalls zu dieser Zeit und hängt wesentlich von der Interaktion mit den begleitenden Axonen ab (Willem et al. 2006). Dabei spielt ein Faktor eine besondere Rolle: Neuregulin 1 (NRG1) Typ III, das zur Familie der epidermalen Wachstumsfaktoren (epidermal growth factor, EGF) gehört und von Axonen exprimiert wird (Willem et al. 2006). Als axonales Signal aktiviert es heteromere ErbB2- und ErbB3Rezeptoren auf Schwann-Zellen (Willem et al. 2006). ErbB-Rezeptoren gehören zur Familie der EGF-Rezeptoren. Dies macht NRG1 Typ III zu einem wichtigen Baustein der Kontrolle der korrekten Myelinisierung des PNS (Garratt et al. 2000a; Michailov et al. 2004; Ogata et al. 2004; Taveggia et al. 2005; Lemke 2006) und des ZNS (Calaora et al. 2001; Sussman et al. 2005). Bereits 2003 war ein juxtakriner Wirkmechanismus von NRG1 Typ III, der eine Spaltung des Transmembranproteins auf der luminalen Seite benötigen würde, postuliert worden (Falls 2003). Weiterhin wurde gezeigt, dass eine Abschwächung des NRG1-Typ-III-Signalwegs in SchwannZellen durch knock out von NRG1 Typ III oder der ErbB-Rezeptoren zu einer Hypomyelinisierung des PNS führt, während eine Überexpression von NRG1 Typ III mit einer Hypermyelinisierung einhergeht (Garratt et al. 2000b; Michailov et al. 2004; Taveggia et al. 2005). Mittels in-situ-Hybridisierung wurde gezeigt, dass die Protease BACE1 mit NRG1 Typ III in motorischen und sensorischen Neuronen des PNS koexprimiert wird, während weder BACE1 noch NRG1 Typ III in Schwann-Zellen und der Satellitenglia nachgewiesen werden konnten (Willem et al. 2006).

Um den Einfluss von BACE1 auf die Myelinisierung im PNS zu untersuchen, wurden die Ischiasnerven von BACE1-ko-Mäusen mittels Elektronenmikroskopie untersucht. Sowohl im Alter von 8, 12 und 17 Tagen als auch bei erwachsenen Tieren ließ sich mittels G-Ratio eine Hypomyelinisierung nachweisen. Zusätzlich fanden sich bei den 8 Tage alten Mäusen Axone großer Durchmesser, die zwar von einer Schwann-Zellen umgeben waren, um welche jedoch die Myelinscheide nicht ausgebildet worden war. Schließlich zeigten sich auch in den Remak-Bündeln (CFasern, die von einer Schwann-Zelle zusammengehalten werden) Unterschiede zwischen den BACE1-ko-Tieren und den Kontrollen: Ohne BACE1 bestanden die Remak-Bündel aus deutlich mehr Axonen, die direkt aneinander anlagen. Bei den Kontrolltieren umfassten die Bündel weniger Axone, die durch eine Schwann-Zelle voneinander getrennt wurden (Willem et al. 2006). Da auch BACE2 in vitro eine $\beta$ Sekretase-Aktivität entfaltet, wurden zusätzlich BACE2-ko-Mäuse untersucht. Hier war die Myelinisierung ungestört verlaufen. In ähnlicher Weise wie bei den BACE1ko-Tieren war sie bei Mäusen, denen sowohl BACE1 als auch BACE2 fehlten, beein- 
trächtigt (Willem et al. 2006). Die $\beta$-Sekretase-Aktivität, die für die Regulation der Myelinisierung im PNS verantwortlich ist, geht also am ehesten von BACE1 aus (Willem et al. 2006)

Da der beschriebene Myelinphänotyp frappierend dem der Tiere mit eingeschränktem NRG1-Typ-III-Signalweg ähnelt (Garratt et al. 2000b; Michailov et al. 2004; Taveggia et al. 2005; Chen et al. 2006), rückte die Möglichkeit, dass BACE1 NRG1 Typ III prozessiert, in den Fokus des Interesses (Willem et al. 2006). Tatsächlich fanden sich im Immunoblot in Gehirnlysaten von BACE1-ko-Mäusen große Mengen des Vorläuferproteins von NRG1 Typ III, welches in den Kontrollen nur in deutlich geringerer Menge nachgewiesen werden konnte (Willem et al. 2006). Dies wurde durch eine weitere Arbeitsgruppe bestätigt, die zusätzlich verringerte Mengen des N-terminalen Fragments von NRG1 als Ausdruck der verminderten Spaltung fand (Hu et al. 2006). Gleichsam wurde ein Fusionsprotein aus sezernierten alkalischen Phosphatasen und NRG1- $\beta 1$-Sequenzen (SEAP-NRG1- $\beta 1$ ) durch Koexpression mit BACE1 in der Zellkultur signifikant häufiger gespalten als unter Kontrollbedingungen. Dieser Effekt konnte durch Zugabe von C3, einem BACE1-spezifischen Inhibitor (Stachel et al. 2004), dosisabhängig rückgängig gemacht werden (Willem et al. 2006).

Ähnliche Befunde konnten wenig später erhoben werden: Eine weitere Arbeit bestätigte, dass der Ischiasnerv von BACE1-ko-Mäusen in der Elektronenmikroskopie signifikant dünnere Myelinscheiden aufweist als der gesunder Kontrolltiere (Hu et al. 2006). Weiterhin wurde eine Zunahme der relativen Menge kleiner myelinisierter Axone mit einem Durchmesser von weniger als 3 Mikrometer bei BACE1ko-Tieren beschrieben (Hu et al. 2006). Zusammenfassend lässt sich also feststellen, dass das NRG1-Typ-III-Vorläuferprotein ein Substrat von BACE1 ist. Seine Spaltung dient vermutlich dazu, sowohl Myelinisierung als auch Ausbildung von Remak-Bündeln im PNS via NRG1 Typ III zu steuern.

Auch der Zusammenhang zwischen BACE1 und der Myelinisierung im ZNS wurde näher beleuchtet (Hu et al. 2006). Mittels Immunfluoreszenz konnte gezeigt werden, dass sowohl zerebraler Kortex als auch Hippokampus bei BACE1-ko-Mäusen hypomyelinisiert sind (Hu et al. 2006). Dieser Phänotyp konnte sowohl bei 15 als auch bei 30 Tage alten Mäusen beobachtet werden (Hu et al. 2006). Der Durchmesser der Myelinscheiden war im Vergleich zu Kontrolltieren ebenfalls reduziert: In der Elektronenmikroskopie zeigten vier Monate alte Tiere signifikant dünnere Myelinscheiden im optischen Nerv als die Kontrolltiere (Hu et al. 2006). Dabei war die Myelinscheidendicke bei Axonen aller Durchmesser verringert, wobei die 
BACE1-ko-Tiere prozentual einen größeren Anteil an myelinisierten Axonen mit geringem Durchmesser von unter 3 Mikrometer aufwiesen (Hu et al. 2006). Dieser Phänotyp ähnelt dem für das PNS beschriebenen (Hu et al. 2006; Willem et al. 2006). In einem Mausmodell für Hypomyelinisierung im ZNS war bereits ein verwandter Phänotyp beschrieben worden: Das Fehlen von Brain-Derived Neurotrophic Factor führte bei Mäusen zu einem prozentual höheren Anteil an myelinisierten Axonen mit geringem Axondurchmesser im optischen Nerv, nicht jedoch im Nervus facialis (Cellerino et al. 1997).

Bisher blieb offen, ob insgesamt weniger Myelin gebildet wird, oder ob nur ein oder wenige Bestandteile des Myelins vermindert oder nicht mehr gebildet werden können, was dann wiederum die Hypomyelinisierung hervorrufen könnte. Um diese Frage zu beantworten, wurden die Myelinproteine MBP, PLP, MOG und MAG in Gehirnlysaten mittels Immunoblot quantifiziert (Hu et al. 2006). Die erstgenannten Proteine sind Bestandteil des sogenannten kompakten Myelins, das den größten Anteil des Myelins ausmacht. MAG kommt vor allem in der periaxonalen Membran vor (Hu et al. 2006). Im Immunoblot zeigte sich eine Abnahme der Proteine des kompakten Myelins MBP, PLP und MOG bei den BACE1-ko-Tieren im Alter von 15, 30 und 60 Tagen gegenüber den Kontrollen (Hu et al. 2006). MAG wurde nicht unterschiedlich stark exprimiert. Für MBP wurde zusätzlich mittels Northernblot ein erniedrigtes mRNA-Niveau im zerebralen Kortex festgestellt (Hu et al. 2006).

Da sich das Myelin der BACE1-ko-Tiere qualitativ und quantitativ deutlich von dem der gesunden Kontrolltiere unterschied, wurden Versuche unternommen, den neurologischen Phänotyp dieser Veränderungen zu erfassen. Dazu wurden zwei Systeme untersucht: die Schmerzempfindlichkeit und die Motorik. Um die Schmerzempfindlichkeit messen zu können, wird die Zeit gemessen, bis die Tiere ihre Pfoten von einer erhitzten Platte abheben und lecken (paw lick response). Hier zeigten sowohl 2 als auch 5 Monate alte BACE1-ko-Tiere eine signifikant kürzere Zeitspanne, bis sie ihre Pfoten abhoben (Hu et al. 2006). Dieser Befund spricht für eine erhöhte Schmerzempfindlichkeit. Um die motorische Funktion zu erfassen, wurde die Griffstärke der Vorderpfoten (forelimb grip strength test) mittels eines Griffstärkemessers gemessen. Hier zeigten die BACE1-ko-Tiere eine signifikant reduzierte Griffstärke gegenüber ihren Kontrollen (Hu et al. 2006). Zusammenfassend lässt sich feststellen, dass der Verlust von BACE1 in einer Störung der neurologischen Funktion resultiert (Hu et al. 2006).

Die beschriebenen Befunde zeigen deutlich, dass BACE1 eine wichtige Rolle bei der Myelinisierung sowohl im PNS als auch im ZNS spielt, und belegen, dass 
BACE1-ko-Mäuse entgegen der initialen Berichte einen klinisch relevanten Phänotyp aufweisen. Daher ist es unabdingbar, diese mögliche schwerwiegende Nebenwirkung einer therapeutischen Inhibition von BACE1 besser zu verstehen. Ein genaueres Verständnis der Prozesse der Myelinisierung beinhaltet gleichzeitig die Möglichkeit neuer Therapieverfahren für demyelinisierende Erkrankungen wie der Multiplen Sklerose. Es ist also sinnvoll, das in der Myelinforschung gewonnene Wissen und die damit verbundenen Verfahren auf diese Fragestellung zu übertragen. Dazu eignen sich insbesondere etablierte Modelle für De- und Remyelinisierung.

\subsection{De- und Remyelinisierung im Tiermodell}

Demyelinisierung bezeichnet den Untergang der Myelinscheiden um Axone. Unterschieden werden primäre und sekundäre Demyelinisierung. Bei der primären Demyelinisierung handelt es sich um eine Schädigung des Oligodendrozyten, entweder durch angeborene Störungen (klinisch die Gruppe der Leukodystrophien) oder durch Entzündungsreaktionen an Oligodendrozyt oder Myelin wie beispielsweise bei der Multiplen Sklerose (Franklin und ffrench-Constant 2008). Sekundäre Demyelinisierung bezeichnet den Untergang von Oligodendrozyten nach axonalen Schäden, die sogenannte Wallersche Degeneration (Franklin und ffrench-Constant 2008). Es zeigt sich also, dass nicht nur wie bereits dargestellt Axone eine intakte Myelinscheide benötigen, sondern auch die Myelinscheide zu ihrem Erhalt auf intakte Axone angewiesen ist. Axon und Myelinscheide müssen demnach als unzertrennliche Funktionseinheit aufgefasst werden. So führt Demyelinisierung durch Leitungsblöcke zu neurologischen Beeinträchtigungen (Franklin und ffrench-Constant 2008). Durch Remyelinisierung kann die saltatorische Reizweiterleitung wiederhergestellt werden (Smith et al. 1979). Die neugebildeten Internodien sind jedoch dünner und kürzer als die ursprüngliche Ummantelung (Smith et al. 1979; Franklin und ffrench-Constant 2008). Remyelinisierung bezeichnet speziell den Ersatz zerstörter Myelinscheiden durch Ausdifferenzierung von Oligodendrozyten eine bloße Reparatur schadhaften Myelins findet nach aktuellem Kenntnisstand nicht statt (Franklin und ffrench-Constant 2008). Bei der MS kommt es im Verlauf der Erkrankung zu fortschreitenden fokalen Demyelinisierungen im ZNS - doch bei etwa 20 \% der Patienten findet eine umfangreiche Remyelinisierung der Läsionen statt (Patrikios et al. 2006). Die für die Remyelinisierung notwendigen Vorläufer- 
zellen der Oligodendrozyten lassen sich auch in MS-Läsionen nachweisen (Chang et al. 2000, 2002). Daher lautet eine der möglichen Antworten auf die Frage „Why does Remyelination fail in Multiple Sclerosis?" (Franklin 2002): Weil die Differenzierung der Vorläuferzellen gestört ist (Franklin 2002). Um neue Therapieverfahren $\mathrm{zu}$ entwickeln, müssen also Remyelinisierungsprozesse genauer untersucht werden. Dazu stehen verschiedene Tiermodelle zur Verfügung, darunter das Cuprizonemodell und die schon erwähnte Experimentelle Autoimmune Enzephalomyelitis (EAE). Hier wird auf unterschiedliche Weise eine Demyelinisierung induziert. So lassen sich Regenerationsvorgänge untersuchen. Bei der EAE steht dabei als Auslöser der Demyelinisierung die Autoimmunreaktion im Vordergrund, beim Cuprizonemodell die toxische Wirkung von Cuprizone.

\subsubsection{Das Cuprizonemodell}

Das Cuprizonemodell ist ein verbreitete Methode, um Remyelinisierung zu untersuchen. Cuprizone ist ein Kupferchelator (Matsushima und Morell 2001). Mit der Nahrung aufgenommen führt es in Mäusen regelhaft zu einer großflächigen Demyelinisierung im ZNS (Matsushima und Morell 2001). Akute Intoxikationen, üblicherweise über sechs Wochen, werden in Mäusen mit einer nahezu vollständigen Remyelinisierung der betroffenen Areale überstanden (Matsushima und Morell 2001). Diese Remyelinisierung umfasst nach einem Monat ohne Cuprizonegabe etwa 90 \% der Axone (Matsushima und Morell 2001). Chronische Intoxikationen führen je nach verwendetem Mausstamm zu anhaltender Demyelinisierung und schließlich dem Tod der Versuchstiere (Matsushima und Morell 2001). Der genaue Wirkmechanismus ist unklar. Es wird vermutet, dass das Spurenelement Kupfer für die Energieversorgung im ZNS notwendig ist, und die Oligodendrozyten zur Aufrechterhaltung der Myelinscheiden große Mengen Energie benötigen (Matsushima und Morell 2001). Im Gehirn sinken die Kupferspiegel nach Cuprizonegabe (Matsushima und Morell 2001). Dies könnte erklären, warum in der Folge spezifisch Oligodendrozyten in die Apoptose gehen (Matsushima und Morell 2001). Dadurch kommt es zu einem Untergang der Myelinscheiden. Der Debris wird dann von Mikroglia abgeräumt (Matsushima und Morell 2001). Dabei ist festzuhalten, dass es sich um eine toxisch induzierte Demyelinisierung handelt. Im Gegensatz zu Modellen mit einem autoimmunen Auslöser sind dabei T-Zellen nur in geringer Menge nachweisbar (Matsushima und Morell 2001). So ist ein Vorteil des Cuprizonemodells gegenüber der EAE, dass das komplexe Immunsystem in geringerem Maße 
betrachtet werden muss (Matsushima und Morell 2001). Auch der strenge zeitliche Ablauf prädestiniert das Cuprizonemodell für vergleichende Untersuchungen (Matsushima und Morell 2001). Schließlich ist die uniforme, großflächige Lokalisation der Demyelinisierung ein weiterer Vorzug des Cuprizonemodells (Matsushima und Morell 2001).

In der Forschung wurde oft das ausgiebig myelinisierte Corpus callosum untersucht. Neuere Forschungen zeigen jedoch, dass auch der zerebrale Kortex reproduzierbar durch Cuprizone demyelinisiert wird (Skripuletz et al. 2008). Auch hier findet eine erfolgreiche Remyelinisierung statt (Skripuletz et al. 2008). Das Ausmaß der Demyelinisierung und damit der darauffolgenden Vorgänge unterscheidet sich jedoch wesentlich zwischen unterschiedlichen Mausstämmen (Skripuletz et al. 2008). Damit eignet sich das Cuprizonemodell hervorragend, um den Einfluss einzelner Faktoren auf die De- und Remyelinisierung zu untersuchen.

\subsubsection{Die Experimentelle Autoimmune Enzephalomyelitis}

Die Experimentelle Autoimmune Enzephalomyelitis ist ein Modell der entzündlichen Demyelinisierung, das schon seit vielen Jahrzehnten in der Forschung eingesetzt wird. Seine Ursprünge gehen auf den Versuch in den dreißiger Jahren zurück, die Enzephalitis, die als Nebenwirkung der Tollwutimpfung auftrat, im Tiermodell nachzustellen (Gold et al. 2006). Dazu wurden Affen Gehirnextrakte intramuskulär verabreicht, die bei manchen Versuchstieren eine Enzephalitis mit Demyelinisierung auslöste (Rivers et al. 1933). Die Frage, was für neue Erkenntnisse man aus einem solch alten Modell ziehen kann, ist nicht unberechtigt. Zum einen gibt es in der modernen Forschung natürlich neue Analysemethoden, die wertvolle neue Erkenntnisse ermöglichen - zum anderen ist die EAE, im Gegensatz zum Cuprizonemodell, eine besonders heterogene Erkrankung. So gibt es nicht nur deutliche Unterschiede im klinischen Bild der EAE bei unterschiedlichen Spezies (Baxter 2007), selbst innerhalb der häufig verwendeten Gruppe der Nagetiere ist der Verlauf nicht immer homogen (Gold et al. 2006). Ein Grund dafür ist die im Verlauf verfeinerte Methodik der Induktion: Nicht nur Gehirnextrakte werden verwendet, sondern vor allem einzelne Myelinbestandteile wie PLP, MBP oder MOG bzw. einzelne Fragmente dieser Proteine (Gold et al. 2006). Auch die Übertragung von MBP-spezifischen T-Zellen in gesunde Ratten kann eine EAE auslösen (Ben-Nun et al. 1981), was - ebenfalls im Gegensatz zum Cuprizonemodell - den autoimmunen Charakter der Erkrankung unterstreicht (Gold et al. 2006). Der Nachteil der EAE ist 
der heterogene Verlauf sowie die mangelhafte anatomische Reproduzierbarkeit der Läsionen im ZNS. Vergleiche sind daher am ehesten bei genetisch sehr ähnlichen Versuchstieren möglich. In der vorliegenden Arbeit wurden Hirnstammpräparate von LEW.1N-Ratten und Kontrolltieren aus einer früheren Studie (Schneider et al. 2004) analysiert. Die EAE wurde mit MOG induziert, was zu einer ausgeprägten Demyelinisierung im ZNS führt. Der Verlauf zeigt eine an der Schwanzspitze beginnende, aufsteigende Parese, die nach einem klinischen Score bewertet wird.

Analog zu den jüngsten Entwicklungen beim Cuprizonemodell ist es auch bei der EAE gelungen, eine kortikale Demyelinisierung in Ratten zu induzieren (Merkler et al. 2006). Wie im Cuprizonemodell zeigte sich auch hier eine schnelle Remyelinisierung (Merkler et al. 2006). Die EAE ist also auch nach Jahrzehnten der Forschung weiterhin ein unverzichtbares Modell, um Remyelinisierungsvorgänge zu untersuchen.

\subsection{Fragestellung und Zielsetzung der Arbeit}

Diese Einleitung sollte den weiten Bogen von der Demenz zu den demyelinisierenden Erkrankungen schlagen, um das Fundament für die eigene Forschung zu bereiten. Ziel der Arbeit war es, eine mögliche neue physiologische Rolle für die $\beta$-Sekretase als Faktor in der Remyelinisierung des ZNS zu finden. Zu dieser Frage gab und gibt es nach Kenntnis des Verfassers zu diesem Zeitpunkt (Stand: August 2013) außer der eigenen (Treiber et al. 2012) keine weiteren Publikationen.

Die zentralen Fragen lassen sich stichpunktartig formulieren:

1. Ist die Expression von BACE1 in Modellen der Demyelinisierung (Cuprizone und EAE) verändert?

2. Ist das Cuprizonemodell in BACE1-ko-Mäusen anwendbar?

3. Unterscheiden sich BACE1-ko-Mäuse klinisch von ihren Wildtypartgenossen im Cuprizonemodell?

4. Bestätigt sich die berichtete Hypomyelinisierung im ZNS von BACE1-ko-Mäusen mittels elektronenmikroskopischer Auswertung?

5. Zeigt sich elektronenmikroskopisch und statistisch ein Unterschied in der Myelinisierung von BACE1-ko-Mäusen und Wildtyptieren nach einer Remyelinisierungsphase im Cuprizonemodell? 


\section{Materialien}

Alle Chemikalien wurden von AppliChem (AppliChem GmbH, Darmstadt, Deutschland), Merck (Merck KGaA, Darmstadt, Deutschland), SERVA (SERVA Electrophoresis $\mathrm{GmbH}$, Heidelberg, Deutschland) Science Services (Science Services $\mathrm{GmbH}$, München, Deutschland) oder Sigma-Aldrich (Sigma-Aldrich Chemie GmbH, München, Deutschland) bezogen. Medien, Seren, Zusätze und Antibiotika wurden von Gibco/Invitrogen (Invitrogen GmbH, Darmstadt, Deutschland) und PAA (PAA Laboratories GmbH, Cölbe, Deutschland) bezogen. Gebrauchsartikel wurden von BD (Becton, Dickinson and Company, Heidelberg, Deutschland), Eppendorf (Eppendorf AG, Hamburg, Deutschland), Science Services (Science Services GmbH, München, Deutschland) und Sigma-Aldrich (Sigma-Aldrich Chemie GmbH, München, Deutschland) bezogen. Bei abweichenden Bezugsquellen sind diese im Text aufgeführt.

\subsection{Puffer und Lösungen}

\subsubsection{Avertin}

Zusammensetzung: $2 \%[\mathrm{w} / \mathrm{v}]$ Tribromethanol, $2 \%$ [v/v] Amylalkohol in aqua dest

\subsubsection{Bleicitrat nach Reynolds}

Zusammensetzung: 1,33 g $\mathrm{Pb}\left(\mathrm{NO}_{3}\right)_{2}$ und 1,76 $\mathrm{g} \mathrm{Na}_{3}\left(\mathrm{C}_{6} \mathrm{H}_{5} \mathrm{O}_{7}\right)\left[2 \mathrm{H}_{2} \mathrm{O}\right]$ in $30 \mathrm{ml}$ aqua dest. $8 \mathrm{~mL} 1 \mathrm{~N} \mathrm{NaOH}$-Lösung zugeben, auf 50mL mit aqua dest.

\subsubsection{Blockierlösungen}

Zusammensetzung für Gefrierschnitte: $2 \%$ [w/v] BSA, $2 \%$ [v/v] fetales Kälberserum, $2 \%[v / v]$ Fischgelatine in PBS 
Zusammensetzung für Paraffinschnitte: $25 \%[\mathrm{v} / \mathrm{v}]$ Ziegenserum, 0,5 \% [v/v] Triton $\mathrm{X}-100$ in $\mathrm{PBS} / \mathrm{BSA}$

Zusammensetzung für Westernblot: $4 \%$ Slim fast in PBS-T

\subsubsection{Citratpuffer}

Zusammensetzung: 0,01 M Citratpuffer (pH 6,0)

\subsubsection{EGTA-Lösung}

Zusammensetzung: 0,5 M EGTA in aqua dest. Mit Natronlauge versetzt, bis klare Lösung entsteht.

\subsubsection{Epoxidharz (Epon)}

Mischungsansatz:

\begin{tabular}{|c|c|}
\hline Glycidether 100 & $21.4 \mathrm{~g}$ \\
\hline 2-Dodecenylsuccinic acid anhydride & $14.4 \mathrm{~g}$ \\
\hline Methylnadic anhydride & $11.3 \mathrm{~g}$ \\
\hline gesamt: & $47.1 \mathrm{~g}$ \\
\hline \multicolumn{2}{|c|}{10 min rühren } \\
\hline 2,4,6-Tris(dimethylaminomethyl)phenol & $0.84 \mathrm{ml}$ \\
\hline
\end{tabular}

\subsubsection{Ethylenglykol-Glycerol-Lösung}

Zusammensetzung: $25 \%$ [v/v] Ethylenglykol, $25 \%$ [v/v] Glycerol in PBS 


\subsubsection{Gele für SDS-PAGE}

Zusammensetzung der Gele (in $\mathrm{mL}$ ):

\begin{tabular}{llll}
\hline & Trenngel 10 \% & Trenngel 12 \% & Sammelgel \\
\hline Aqua & 4,1 & 3,4 & 6,1 \\
TRIS/HCl 1,5 M (pH 8,8) & 2,5 & 2,5 & 0 \\
TRIS/HCl 0,5 M (pH 6,8) & 0 & 0 & 2,5 \\
Acrylamid-Bisacrylamid (30 \%) [w/v] & 3,3 & 4,0 & 1,3 \\
SDS (10 \%) [w/v] & 0,1 & 0,1 & 0,1 \\
APS (10 \%) [w/v] & 0,05 & 0,05 & 0,05 \\
TEMED [v/v] & 0,02 & 0,02 & 0,05 \\
\hline
\end{tabular}

\subsubsection{Karlsson-Schultz-Fixans:}

Zusammensetzung: 0,5\% [w/v] NaCl, $4 \%$ [w/v] Formaldehyd, 2,5 \% [w/v] Glutaraldehyd in 0,1 $\mathrm{M}$ Phosphatpuffer $(\mathrm{pH} \mathrm{7,4)}$

\subsubsection{Laufpuffer}

Zusammensetzung: 85 mM Glycin, 25 mM TRIS, $1 \%$ [w/v] SDS in aqua dest

\subsubsection{Lysepuffer}

Zusammensetzung: $2 \%$ [v/v] Nonidet P-40, 0,2 \% [w/v] SDS, 0,5 mM EGTA, $1 \%$ Proteaseinhibitor in PBS

\subsubsection{Osmium-Tetroxid}

Zusammensetzung: $2 \%$ [w/v] $\mathrm{OsO}_{4}$ in $0,1 \mathrm{M}$ Phosphatpuffer $(\mathrm{pH} 7,4)$

\subsubsection{Phosphatgepufferte Salzlösung (phosphate buffered saline, PBS)}

Zusammensetzung: $137 \mathrm{mM} \mathrm{NaCl}, 2,7 \mathrm{mM} \mathrm{KCl}, 10 \mathrm{mM} \mathrm{Na}_{2} \mathrm{HPO}_{4}, 2 \mathrm{mM} \mathrm{KH}_{2} \mathrm{PO}_{4}$ in aqua dest 


\subsubsection{Phosphatpuffer}

Zusammensetzung für 0,1 M Phosphatpuffer ( $\mathrm{pH}$ 7,4): $20 \mathrm{mM} \mathrm{NaH}{ }_{2} \mathrm{PO}_{4}, 80 \mathrm{mM}$ $\mathrm{Na}_{2} \mathrm{HPO}_{4}$ in aqua dest

\subsubsection{PBS-Tween (PBS-T)}

Zusammensetzung: 0,1 \% [v/v] Tween 20 in PBS

\subsubsection{PBS/BSA}

Zusammensetzung: 0,5\% [w/v] BSA in PBS

\subsubsection{Ponceau S}

Zusammensetzung: 0,1\% [w/v] Ponceau S in 5 \% [v/v] Essigsäure

\subsubsection{Probenpuffer}

Zusammensetzung: $10 \%$ [v/v] Glycerol, 2 mM EDTA, $2 \%$ [w/v] SDS, $144 \mathrm{mM} \beta$ Mercaptoethanol, $50 \mathrm{mM}$ TRIS/HCl (pH 6,8) in aqua dest

\subsubsection{Proteaseinhibitor}

Verwendet wurde der Proteaseinhibitor Complete Mini (Roche Applied Science, Mannheim, Deutschland). Eine Tablette wurde in 1 mL PBS gelöst.

\subsubsection{TRIS-Puffer}

Verwendete Konzentrationen und Zusammensetzungen:

- 1,5 M TRIS/HCl (pH 8,8) für Trenngel

- $\quad$ 0,5 M TRIS/HCl (pH 6,8) für Sammelgel

- $\quad$ 0,05 M TRIS/HCl (pH 7,6) für Histologie

- $\quad$ TRIS + $2 \%$ Milchpulver: $2 \%$ Milchpulver in 0,05 M TRIS (pH 7,6) für Histologie 


\subsubsection{TRIS-Acetat-Puffer (TAE-Puffer)}

Zusammensetzung: 40 mM TRIS, 1,14 \% [v/v] Essigsäure, 2 mL 0,5 M EDTA in 1 L aqua bidest. Der pH wurde auf 8,5 eingestellt.

\subsubsection{Transferpuffer}

Zusammensetzung: 85 mM Glycin, 25 mM TRIS in $20 \%$ [v/v] Methanol

\subsubsection{Zellkulturmedium DMEM/MCSF}

Zusammensetzung: $10 \%$ [v/v] fetales Kälberserum, $1 \%$ [v/v] Pyruvat, $1 \%$ [v/v] L-Glutamat, $100 \mathrm{ng} / \mathrm{mL}$ mouse recombinant macrophage colony-stimulating factor in DMEM high glucose $(4,5 \mathrm{~g} / \mathrm{l})$

\subsection{Der BACE1-Antikörper 10B8}

Die Grundlage des ersten Teils dieser Arbeit war der von B. De Strooper, Katholieke Universiteit Leuven, Niederlande, entwickelte und M. Simons, MaxPlanck-Institut für Experimentelle Medizin Göttingen, zur Verfügung gestellte Antikörper 10B8. Es handelt sich dabei um einen monoklonalen Antikörper der Spezies Maus, der gegen BACE1 gerichtet ist. Dieser Antikörper war bereits in der Arbeitsgruppe von B. De Strooper im Westernblot getestet worden (Sannerud et al. 2011; Zhou et al. 2011).

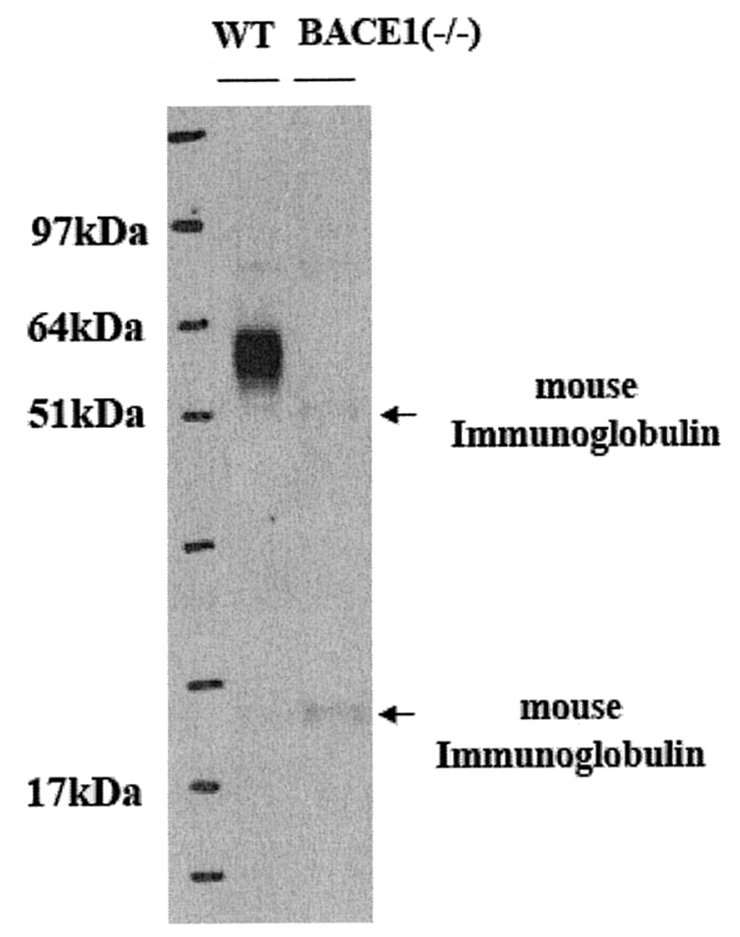

Abbildung 2.1: Westernblot des BACE1-Antikörpers 10B8 mit Positiv- und Negativkontrolle. Abbildung von L. Zhou, Katholieke Universiteit Leuven, Niederlande. 


\subsection{Weitere verwendete Antikörper}

\subsubsection{Primärantikörper}

\begin{tabular}{lllll}
\hline Ziel & Klon & Spezies & Quelle & Verdünnung \\
\hline Aktin & AC-40 & Maus & Sigma & $1: 1000$ (Westernblot) \\
Calnexin & SPA-860 & Hase & Stressgen & $1: 2000$ (Westernblot) \\
MPB & SMI-94 & Maus & Covance & $1: 500$ (Immunhistochemie)
\end{tabular}

\subsubsection{Sekundärantikörper}

Sekundärantikörper wurden von Dianova (Dianova GmbH, Hamburg, Deutschland) bezogen.

\subsection{Zellen}

Zur Simulation von inflammatorischen Prozessen im ZNS wurde eine immortalisierte murine Mikroglia-Zelllinie (EOC-Zellen, ATCC CRL-2469: LGC Standards $\mathrm{GmbH}$, Wesel, Deutschland) verwendet.

Primärzellkulturen von hippokampalen und kortikalen Neuronen, Oligodendrozyten, Astrozyten und Mikroglia von NMRI-Mäusen wurden freundlicherweise von Mitarbeitern der Arbeitsgruppe (AG) Simons, Max-Planck-Institut für Experimentelle Medizin Göttingen, in Zellkulturplatten zum Lysieren zur Verfügung gestellt.

\subsection{Versuchstiere}

Zur Untersuchung der Funktion von BACE1 wurden BACE ${ }^{-/-}$-C57BL/6-Mäuse (Jaxmice B6.129-Bace ${ }^{\text {tm1Pcw }} /$ J: Charles River Germany, Sulzfeld, Deutschland) verwendet. Diese wurden im Tierhaus des Max-Planck-Instituts für Experimentelle Medizin Göttingen gehalten und gezüchtet. Sie wurden heterozygot verpaart. Mäuse mit zwei Wildtypallelen sowie zusätzliche C57BL/6-Tiere dienten in den Experimenten als Kontrollen.

Das Gehirnlysat einer Wistar-Ratte als Positivkontrolle der BACE1-ExpressionsStudie wurde freundlicherweise von S. Schmitt, AG Simons, Max-Planck-Institut für 
Experimentelle Medizin Göttingen, zur Verfügung gestellt. Die Gehirnlysate von C57-BL/6-Mäusen zur Untersuchung der BACE1-Expression im Rahmen des Cuprizonemodells wurden freundlicherweise von A. Schneider, AG Simons, Max-PlanckInstitut für Experimentelle Medizin Göttingen, zur Verfügung gestellt. Die Lysate der Hirnstämme von weiblichen LEW.1N-Ratten zur Untersuchung der BACE1Expression im Rahmen der EAE wurden von G. Wright-Araújo erstellt und freundlicherweise von M. Simons, AG Simons, Max-Planck-Institut für Experimentelle Medizin Göttingen, zur Verfügung gestellt. Sie stammen jeweils aus vorhergehenden Untersuchungen (Schneider et al. 2004). 


\section{Methoden}

\subsection{Zellkultur}

\subsubsection{Wachstumsbedingungen}

Die verwendete Zelllinie EOC wurde in Zellkulturschalen und -flaschen sowie in 12-Loch-Platten kultiviert. In den Brutschränken herrschten konstant $37{ }^{\circ} \mathrm{C}$ bei $7,5 \% \mathrm{CO}_{2}$. Für immunzytochemische Analysen wurden zusätzlich Deckgläschen in die 12-Loch-Platten eingelegt. Zellkulturflaschen, -schalen und Deckgläser waren mit Poly-L-Lysin (PLL) beschichtet worden. Dazu wurde $33 \mu \mathrm{g} / \mathrm{mL}$ PLL in PBS für 30 Minuten bei Raumtemperatur auf die Oberfläche gegeben und anschließend mit PBS gespült. Das Zellkulturmedium DMEM/MCSF wurde alle 2-3 Tage gewechselt. Bei Erreichen einer konfluenten Zellschicht in den Flaschen wurden die Zellen mit einem Zellschaber von der Oberfläche gelöst und in neue Flaschen passagiert.

\subsubsection{Erstellung von Zelllysaten}

Zur qualitativen und quantitativen Untersuchung der exprimierten Proteine wurden Zelllysate erstellt. Dabei werden Zellen durch Lysepuffer aufgeschlossen. Das Vorgehen war für Primärzellen und Zelllinien identisch. Der Lysepuffer enthält Nonidet P-40, ein nicht denaturierendes Detergens, das dazu dient, Membranproteine aus der Zellmembran herauszulösen. EGTA ist ein Chelator für zweiwertige Kationen, die von vielen Proteasen als Kofaktor benötigt werden. Durch die Komplexbildung mit EGTA stehen die Kationen nicht mehr zur Verfügung, die Metalloproteasen sind somit inhibiert.

Zunächst wurde das Kulturmedium abgenommen und die Zellen zweimal mit PBS gewaschen, wobei vorsichtig auf den Rand und nicht in die Mitte der Petrischale pipettiert wurde. Die Petrischalen wurden auf Eis gestellt. Danach wurde Lysepuffer zu den Zellen gegeben, bei einer 6-cm-Petrischale $200 \mu \mathrm{L}$. Mit einem Zell- 
schaber wurden die Zellen zusammengekratzt und so von der Petrischale gelöst. Mit einer Pipette wurde das Lysat in ein Tube überführt. Danach wurde es weitere zehn Minuten auf Eis inkubiert. Das Lysat wurde nun direkt für Experimente verwendet oder zunächst bei $-20^{\circ} \mathrm{C}$ gelagert.

\subsubsection{Stimulation von EOC-Zellen}

Zur Simulation von inflammatorischen Prozessen im Organismus wurden EOC-Zellen mit proinflammatorischen Chemokinen und Liganden von toll-like-Rezeptoren stimuliert. Dazu wurden gleiche Mengen EOC-Zellen auf 6-cm-Zellkulturschalen mit 5 ml Medium ausgesät. Am 3. Tag erfolgte der Mediumwechsel. Am 5. Tag wurde das Medium entfernt und durch Stimulanzien-enthaltendes Medium ersetzt. Nach Inkubation für 24 Stunden erfolgte die Lyse der Zellen.

\begin{tabular}{lll}
\hline Stimulanz & Quelle & Konzentration \\
\hline CpG (TLR 9) & InvivoGen & $10 \mu \mathrm{g} / \mathrm{mL}$ \\
LPS (TLR 4) & Sigma-Aldrich & $1 \mu \mathrm{g} / \mathrm{mL}$ \\
Rantes & Sigma-Aldrich & $0,5 \mu \mathrm{g} / \mathrm{mL}$ \\
MIP-1 $\alpha$ & R\&D Systems & $100 \mathrm{ng} / \mathrm{mL}$ \\
\hline
\end{tabular}

\subsection{Biochemische Methoden}

\subsubsection{Quantitative Proteinbestimmung mittels BCA-Reaktion}

Bei allen Westernblots wurden jeweils gleiche Proteinmengen pro Blot verwendet. Zur präzisen Bestimmung der gesamten Proteinmenge in einer Lösung diente die quantitative Proteinbestimmung mittels Bicinchonsäure-Reaktion.

Verwendet wurde das Pierce BCA Protein Assay Kit (Fischer Scientific - Germany GmbH, Schwerte, Deutschland). Zur optimalen Vergleichbarkeit der Ergebnisse wurde für die Proteinstandards entgegen der Anweisung des Kits nicht destilliertes Wasser, sondern Lysepuffer als Solvens verwendet. Dazu wurden $2 \mathrm{mg} / \mathrm{mL}$ BSAVorratslösung in Lysepuffer angesetzt und aus ihr die Proteinstandards in absteigender Konzentration nach dem Pipettierschema des Kits erstellt. Die BCA-Vorratslösung und die fertigen Proteinstandards wurden bei $-20^{\circ} \mathrm{C}$ gelagert. 
Die benötigte Menge der BCA-Arbeitslösung, bestehend aus Bichinchonsäure, Natriumtartrat und $\mathrm{CuSO}_{4}$, wurde nach Vorgabe des Kits in einem Tube gemischt und dann verschlossen gelagert. Anschließend wurden die Proteinstandards als Dreifachansatz und die Proben als Doppelansatz in eine 96-Loch-Platte gegeben. Pro Loch wurden jeweils $10 \mu \mathrm{L}$ Proteinlösung verwendet, die dann mit $200 \mu \mathrm{L}$ BCA-Arbeitslösung versetzt wurden. Der Ansatz inkubierte für eine halbe Stunde im Dunkeln, wurde daraufhin photometrisch gemessen und anhand der Extinktion die Proteinkonzentration berechnet (Dynex Revelation 4.02: DYNEX Technologies GmbH, Berlin, Deutschland).

\subsubsection{SDS-PAGE}

Bei der SDS-PAGE (sodium dodecyl sulfate polyacrylamide gel electrophoresis, Natriumdodecylsulfat-Polyacrylamidgelelektrophorese) werden Proteine nach ihrem Molekulargewicht in einem Polyacrylamidgel aufgetrennt. Um dieses Ziel zu erreichen, müssen die Proteine durch Kochen denaturiert werden und ihre Eigenladungen überdeckt werden. Dazu dient SDS, welches sich an die Aminosäuren anlagert und das Protein so mit negativen Ladungen versieht. Eine weitere Linearisierung des Proteins hin zur Primärstruktur wird durch Zugabe von $\beta$-Mercaptoethanol erreicht, wodurch intra- und intermolekulare Disulfidbrücken gespalten werden.

Verwendet wurde die Mini-Protean 3 Cell (Bio-Rad Laboratories GmbH, München, Deutschland) für die von Laemmli verbesserte Form der SDS-PAGE (Laemmli 1970), bei der das Gel aus einem oberen Sammel- und einem unteren Trenngel besteht. Das Sammelgel dient dazu, die Proben vor dem Übertritt ins Trenngel aufzukonzentrieren, um saubere Banden zu erhalten.

Die Gele unterscheiden sich ihren unterschiedlichen Aufgaben gemäß in ihrer chemischen Zusammensetzung. Das Sammelgel enthält weniger Acrylamid als das Trenngel und hat einen $\mathrm{pH}$ von 6,8. Der pH des Trenngels liegt bei 8,8. Die Porengröße der Trenngele ist zur besseren Auftrennung verschiedener Proteingrößen variabel und wird mittels der verwendeten Menge Acrylamid-Bisacrylamid (30 \%) eingestellt. Für Proteingrößen von 20 bis 300 kDa wurden 10\%ige [w/v] Gele verwendet, bei kleineren Proteinen von 10 bis $200 \mathrm{kDa}$ kamen 12\%ige [w/v] Gele zum Einsatz.

Zur Gelherstellung wurden zunächst Wasser, TRIS-Puffer, Acrylamid-Bisacrylamid und SDS (10 \%) [w/v] gemischt. Die Polymerisation des Acrylamids wurde durch Zugabe des Radikalstarters APS (10 \%) und des Katalysators TEMED ein- 
geleitet. Das noch flüssige Trenngel wurde umgehend gegossen. Um eine gerade Oberkante zu erhalten, wurde das Gel mit Ethanol überschichtet. Nach der Polymerisation wurde das Ethanol entfernt und das Sammelgel über das Trenngel gegossen.

Die Proteinproben wurden im Verhältnis 1:1 [v/v] mit Probenpuffer in einem 1,5 mL Tube gemischt, daraufhin für fünf Minuten bei $95{ }^{\circ} \mathrm{C}$ denaturiert, anschließend für wenige Sekunden bei 13.000 Umdrehungen pro Minute zentrifugiert und umgehend in die Taschen des Sammelgels pipettiert. Die erste Tasche wurde mit einem Marker befüllt, um die Proteine anhand ihrer Größen unterscheiden zu können. Die Elektrophorese wurde mit durchgängig $100 \mathrm{~V}$ gestartet und die Proteine für etwa 1,5 Stunden aufgetrennt, bis die Lauffront die Unterkante des Trenngels erreicht hatte.

\subsubsection{Westernblot}

Westernblot ist das Verfahren, mit dem die in einem Polyacrylamidgel aufgetrennten Proteine auf eine Nitrocellulosemembran übertragen werden, um sie weiteren Untersuchungen zugänglich zu machen.

Der Aufbau des Transfersandwichs erfolgte nach den Vorgaben des Herstellers (Mini-Protean 3 Cell:Bio-Rad Laboratories GmbH, München, Deutschland). Es wurde mit konstant $100 \mathrm{~V}$ für eine Stunde transferiert.

\subsubsection{Ponceau-S-Färbung}

Zur Kontrolle des Gellaufs und des Transfers wurden die Membranen mit Ponceau $S$ angefärbt. Hierbei bindet der Azofarbstoff sequenzunabhängig an die auf die Membran transferierten Proteine.

Zur Anfärbung wurden die Membranen für fünf bis zehn Minuten in Ponceau S inkubiert. Es zeigte sich das charakteristische Bandenmuster der SDS-PAGE. Ponceau S wurde wiederverwendet, Rückstände auf den Membranen mit destilliertem Wasser abgespült.

\subsubsection{Immunodetektion von Proteinen}

Zum Nachweis der zu untersuchenden Proteine diente die Immunodetektion, bei der spezifisch gegen ein Zielprotein gerichtete (Primär-)Antikörper eingesetzt werden. In einem zweiten Schritt werden Sekundärantikörper zugegeben, welche spe- 
zifisch an die Primärantikörper binden. Die Sekundärantikörper sind an das Enzym Meerrettichperoxidase (horseradish peroxidase, HRP) gekoppelt. HRP katalysiert die Oxidation von Luminol, was mit Lumineszenz einhergeht, die proportional zur Menge gebundener Antikörper und somit zur Proteinmenge ist. Sie kann mithilfe eines Röntgenfilms detektiert werden. Hierbei kann die Schwärzung des Films als Maß der Proteinmenge angesehen werden.

Praktisch wurde folgendermaßen vorgegangen: Zunächst wurden die Membranen in 4\%iger Slim-Fast-Lösung in PBS-T für 30 Minuten auf einem Taumelrollenmischer inkubiert, um unspezifische Proteinbindungskapazitäten der Membranen abzusättigen und eine spezifische Detektion durch die Primärantikörper zu ermöglichen. Danach wurde die Blockierlösung durch $2 \mathrm{~mL}$ der Antikörperlösung in PBST ersetzt. Die Membranen wurde über Nacht bei $4{ }^{\circ} \mathrm{C}$ oder alternativ für eine Stunde bei Raumtemperatur auf einem Taumelrollenmischer inkubiert. Daraufhin wurden die Membranen drei Mal für jeweils fünf Minuten in $5 \mathrm{~mL}$ PBS-T gewaschen. Schließlich wurden $2 \mathrm{~mL}$ Sekundärantikörperlösung zugegeben und für $30 \mathrm{Minu}$ ten bei Raumtemperatur, ebenfalls auf dem Taumelrollenmischer, inkubiert. Nach erneutem dreimaligen Waschen (jeweils fünf Minuten in $5 \mathrm{~mL}$ PBS-T) wurden die Membranen in eine vorbereitete Entwicklungskassette zwischen zwei Plastikfolien gelegt. Dann wurde das Luminol-Reagenz im Verhältnis 1:1 gemischt und $800 \mu \mathrm{L}$ über jede Membran pipettiert. Die Filme (CL-XPosure: Thermo Fischer Scientific, Bonn, Deutschland) wurden aufgelegt und in der geschlossenen Entwicklungskassette für wenige Sekunden bis 30 Minuten belichtet und anschließend entwickelt.

\subsubsection{Quantifizierung von Westernblots}

Zur Quantifizierung von Westernblots wurde die Software ImageJ (National Institutes of Health, Bethesda, Maryland, USA), verwendet. Dazu wurden die Filme der Westernblots eingescannt und das Bildmaterial mit ImageJ geladen. Die erste Bande wurde mit einer rechteckigen Auswahl als ebensolche markiert. Das Kästchen der gewählten Größe wurde auf weitere auszuwertende Banden verschoben. Diese wurden ebenfalls markiert. Nach Markierung aller Banden wurden diese geplottet. Mit einer geraden Linie wurde das Hintergrundrauschen von der Kurve der Bandenmessungen abgetrennt. Nun kann die Fläche unter der Kurve gemessen werden. Die gemessenen Werte wurden ausschließlich zu Werten, die aus dem selben Blot resultierten, in Beziehung gesetzt, um die Vergleichbarkeit zu gewährleisten. Es ist einschränkend anzumerken, dass methodenbedingt bei geringen Abständen 
zwischen zwei Banden die Kästchen teilweise überlappen und daher die Quantifizierung in solchen Fällen nur von orientierender Genauigkeit sein kann.

\subsection{Immunhistochemie}

Die Immunhistochemie dient zum Nachweis von Proteinen mittels Antikörpern. Ihre Stärke ist die Möglichkeit, die Verteilung der Proteine in situ bis in die subzellulären Kompartimente darstellen zu können. Dabei werden mit Fluoreszenzfarbstoffen markierte Antikörper verwendet. Der Fluoreszenzfarbstoff wird mittels UVLicht oder Laser stimuliert. Die Proben können unter einem Mikroskop mit einem geeigneten Filtersystem analysiert werden. Auch multiple Färbungen mit Fluoreszenzfarbstoffen, die unterschiedliche Stimulations- und Emissionsspektren besitzen, sind möglich. In dieser Arbeit wurde das indirekte Verfahren verwendet. Hierbei sind die Fluoreszenzfarbstoffe nicht an die direkt gegen das gesuchte Epitop gerichteten Primärantikörper gekoppelt, sondern an sogenannte Sekundärantikörper, die die bereits gebundenen Primärantikörper nachweisen.

\subsubsection{Perfusion der Versuchstiere}

Die Perfusion dient dem vollständigen Austausch des Blutes eines Versuchstiers gegen PBS und dann gegen eine 4\%ige [w/v] Formaldehyd-Lösung. Damit wird eine Beeinflussung von Versuchen, etwa immunhistologischen Färbungen, durch die zellulären Bestandteile des Blutes verhindert. Die FA-Lösung ermöglicht eine optimale Fixierung des Gewebes. Formaldehyd vernetzt Proteine und inhibiert somit Proteasen, die sonst zur Autolyse des Gewebes führen würden. Da die Tiere intravital fixiert wurden, resultierten Präparate ohne jegliche Lyseerscheinungen.

Zuerst wurden die Tiere anästhesiert. Dazu wurde ihnen 0,2 mL Avertin pro 10 g Körpergewicht intraperitoneal gespritzt. Die Wirkung wurde durch Setzen eines Schmerzreizes mittels Kneifen zwischen die Zehen eines Hinterbeins mit einer Pinzette überprüft. Sobald auf diesen Schmerzreiz keine Reaktion mehr erfolgte wurde mit der eigentlichen Perfusion begonnen. Dazu wurden die Tiere auf einem Styroporblock fixiert. Der Bauch wurde mit Ethanol getränkt, dann wurde dort das Fell mit einer Präparierschere eröffnet. Entlang dieses Schnittes wurde das Fell um den Brustkorb herum eröffnet. Dann wurde unter Schonung der Leber der knöcherne Thorax mit der Präparierschere eröffnet. Die Perfusionskanüle wurde im 
linken Ventrikel positioniert. Nun wurde der rechte Vorhof mit einem Schnitt eröffnet, sodass das Blut herauslaufen konnte. Dann wurde der Perfusionsmotor mit einer Geschwindigkeit von $1 \mathrm{~mL} / \mathrm{min}$ eingeschaltet. Die Tiere wurden zunächst mit PBS perfundiert. Wenn die Tiere vollständig mit PBS gespült worden waren (erkennbar an der Entfärbung der Leber) wurde mit FA-Lösung weiter perfundiert, bis der Körper als Zeichen der gelungenen Fixierung hart geworden war. Erstes Zeichen der beginnenden Fixierung ist ein Zucken der Extremitäten. Danach wurden die Gehirne entnommen und über Nacht zur Postfixierung in FA-Lösung eingelegt. Die Gehirne wurden nun in Paraffin eingebettet oder für die Erstellung von Kryoschnitten vorbereitet. Hierfür wurden sie zur Kryoprotektion für zwei bis vier Tage in einer 30\%igen [w/v] Saccharose-Lösung eingelegt.

\subsubsection{Einbettung der Gehirne in Paraffin}

Die präparierten Gehirne wurden in Paraffin eingebettet. Dieser Arbeitsschritt wurde freundlicherweise von S. Sperling, AG Ehrenreich, Max-Planck Institut für Experimentelle Medizin Göttingen, durchgeführt. Dazu wurden sie zunächst mit PBS gewaschen. Zur Einbettung wurde ein Microm HMP 110 (Thermo Scientific, Walldorf, Deutschland) mit folgendem Programm verwendet:

\begin{tabular}{ll} 
HMP 110 Einbettungsschema & \\
\hline $50 \%$ Ethanol & $1 \mathrm{~h}$ \\
$70 \%$ Ethanol & $2 \mathrm{~h}$ \\
$70 \%$ Ethanol & $2 \mathrm{~h}$ \\
$96 \%$ Ethanol & $1 \mathrm{~h}$ \\
$96 \%$ Ethanol & $1 \mathrm{~h}$ \\
$100 \%$ Ethanol & $1 \mathrm{~h}$ \\
$100 \%$ Ethanol & $1 \mathrm{~h}$ \\
Isopropyl & $1 \mathrm{~h}$ \\
Xylol & $2 \mathrm{~h}$ \\
Xylol & $2 \mathrm{~h}$ \\
Paraffin & $2 \mathrm{~h}$ \\
Paraffin & $2 \mathrm{~h}$
\end{tabular}




\subsubsection{Erstellung von Paraffinschnitten}

Mit einem Schlittenmikrotom wurden Paraffinschnitte für immunhistologische Färbungen mit einer Schnittdicke von $5 \mu \mathrm{m}$ hergestellt. Es wurden ausschließlich koronare Schnitte zur Untersuchung des Corpus callosum und des Hippokampus erstellt. Nach dem Schneiden wurden die Paraffinläppchen mit zwei Pinseln in einen mit destilliertem Wasser bei Raumtemperatur gefüllten Behälter überführt. Dort strecken sich die Läppchen ein wenig, woraufhin sie mit einem Objektträger aufgenommen und für 10-20 Sekunden in einen zweiten Behälter, der destilliertes Wasser bei $40{ }^{\circ} \mathrm{C}$ enthält, transferiert wurden. Durch die erhöhte Temperatur strecken sich die Schnitte, bis sie völlig glatt sind. Daraufhin wurden sie wieder mit einem Objektträger aufgenommen.

\subsubsection{Entparaffinieren und Rehydrieren von Paraffinschnitten}

Zunächst wurden die zu färbenden Schnitte für 3,5 Stunden bei $60^{\circ} \mathrm{C}$ inkubiert. Die so vorbereiteten Schnitte wurden nun durch Xylol entparaffiniert. Dazu wurden sie zunächst für zwei Mal 10 Minuten in Xylol und schließlich weitere 10 Minuten in Isopropanol/Xylol [1:1, v/v] inkubiert.

Anschließend wurden die Schnitte mittels einer absteigenden Alkoholreihe rehydriert. Dazu wurden sie für jeweils 5 Minuten zuerst in 100 \% [v/v] Ethanol inkubiert, daraufhin in einer 90\%igen [v/v] Ethanol-Lösung, gefolgt von Lösungen mit $70 \%[\mathrm{v} / \mathrm{v}]$ und $50 \%[\mathrm{v} / \mathrm{v}]$ Ethanolgehalt. Zuletzt wurden die Schnitte für $5 \mathrm{Mi}-$ nuten in destilliertem Wasser inkubiert.

\subsubsection{Antigenrückgewinnung bei Paraffinschnitten}

Bei der Antigenrückgewinnung werden die Antigene nach den vorigen Behandlungen wieder für Antikörper zugänglich und erkennbar gemacht. Hierzu wurden die Schnitte für 5 Minuten bei Raumtemperatur in Citratpuffer inkubiert. Währenddessen wurden $300 \mathrm{~mL}$ Citratpuffer auf $100{ }^{\circ} \mathrm{C}$ erhitzt. Die Schnitte wurden in den heißen Citratpuffer überführt und die Füllhöhe des Gefäßes markiert. Sodann wurden die Schnitte vier Mal für jeweils 5 Minuten in einer Mikrowelle gekocht. Flüssigkeitsverluste durch Verdampfen wurden mit destilliertem Wasser ausgeglichen. Anschließend wurden die Schnitte im Citratpuffer für eine halbe Stunde langsam abgekühlt. 


\subsubsection{Blocking und Antikörperfärbung von Paraffinschnitten}

Bevor die eigentliche Färbung durch Antikörper durchgeführt werden kann, müssen zunächst unspezifische Bindungsstellen für Antikörper durch Zugabe von Protein blockiert werden. Dadurch wird eine unspezifische Anfärbung des Hintergrunds vermieden.

Zunächst wurden die Schnitte einmal für 5 Minuten in TRIS-Puffer + $2 \%$ [w/v] Milchpulver gewaschen. Alle folgenden Schritte wurden in einer abgedunkelten feuchten Kammer durchgeführt. Die Objektträger wurden vorsichtig abgetrocknet, ohne dabei die Präparate zu berühren. Mit einer Pipette wurden $75 \mu \mathrm{L}$ Blockierlösung (25\% [v/v] Ziegenserum, 0,5\% [v/v] Triton X-100 in PBS/BSA) auf die Schnitte gegeben. Sofort wurden die Schnitte mit einem Stück Parafilm bedeckt, um ein Austrocknen zu verhindern. So präpariert inkubierten die Schnitte für 1 Stunde bei Raumtemperatur in der feuchten Kammer. Dieser Schritt dient der Absättigung der unspezifischen Bindungsstellen. Anschließend wird mit der Antikörperfärbung fortgefahren.

Zunächst wurde die gewünschte Verdünnung der Primärantikörper in PBS/BSA + 0,5 \% [v/v] Triton X-100 hergestellt. Daraufhin wurde die Blockierlösung von den Objektträgern dekantiert und $75 \mu \mathrm{L}$ der Antikörperlösung aufpipettiert. Mit Parafilm bedeckt wurden die Schnitte über Nacht bei $4^{\circ} \mathrm{C}$ in der feuchten Kammer inkubiert. Am nächsten Tag wurden die Schnitte drei Mal mit 5 Minuten in TRIS + $2 \%$ Milchpulver gewaschen, die Objektträger abgetrocknet und je $75 \mu \mathrm{L}$ der vorbereiteten Lösung aus Sekundärantikörper und PBS/BSA + 0,5 \% Triton X-100 aufpipettiert. Die mit Parafilm bedeckten Schnitte wurden für 1 Stunde bei Raumtemperatur in der feuchten Kammer inkubiert. Um ein rasches Ausbleichen der Schnitte zu vermeiden, wurde dieser und alle folgenden Schritte schnellstmöglich und soweit umsetzbar im Dunkeln durchgeführt. Nach der Inkubation wurden die Schnitte drei Mal für 5 Minuten in TRIS-Puffer ohne Milchpulver gewaschen. Zuletzt wurden die Schnitte in Aqua-Poly/Mount (Polysciences Europe GmbH, Eppelheim, Deutschland) eingebettet.

\subsubsection{Erstellung von Gefrierschnitten}

Gefrierschnitte sind ein schnelles Routineverfahren, um histologische Präparate von Organen anzufertigen. Dabei wird das Organ zunächst vor Beschädigungen durch den Gefrierprozess geschützt, indem es für zwei bis vier Tage in eine 30\%ige [w/v] Saccharose-Lösung eingelegt wird. Danach kann es mit flüssigem Stickstoff 
gefroren werden, um daraufhin mit Gefriereinbettmedium eingebettet werden. So vorbereitet kann es mit einem Kryostat bei $-20{ }^{\circ} \mathrm{C}$ geschnitten werden. Als Schnittdicke wurden $30 \mu \mathrm{m}$ gewählt. Es wurden ausschließlich koronare Schnitte von Corpus callosum und Hippokampus erstellt. Die Schnitte wurden mit einem Pinsel aufgenommen und in eine 24-Loch-Platte gefüllt mit Ethylenglykol-Glycerol-Lösung überführt. Die Lagerung erfolgt bis zur weiteren Verwendung bei $-20^{\circ} \mathrm{C}$.

\subsubsection{Blocking und Antikörperfärbung von Gefrierschnitten}

Für die Antikörperfärbung der Gefrierschnitte wurden zwei unterschiedliche Protokolle angewendet, um den BACE1-Antikörper 10B8 zu erproben. Die Gefrierschnitte wurden zu jedem Zeitpunkt auf einem Schüttler gelagert. Ab Zugabe der fluorophortragenden Sekundärantikörper wurden alle Schritte unter Lichtausschluss durchgeführt.

\begin{tabular}{|c|c|c|}
\hline & Ursprüngliches Protokoll & Optimiertes Protokoll \\
\hline Waschen & $3 \times 5$ min in PBS & $3 \times 5$ min in PBS \\
\hline Permeabilisierung & $\begin{array}{l}1 \% \text { Triton X-100 in PBS, } 1 \mathrm{~h} \text { bei } \\
\text { RT oder über Nacht bei } 4{ }^{\circ} \mathrm{C}\end{array}$ & $\begin{array}{l}\text { Lösung aus } 5 \%[\mathrm{v} / \mathrm{v}] \text { Pferdeserum } \\
\text { und } 0,3 \%[\mathrm{v} / \mathrm{v}] \text { Triton X-100 in PBS, } \\
1 \text { h bei RT oder über Nacht bei } 4{ }^{\circ} \mathrm{C}\end{array}$ \\
\hline Blocking & Blockierlösung, $1 \mathrm{~h}$ bei RT & (entfällt) \\
\hline Primärantikörper & $\begin{array}{l}\text { Blockierlösung, } 2 \mathrm{~h} \text { bei Raumtem- } \\
\text { peratur oder über Nacht bei } 4{ }^{\circ} \mathrm{C}\end{array}$ & $\begin{array}{l}\text { Lösung aus } 5 \%[\mathrm{v} / \mathrm{v}] \text { Pferdeserum } \\
\text { und } 0,3 \% \text { Triton X-100 [v/v] in PBS, } \\
\text { immer über Nacht bei } 4{ }^{\circ} \mathrm{C}\end{array}$ \\
\hline Waschen & $3 \times 5$ min in PBS & $3 \times 5$ min in PBS \\
\hline Sekundärantikörper & $\begin{array}{l}\text { Blockierlösung, } 2 \mathrm{~h} \text { bei Raumtem- } \\
\text { peratur }\end{array}$ & $\begin{array}{l}2 \%[\mathrm{v} / \mathrm{v}] \text { Pferdeserum in PBS, } 1 \mathrm{~h} \\
\text { bei RT oder über Nacht bei } 4{ }^{\circ} \mathrm{C}\end{array}$ \\
\hline Waschen & $\begin{array}{l}2 \times 5 \text { min unter Lichtausschluss } \\
\text { in PBS }\end{array}$ & (entfällt) \\
\hline
\end{tabular}

Die Schnitte wurden zuletzt mit Leitungswasser gefüllte Petrischale transferiert und von dort mit einem Objektträger aufgenommen. Zur Einbettung wurde AquaPoly/Mount (Polysciences Europe GmbH, Eppelheim, Deutschland) verwendet. 


\subsubsection{Konfokale Laser-Scanning-Mikroskopie}

Bei der konfokalen Laser-Scanning-Mikroskopie wird zu einem Zeitpunkt immer nur ein einzelner Punkt des Präparates mit einem Laser belichtet und aufgenommen. Dadurch ist es möglich, Schnittbilder eines Präparates mit besonders hohem Kontrast zu erzeugen. Die in dieser Arbeit gezeigten Bilder wurden mit einem Zeiss LSM 510 Meta (Carl Zeiss MicroImaging GmbH, Jena, Deutschland) erstellt. Zur Anregung der Fluoreszenz wurde ein 488nm-Argon-Laser sowie ein 543nm-HeNeLaser verwendet. Zur Bildgewinnung wurde ein Plan-Neofluar-20x/0.5-Objektiv ohne Immersion verwendet.

\subsection{Elektronenmikroskopie}

\subsubsection{Fixierung der Präparate}

Die Mäuse wurden wie in 3.3.1 beschrieben perfundiert. Die entnommenen Gehirne wurden mit einem Medianschnitt zerteilt. Eine Hemisphäre wurde für die Immunfluoreszenz in Paraffin eingebettet (s. 3.3.2), die andere Hemisphäre wurde zur elektronenmikroskopischen Auswertung vorbereitet. Dazu wurde sie zunächst für 48 Stunden in Karlsson-Schultz-Fixans (Karlsson und Schultz 1965) postfixiert. Diese Lösung besteht aus $4 \%$ [w/v] Formaldehyd, 2,5 \% [w/v] Glutaraldehyd, $0,5 \%[\mathrm{w} / \mathrm{v}] \mathrm{NaCl}$ in 0,1 M Phosphatpuffer (pH 7,4).

\subsubsection{Einbettung der fixierten Präparate in Epoxidharz}

Diese Arbeit wurde freundlicherweise durch T. Ruhwedel, Max-Planck-Institut für Experimentelle Medizin, Göttingen, durchgeführt. Die Proben wurden mittels des EMTP II (Leica, Wetzlar, Deutschland) in Epoxidharz (Epon) eingebettet. Dazu wurde folgendes Protokoll verwendet: 


\section{EMTP II Einbettungsschema}

\begin{tabular}{|c|c|c|c|}
\hline Reagenz & Dauer & Gesamtzeit & Temperatur \\
\hline 1. Phosphatpuffer & $10 \mathrm{~min}$ & $10 \mathrm{~min}$ & $4^{\circ} \mathrm{C}$ \\
\hline 2. Phosphatpuffer & $10 \mathrm{~min}$ & $20 \min$ & $4^{\circ} \mathrm{C}$ \\
\hline 3. Phosphatpuffer & $10 \min$ & $30 \min$ & $4^{\circ} \mathrm{C}$ \\
\hline $4.2 \% \mathrm{OsO}_{4}$ & $4 \mathrm{~h}$ & $4: 30 \mathrm{~h}$ & $4^{\circ} \mathrm{C}$ \\
\hline 5. Phosphatpuffer & $10 \mathrm{~min}$ & $4: 40 \mathrm{~h}$ & $4^{\circ} \mathrm{C}$ \\
\hline 6. Phosphatpuffer & $10 \mathrm{~min}$ & $4: 50 \mathrm{~h}$ & $4^{\circ} \mathrm{C}$ \\
\hline 7. Phosphatpuffer & $10 \mathrm{~min}$ & $5: 00 \mathrm{~h}$ & $4^{\circ} \mathrm{C}$ \\
\hline 8. $30 \%$ Ethanol & $20 \mathrm{~min}$ & $5: 20 \mathrm{~h}$ & $4^{\circ} \mathrm{C}$ \\
\hline 9. $50 \%$ Ethanol & $20 \mathrm{~min}$ & $5: 40 \mathrm{~h}$ & $4{ }^{\circ} \mathrm{C}$ \\
\hline 10. $70 \%$ Ethanol & $20 \mathrm{~min}$ & $6: 00 \mathrm{~h}$ & $4^{\circ} \mathrm{C}$ \\
\hline 11. $90 \%$ Ethanol & $20 \min$ & $6: 20 \mathrm{~h}$ & $4^{\circ} \mathrm{C}$ \\
\hline 12. $100 \%$ Ethanol & $10 \mathrm{~min}$ & $6: 30 \mathrm{~h}$ & $4^{\circ} \mathrm{C}$ \\
\hline 13. $100 \%$ Ethanol & $10 \mathrm{~min}$ & $6: 40 \mathrm{~h}$ & $4^{\circ} \mathrm{C}$ \\
\hline 14. $100 \%$ Ethanol & $10 \min$ & $6: 50 \mathrm{~h}$ & $4^{\circ} \mathrm{C}$ \\
\hline 15. 2-Propanol & $10 \mathrm{~min}$ & $7: 00 \mathrm{~h}$ & $4^{\circ} \mathrm{C}$ \\
\hline 16. Propylenoxid & $10 \mathrm{~min}$ & $7: 10 \mathrm{~h}$ & RT \\
\hline 17. Propylenoxid & $10 \mathrm{~min}$ & $7: 20 \mathrm{~h}$ & RT \\
\hline 18. Propylenoxid & $10 \mathrm{~min}$ & $7: 30 \mathrm{~h}$ & RT \\
\hline 19. Propylenoxid/Epon 2:1 & $2 \mathrm{~h}$ & $9: 30 \mathrm{~h}$ & RT \\
\hline 20. Propylenoxid/Epon 1:1 & $2 \mathrm{~h}$ & $11: 30 \mathrm{~h}$ & $\mathrm{RT}$ \\
\hline 21. Propylenoxid/Epon 1:2 & $4 \mathrm{~h}$ & $15: 30 \mathrm{~h}$ & RT \\
\hline 22. Epon rein & $4 \mathrm{~h}$ & $19: 30 \mathrm{~h}$ & RT \\
\hline
\end{tabular}

Die Präparate wurden anschließend in Gelatinegussformen (Leica, Wetzlar, Deutschland) gegeben und bei $60{ }^{\circ} \mathrm{C}$ für $24 \mathrm{~h}$ polymerisiert. Zuletzt wurden die Präparate 30 Minuten bei $50{ }^{\circ} \mathrm{C}$ im Wasserbad gerührt, um die Gelatine aufzulösen. 


\subsubsection{Trimmen der in Epon eingebetteten Proben}

Das Trimmen der Eponblöcke dient der groben Orientierung des Präparates in der gewünschten anatomischen Ausrichtung. Dazu wurde ein EM-Trim (Leica, Wetzlar, Deutschland) verwendet.

\subsubsection{Erstellen von Semi- und Ultradünnschnitten}

Semi- und Ultradünnschnitte dienen der licht- und elektronenmikroskopischen Auswertung der Präparate. Verwendet wurde dazu ein Reichert Ultracut S (Leica, Wetzlar, Deutschland). Für Semidünnschnitte zur anatomischen Orientierung wurde ein Histo $8 \mathrm{~mm}, 45^{\circ}$-Diamantmesser (Diatome, Biel, Schweiz) eingesetzt, für Ultradünnschnitte ein Ultra $3 \mathrm{~mm}, 45^{\circ}$-Diamantmesser (Diatome, Biel, Schweiz).

Der vorgetrimmte Eponblock wurde in das Mikrotom eingespannt und in 0,5$\mu \mathrm{m}$-Schritten geschnitten, bis die gesamte Präparatfläche erfasst wurde. Die Schnitte (Dicke: 0,5 $\mu \mathrm{m}$ ) wurden in einem mit Wasser gefüllten Messertrog aufgefangen. Dort wurden sie durch Veränderung der Oberflächenspannung des Wassers mittels Chloroformdampf geglättet. Anschließend wurden sie mit einer abgerundeten Glaspasteuerpipette auf HistoBond-Objektträger (Paul Marienfeld GmbH \& Co. KG, Lauda-Königshofen, Deutschland) überführt. Diese wurden auf einer Heizplatte (HI1220: Leica, Wetzlar, Deutschland) bei $60{ }^{\circ} \mathrm{C}$ getrocknet. Zur Anfärbung wurde eine Lösung mit $1 \%$ [w/v] Azur II- und $1 \%$ [w/v] Methylenblau in destilliertem Wasser verwendet. Die Lösung wurde auf die Schnitte pipettiert und auf der Heizplatte bei $60^{\circ} \mathrm{C}$ für 90 Sekunden inkubiert. Anschließend wurden die Präparate mit aqua dest vorsichtig gespült und auf der Heizplatte abgetrocknet. Die so vorbereiten Proben wurden mit einem Lichtmikroskop (Leica Dialux 20: Leica, Wetzlar, Deutschland) untersucht. War die anatomische Orientierung im Semidünnschnitt zufriedenstellend, wurde mit der Erstellung von Ultradünnschnitten fortgefahren. Ansonsten wurde der Eponblock erneut getrimmt und wieder anhand eines Semidünnschnittes kontrolliert.

Zur elektronenmikroskopischen Auswertung wurden Ultradünnschnitte mit einer Schnittdicke von $50 \mathrm{~nm}$ erstellt. Diese hochempfindlichen Präparate benötigen keine Glättung. Sie wurden daher direkt unter Zuhilfenahme einer an einem Bambusstäbchen befestigten Wimper auf EM-Grids (Kupfer, 0,8 mm dick, hexagonal, 100 mesh) aufgenommen. Die Grids wurden zuvor durch Inkubation in 1,25 \% [w/v] Fomvar in Chloroform beschichtet, um eine erhöhte Adhäsionsfähigkeit und 
Stabilität zu gewährleisten. Die Grids wurden in Gridboxen (Plano, Wetzlar, Deutschland) eingebracht und dort bei Raumtemperatur getrocknet.

\subsubsection{Kontrastierung der Grids}

Die EM-Grids wurden mit $4 \%$ [w/v] Uranylacetat (Spi-Chem, Chester, PA, USA) in destilliertem Wasser für 30 Minuten und dann für 6 Minuten mit Bleicitrat nach Reynolds (Reynolds 1963) kontrasiert.

\subsubsection{Elektronenmikroskopie}

Zur elektronenmikroskopischen Auswertung wurde ein EM 900 (Zeiss, Oberkochen, Deutschland) verwendet. Die Bilder wurden bei 3000facher Vergrößerung erstellt. Die erste Serie wurde analog abfotografiert und als Negativ eingescannt, die zweite Serie wurde aufgrund einer Modernisierung des Elektronenmikroskops mit einer Tröndle sharp:eye-2k-slow-scan-Kamera (Moorenweis, Deutschland) direkt digital aufgenommen. Es wurde eine zufällig gewählte Stelle des Corpus callosum analysiert. Zur Analyse wurden fünf bis sechs nicht überlappende Bilder des Corpus callosum aufgenommen. Jedes Tier wurde einmal analysiert.

\subsubsection{Quantifizierung der Myelinisierung mittels G-Ratio}

Die G-Ratio ist eine dimensionslose Zahl, die das Verhältnis des Durchmessers von Myelinscheide zu Axon beschreibt. Größere Zahlen stehen dabei für eine dünnere, kleinere Zahlen für eine dickere Myelinscheide um das Axon. Zur Berechnung der G-Ratio wurde mit ImageJ v1.44 (National Institutes of Health, Bethesda, Maryland, USA) und einem Grafiktablett (Wacom intuos ${ }_{3}$ : Wacom Europe GmbH, Krefeld, Deutschland) die von den Myelinscheiden umschlossene Fläche sowie die Fläche der dazugehörigen Axone händisch gemessen. Jeder Messwert wurde gelabelt und die erhobenen Daten zur weiteren Verwendung abgespeichert. Aus Ihnen wurde jeweils nach folgenden Formeln Durchmesser und G-Ratio berechnet:
1. $A=\pi \cdot r^{2}$
2. $r=\sqrt{\frac{A}{\pi}}$
3. $G-$ Ratio $=\frac{r(\text { Axon })}{r(\text { Myelinscheide })}$

Für jedes Tier in der Studie wurden mindestens 150 Axone gemessen. 


\subsection{Molekularbiologische Methoden}

\subsubsection{Isolierung und Aufreinigung von genomischer DNA}

Um weiterführende Untersuchungen an der hochmolekularen genomischen DNA durchführen zu können, muss diese zunächst isoliert und aufgereinigt werden. Zu diesem Zweck kam das Invisorb Spin Tissue Mini Kit (STRATEC Molecular GmbH, Berlin, Deutschland) zum Einsatz. Das Kit wurde wie vom Hersteller beschrieben eingesetzt. Die DNA-Proben wurden bis zur weiteren Analyse bei $-20{ }^{\circ} \mathrm{C}$ gelagert.

\subsubsection{Polymerase-Kettenreaktion}

Die Polymerase-Kettenreaktion (polymerase chain reaction, $P C R$ ) ist ein molekularbiologisches Verfahren zur schnellen Vervielfältigung spezifischer Abschnitte der genomischen DNA (Saiki et al. 1985). Dabei wird eine besonders hitzestabile DNAPolymerase verwendet, die ursprünglich aus dem Bakterium Thermus aquaticus isoliert werden konnte (Chien et al. 1976). Die zu vervielfältigen Abschnitte werden durch spezifische Primer bestimmt. In dieser Arbeit wurden dafür Primer verwendet, die freundlicherweise von der DNA Core Facility des Deparment of Molecular Neurobiology des Max-Planck-Instituts für Experimentelle Medizin zur Verfügung gestellt wurden.

\begin{tabular}{cc}
\hline Kennziffer & Sequenz \\
\hline 12888 & 5'-AGG CAG CTT TGT GGA GAT GGT G-3' \\
12889 & 5'-CGG GAA AtG GAA AGG CTA CTC C-3' \\
12890 & 5 '-TGG ATG TGG AAT GTG TGC GAG-3' \\
\hline
\end{tabular}

Hierbei ist 12889 der gemeinsame Primer für Wildtyp- und knock-out-Allel. Liegt das Wildtypallel vor, wird gemeinsam mit Primer 12888 ein 272 Basenpaare langes Produkt amplifiziert. Liegt das knock-out-Allel vor, wird gemeinsam mit Primer 12890 ein 157 Basenpaare langes Produkt amplifiziert. Liegen beide Allele vor, lassen sich beide Produkte in der Agarosegelelektrophorese nachweisen. Zwei Banden zeigen also in der Agarosegelelektrophorese den heterozygoten Genotyp an. Ist nur die obere Bande, gebildet durch das Geprodukt des Wildtypallels, vorhanden, handelt es sich um ein Tier des Wildtyps. Das Vorhandensein ausschließlich der unteren Bande, gebildet durch das Genprodukt des BACE1-ko-Allels, kennzeichnet BACE1-ko-Tiere. Die Genotypen werden für Wildtyp-Tiere auch als +/+, 
für reine knock-out-Tiere als -/- und für heterozygote Tiere als +/- abgekürzt (Abbildung 3.1).

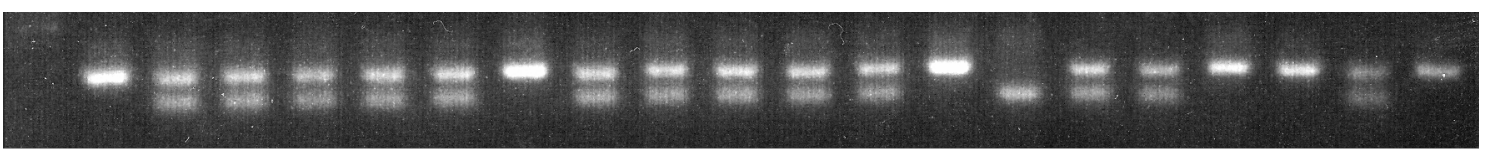

$\mathrm{WT}+/-+/-+/-+/-+/-\mathrm{WT}+/-+/-+/-+/-+/-\mathrm{WT}$ ko +/- +/- WT WT+/- WT

Abbildung 3.1: Genotypisierung. Von 20 Tieren besitzen fünf das Wildtyp-Allel von BACE1 (WT), 14 sind heterozygot (+/-) und genau eines besitzt keine funktionsfähige Kopie (ko).

Es wurde die GoTaq-DNA-Polymerase (Promega, Mannheim, Deutschland) mit dem 5x-Green-GoTaq-Flexi-Buffer (Promega, Mannheim, Deutschland) verwendet. Jeder Reaktionsansatz enthielt $1 \mu \mathrm{L}$ gereinigte genomische DNA, $1 \mu \mathrm{L} 25 \mathrm{mM} \mathrm{MgCL}_{2}$, je $1 \mu \mathrm{L}$ der $10 \mu \mathrm{M}$ Primer-Lösungen 12888, 12889 und 12890, $2 \mu \mathrm{L} 10 \mathrm{mM}$ dNTP, $4 \mu \mathrm{L}$ 5xGreen-GoTaq-Flexi-Buffer, 8,75 $\mu \mathrm{L}$ doppelt destilliertes Wasser und 0,25 $\mu \mathrm{L}$ GoTaqDNA-Polymerase. Erste Versuche ohne zusätzliches $\mathrm{MgCl}_{2}$ zeigten wechselhafte Resultate.

Der Thermocycler war folgendermaßen programmiert:

\section{Thermocycler-Programm BACE1}

Lid $99^{\circ} \mathrm{C}$

$1.95^{\circ} \mathrm{C}$ Pause

$2.95^{\circ} \mathrm{C} 3 \mathrm{~min}$

$3.95^{\circ} \mathrm{C} 45 \mathrm{sec}$

$4.58^{\circ} \mathrm{C} 1 \mathrm{~min}$

$5.72{ }^{\circ} \mathrm{C} 1 \mathrm{~min}-35 x$ zurück zu Schritt 3

$6.72{ }^{\circ} \mathrm{C} 10 \mathrm{~min}$

7. $4^{\circ} \mathrm{C}$ Pause

Die Proben wurden nach Amplifikation umgehend mittels Agarosegelelektrophorese analysiert. 


\subsubsection{Agarosegelelektrophorese}

Mit der Agarosegelelektrophorese ist es möglich, DNA-Fragmente entlang eines elektrischen Gradienten nach ihrer Größe aufzutrennen. Das Agarosegel bildet dabei Poren, deren Größe durch die verwendete Agarosemenge variiert werden kann. Für die BACE1-Genotypisierung wurden Gele mit $2 \%$ Agarose in TAE-Puffer verwendet. Den Gelen wurde $1 \mathrm{mg} / \mathrm{L}$ Ethidiumbromid (EtBr) beigemischt. Zur Größenbestimmung der Amplifikate wurde $5 \mu \mathrm{L}$ GeneRuler 100bp DNA Ladder (Fermentas, St. Leon-Roth, Deutschland) verwendet. Von den PCR-Reaktionsansätzen wurden je $18 \mu \mathrm{L}$ analysiert. Die Elektrophorese erfolgte in TAE-Puffer bei $100 \mathrm{~V}$ für eine Stunde. Nach Abschluss der Trennung wurde das Gel mit einer UV-Lampe belichtet und zur Auswertung und Dokumentation abfotografiert (Intas Gel Documentation System: Intas Science Imaging Instruments GmbH, Göttingen, Deutschland).

\subsection{Das Cuprizonemodell}

Dieser Versuch wurde in Kooperation mit H. Ehrenreich und N. Hagemeyer, AG Ehrenreich, Max-Planck-Institut für Experimentelle Medizin Göttingen, durchgeführt. Der Verfasser etablierte und betreute die Zucht der erworbenen BACE1-ko-Mäuse im Tierhaus des Max-Planck-Instituts für Experimentelle Medizin in Göttingen und etablierte die Genotypisierung mittels PCR in der AG Simons. Insgesamt wurden im Rahmen dieser Doktorarbeit 367 Tiere genotypisiert.

Die Tiere für die Cuprizonestudie wurden aus dem Tierhaus des Max-PlanckInstituts für Eperimentelle Medizin Göttingen in die Versuchstiereinheit der AG H. Ehrenreich transferiert. Dort erfolgte die Tierhaltung nach behandelten und unbehandelten Tieren getrennt in Standard-Plastikkäfigen in Gruppen zu je 5 Tieren. Die Raumtemperatur betrug $21+-2{ }^{\circ} \mathrm{C}$, der Licht-Dunkel-Zyklus 12 Stunden. Die unbehandelten Tiere erhielten die reguläre Diät (ssniff, Soest, Deutschland) ad libitum, während das Futter der behandelten Tiere 0,2 \% [w/w] Cuprizone enthielt (ssniff, Soest, Deutschland). Wasser erhielten beide Gruppen ad libitum. Das Körpergewicht der Tiere wurde regelmäßig erfasst und protokolliert. Vor der Behandlungsphase, an ihrem Ende und nach einer sechswöchige Erholungsphase wurde mit allen Tieren der Startleversuch durchgeführt. 


\subsection{Der Startleversuch}

Der Startleversuch dient der quantitativen Erfassung des Ausmaß der Schreckreaktion der Versuchstiere auf einen akustischen Stimulus (Logue et al. 1997). Dieser Versuch wurde ebenfalls in Kooperation mit H. Ehrenreich und N. Hagemeyer, AG Ehrenreich, Max-Planck-Institut für Experimentelle Medizin Göttingen, durchgeführt. Dazu wurden die Tiere in einem kleinen Metallkäfig von $9 \times 4 \times 4 \mathrm{~cm}$ platziert, in denen ein Sensor vertikale Bewegungen der Bodenplatte misst. Die Käfige wurden in schallgedämmte Kabinen gestellt (TSE GmbH, Bad Homburg, Deutschland), in denen sich ein Lautsprecher befand. Hier wurde als Hintergrundgeräusch weißes Rauschen von 65 dB dargeboten, an das die Tiere sich zwei Minuten habituieren konnten. Danach wurden insgesamt 19 verschiedene akustische Stimuli steigender Intensität (von 65 bis 120 dB in 3-dB-Schritten, Dauer je $40 \mathrm{~ms}$ ) dargeboten. Zwischen den Stimuli herrschte weiterhin weißes Rauschen von 65 dB. Jeder Stimulus wurde zehn Mal in pseudorandomisierter Reihenfolge dargeboten, die Pause zwischen den Stimuli betrug 8 und 22 Sekunden. Die Amplitude der vertikalen Bewegung der Bodenplatte wurde für $100 \mathrm{~ms}$ ab Tonbeginn in arbitrary units (AU) protokolliert. Zur statistischen Auswertung der Stimulus-Antwort-Kurven wurden die Mittelwerte der einzelnen Gruppen verwendet.

\subsection{Statistische Auswertung}

In der vorliegenden Arbeit wurde eine statistische Signifikanz ab einem P-Wert von kleiner als 0,05 angenommen. Sehr signifikante Ergebnisse waren als $\mathrm{P}<0,01$, hoch signifikante Ergebnisse als $\mathrm{P}<0,001$ definiert. Die statistische Auswertung der Quantifizierung der Westernblots mittels eines zweiseitigen t-Tests erfolgte mit dem GraphPad QuickCalcs t test calculator (GraphPad Software, Inc., La Jolla, Kalifornien, USA; http://www.graphpad.com/quickcalcs/ttest1/). Die statistische Auswertung der Cuprizonestudie mittels zweiseitiger Varianzanalayse (two-way analysis of variance, two-way ANOVA) erfolgte mit der Software SigmaPlot des Herstellers Systat Software GmbH (Erkrath, Deutschland). Die statistische Auswertung des Startleversuchs erfolgte mittels Prism5 (GraphPad Software, Inc., La Jolla, Kalifornien, USA) und SPSS für Windows 17.0 (IBM Deutschland GmbH, Ehningen, Deutschland). 


\section{Ergebnisse}

\subsection{Die BACE1-Expression in Modellen der Demyelinisierung}

\subsubsection{Fragestellung und experimentelles Vorgehen}

Die Fragestellung des ersten Teils dieser Arbeit war, ob die Expression von BACE1 in Modellen der Demyelinisierung verändert ist. Im Lichte der Berichte über die Rolle von BACE1 bei der Myelinisierung im Peripheren und Zentralen Nervensystem (Hu et al. 2006; Willem et al. 2006) erschien dies als realistischer Vorgang. Dazu wurden bereits in der Arbeitsgruppe vorliegende Lysate freipräparierter Hirnstämme von Ratten, bei denen eine EAE induziert worden war, sowie von Gehirnen von Mäusen, die mit Cuprizone behandelt worden waren, mittels Westernblot analysiert.

\subsubsection{BACE1-Expression in Zellpopulationen des ZNS}

Um für Aussagen über mögliche Quellen von BACE1 in den Gewebslysaten auf eigene Dateien zurückgreifen zu können und den zur Verfügung stehenden Antikörper gegen BACE1 weiter im Westernblot zu charakterisieren, wurde zunächst die Expression von BACE1 in Zellpopulationen des ZNS untersucht. Dazu wurden Lysate von Maus-Primärzellkulturen der verschiedenen Populationen erstellt. Die Kulturen wurden von Mitgliedern der Arbeitsgruppe zur Verfügung gestellt. Als Positivkontrolle diente ein Gehirnlysat einer Ratte, als Referenzprotein wurde Aktin verwendet. Verglichen wurde der Gehalt an BACE1 in hippokampalen und kortikalen Neuronen, in Oligodendrozyten, in Astrozyten und in Mikroglia. Dabei zeigten sich die höchsten BACE1-Level in Neuronen. Doch auch in Oligodendrozyten ließen sich größere Mengen an BACE1 nachweisen. Astrozyten und Mikroglia wiesen nur Spuren von BACE1 auf. Die Quantifizierung von BACE1 gegen Aktin ergab ein Verhältnis von 2,53 in hippokampalen und von 5,34 in kortikalen Neuronen, von 0,99 in 
Oligodendrozyten, von 0,04 in Astrozyten und von 0,02 in Mikroglia (vgl. Abbildung 4.1 und Abbildung 4.2).

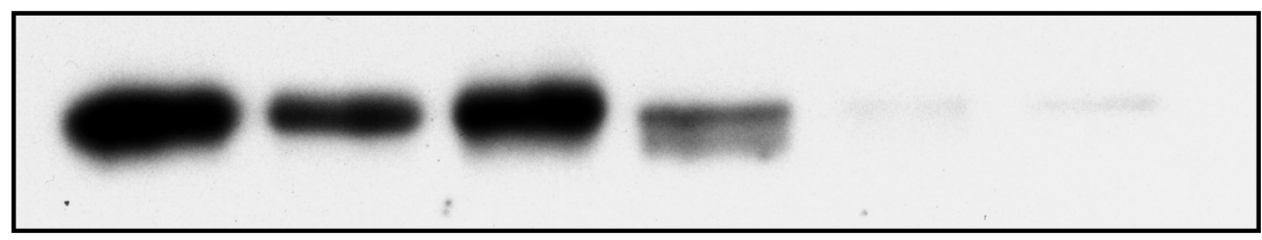

BACE1

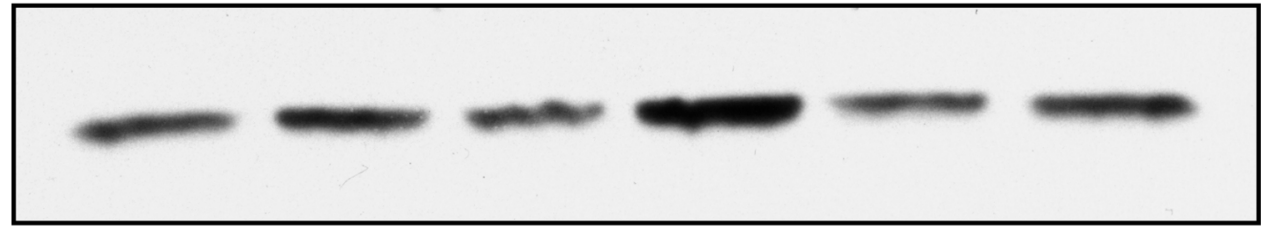

Aktin

\section{Gehirnlysat HippoN KorN Oligo Astrozyten Mikroglia}

Abbildung 4.1: BACE1-Verteilung in Zellpopulationen des ZNS. Als Positivkontrolle diente ein Gehirnlysat. Gehirnlysat einer Ratte, murine Primärzellkulturen. BACE1 lässt sich in allen neuronalen Zellen nachweisen. HippoN = hippokampale Neurone, KorN = kortikale Neurone. Oligo = Oligodendrozyten.

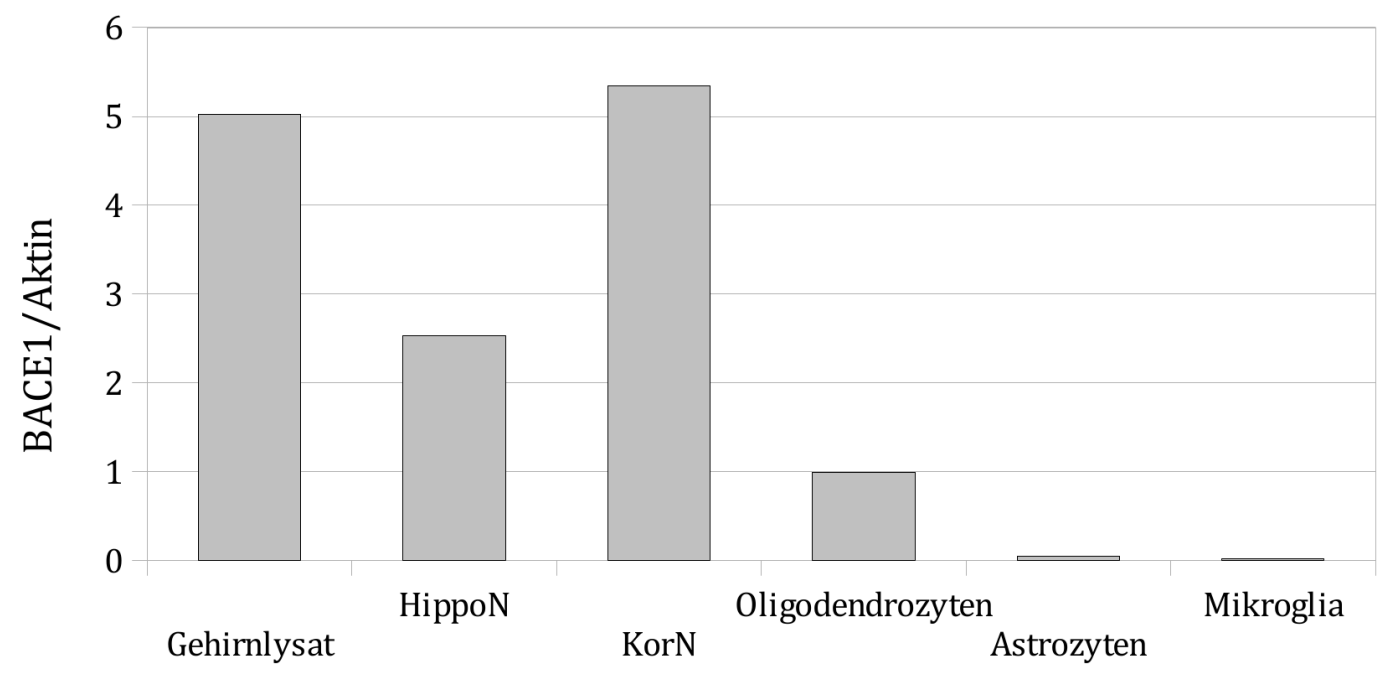

Abbildung 4.2: BACE1-Verteilung in Zellpopulationen des ZNS. Quantifizierung des Westernblots von Abbildung 4.1 Gehirnlysat einer Ratte, murine Primärzellkulturen. HippoN = hippokampale Neurone, KorN = kortikale Neurone. 


\subsubsection{BACE1-Expression in Modellen der Demyelinisierung}

Die Untersuchung der BACE1-Expression in Gehirnlysaten von mit Cuprizone behandelten Mäusen liefert eine erste Annäherung an die Frage, ob BACE1 im Rahmen der De- und Remyelinisierung eine Rolle spielt. Dabei steht im Cuprizonemodell vor allem die toxische Komponente im Vordergrund: Oligodendroyten als Myelinbildner des ZNS werden durch den Kupferchelator Cuprizone in die Apoptose getrieben. Eine umfangreiche Demyelinisierung ist die Folge, die sich nach Absetzen von Cuprizone zurückbildet (Matsushima 2001). Analysiert wurden vier unbehandelte Mäuse als Kontrolle sowie fünf mit Cuprizone behandelte Tiere. Als Referenzprotein diente Calnexin. Die Quantifizierung zeigte dabei durchschnittlich eine Halbierung des Gehalts an BACE1 in mit Cuprizone behandelten Tieren im Vergleich zur Kontrollgruppe (BACE1-Calnexin-Quotient von 0,52 in der Kontrollgruppe zu 0,25 in der Cuprizonegruppe, vgl. Abbildung 4.3 und Abbildung 4.4). Diese Ergebnisse zeigten jedoch keine statistische Signifikanz $(\mathrm{P}=0,12)$.

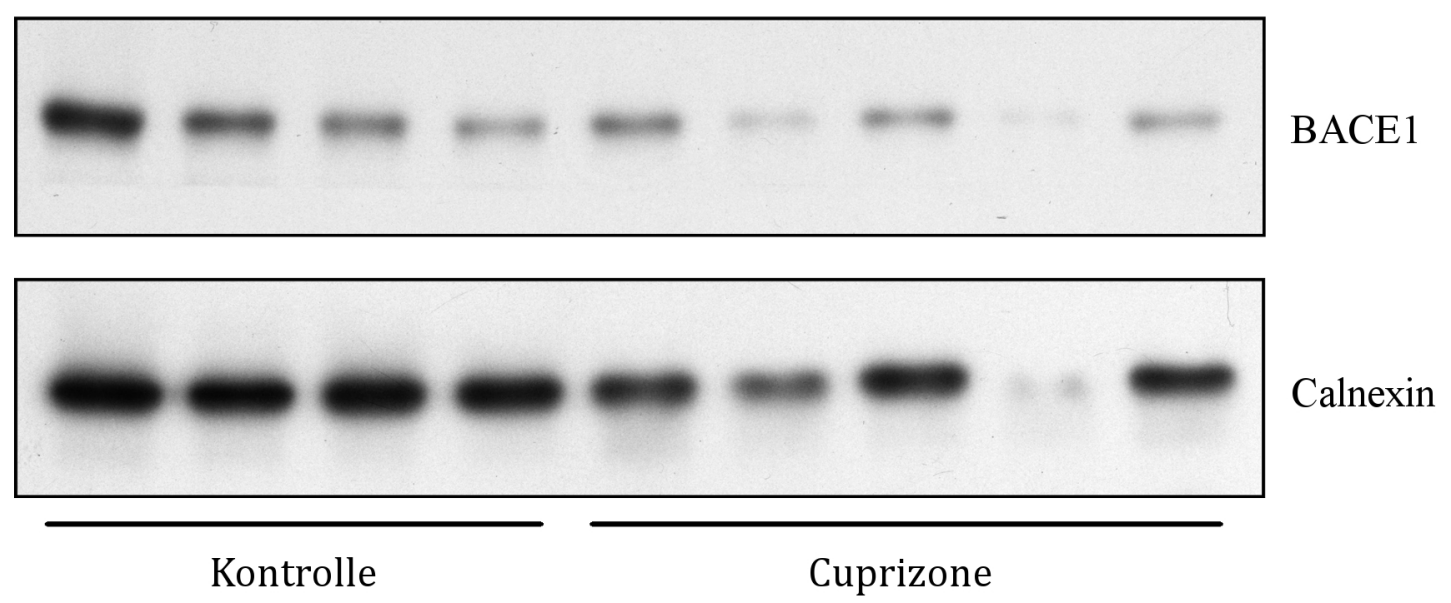




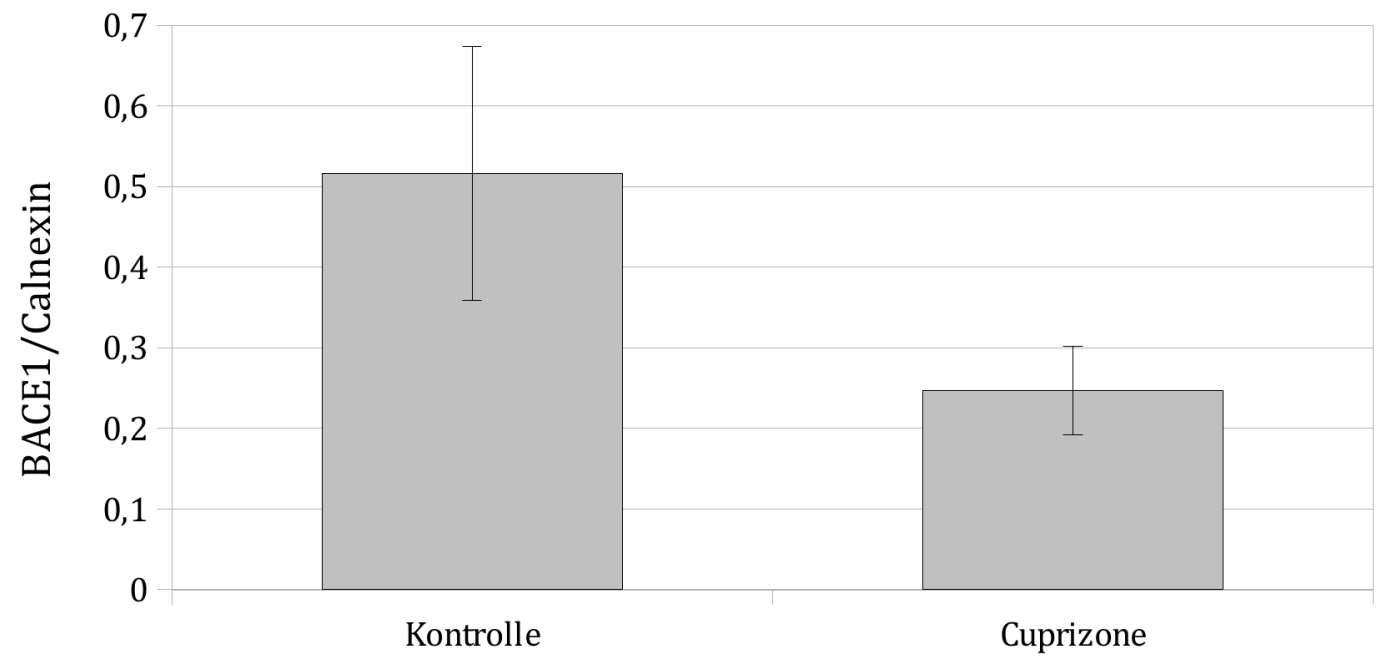

Abbildung 4.4: BACE1-Expression in Gehirnlysaten von Mäusen nach Cuprizonebehandlung. Quantifizierung des Westernblots von Abbildung 4.3. Fehlerbalken zeigt SEM (standard error of the mean).

Um Daten aus einem anderen Aspekt der Demyelinisierung zu erhalten, wurden die freipräparierten Hirnstämme von Ratten, bei denen eine EAE induziert worden war, untersucht. In diesem Modell steht die autoimmune Reaktion im Vordergrund. Im Vergleich mit dem Cuprizonemodell ließen sich so Schlüsse auf die Rolle von BACE1 bei verschiedenen Formen der Demyelinisierung ziehen. Analysiert wurden je vier unbehandelte Tiere als Kontrolle mit vier EAE-Tieren. Als Referenzprotein diente wieder Calnexin. Die Quantifizierung zeigte dabei durchschnittlich eine Verdopplung des Gehalts an BACE1 in behandelten Tieren im Vergleich zur Kontrollgruppe (BACE1-Calnexin-Quotient von 0,46 in der Kontrollgruppe zu 1,24 in der EAE-Gruppe, vgl. Abbildung 4.5 und Abbildung 4.6). Auch diese Ergebnisse zeigten keine statistische Signifikanz $(P=0,089)$. 


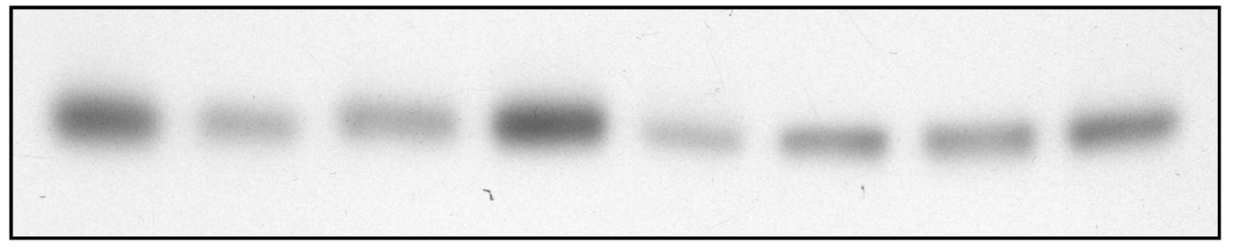

BACE1

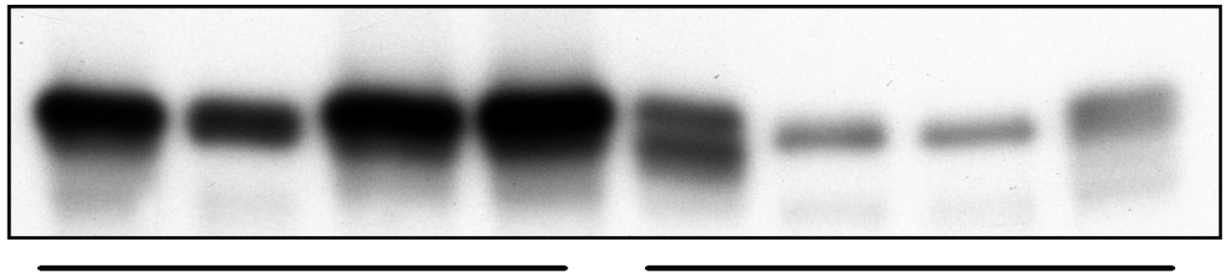

Calnexin

Kontrolle

EAE

Abbildung 4.5: BACE1-Expression in Hirnstammlysaten von Ratten nach Induktion einer EAE.

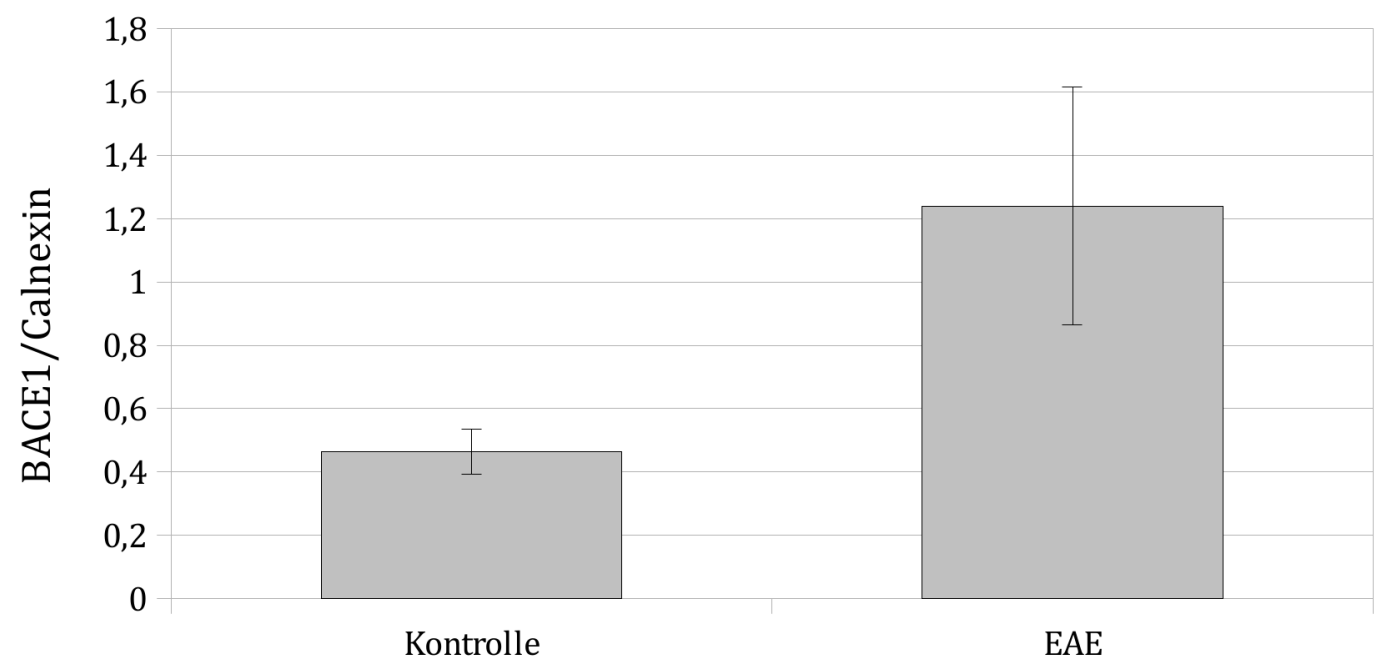

Abbildung 4.6: BACE1-Expression in Hirnstammlysaten von Ratten nach Induktion einer EAE. Quantifizierung des Westernblots von Abbildung 4.5. Fehlerbalken zeigt SEM.

\subsubsection{BACE1-Expression im Rahmen von Inflammation}

Da gerade die Daten der EAE-Ratten einen robusten Trend zur vermehrten Expression von BACE1 im Zusammenhang mit Inflammation erkennen ließen und Mikrogliazellen eine wichtige Rolle in der Pathophysiologie von MS- und EAE-Läsionen spielen (Gold et al. 2006), lag die Hypothese nahe, dass diese Zellpopulation zur BACE1-Vermehrung in der EAE beiträgt. Somit sollten proinflammatorische Fakto- 
ren eine Erhöhung der BACE1-Expression in Mikroglia bewirken. Als Modell wurden EOC-20-Zellen (ATCC-Nummer CRL-2469), eine immortalisierte Zellinie von Mikroglia aus dem Mausstamm C3H/HeJ, verwendet. Diese Zellen wurden für 24h mit Liganden von toll-like-Rezeptoren und proinflammatorischen Chemokinen stimuliert und anschließend ihr Gehalt an BACE1 gemessen. Als Referenzprotein diente Aktin. Dabei zeigte sich bereits in den unbehandelten Kontrollzellen ein niedriger BACE1-Level. In den mit CpG, einem Liganden des TLR 9, stimulierten Zellen zeigte sich eine deutliche Zunahme der BACE1-Expression. Keinen Einfluss auf BACE1 hatten Lipopolysaccharide (LPS) als Liganden von TLR 4, und Rantes, ein Chemokin. Die Quantifizierung zeigte dabei für die unbehandelten Kontrollzellen einen niedrigen Wert von 0,22. Vergleichbare Werte von 0,23 und 0,21 wiesen die mit LPS und mit Rantes behandelten Zellen auf. Eine Verdoppelung auf 0,45 zeigten die mit CpG behandelten Zellen. Das Macrophage Inflammatory Protein $1 \alpha$ (MIP-1 $\alpha$ ), ein Chemokin, führte zu einer Zunahme um etwa die Hälfte auf 0,33 (vgl. Abbildung 4.7 und Abbildung 4.8).

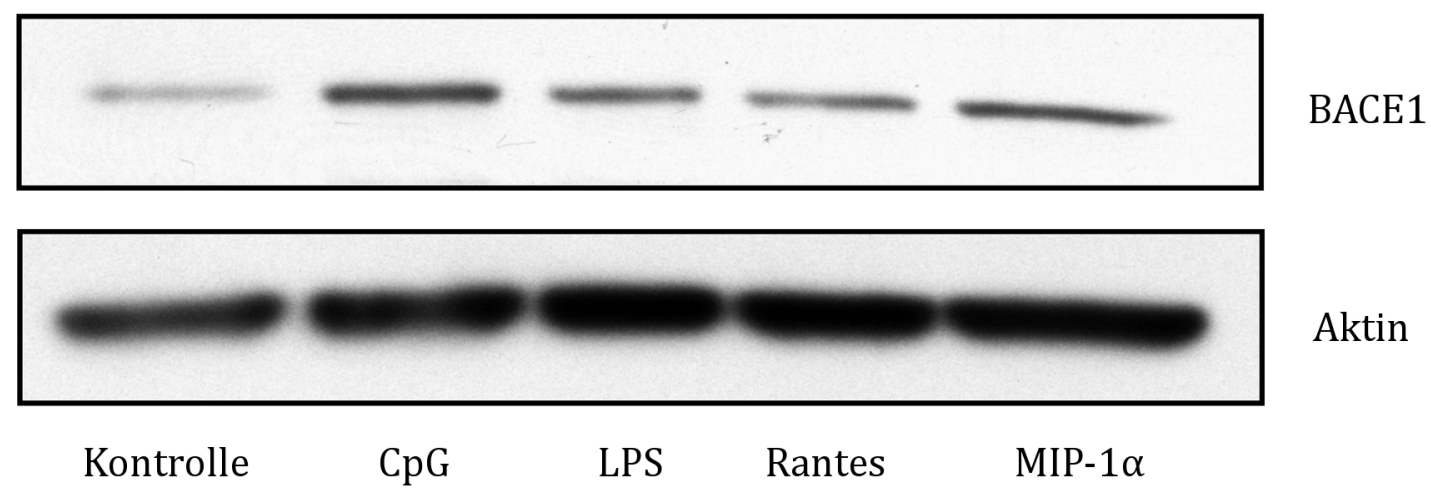

Abbildung 4.7: BACE1-Expression in EOC-Zellen nach Stimulation durch Liganden von toll-like-Rezeptoren und Chemokinen. 


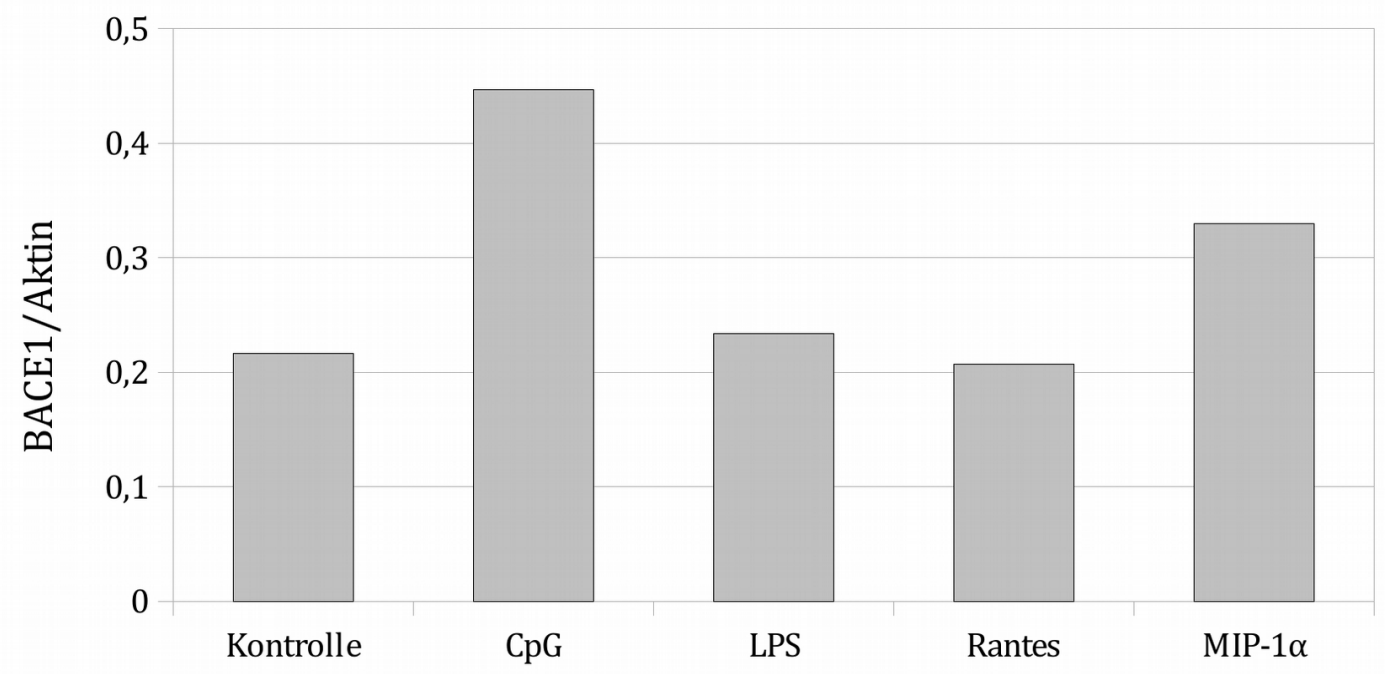

Abbildung 4.8: BACE1-Expression in EOC-Zellen nach Stimulation durch Liganden von toll-like-Rezeptoren und Chemokinen. Quantifizierung des Westernblots von Abbildung 4.7.

\subsection{Der BACE1-Antikörper 10B8 in der Immunfluoreszenz}

In einem zweiten Schritt sollte der BACE1-Antikörper 10B8 näher charakterisiert und erstmals auf seine Eignung zur Färbung von Zellen und Geweben mittels Immunofluoreszenz getestet werden. Sollte der Antikörper in der Immunfluoreszenz einsetzbar sein, wäre es möglich, mittels Kolokalisationsstudien den genauen Zelltyp festzustellen, der für die erhöhten BACE1-Werte in den EAE-Proben verantwortlich ist.

Umfangreiche Versuche in der Immunozytochemie und in der Immunohistochemie an Kryo- und Paraffinschnitten von murinen Gehirnen sowie Rückenmarkspräparaten mit den im Methodenteil dargelegten Färbeprotokollen zeigten jedoch ausschließlich unspezifisches Anfärbeverhalten des Antikörpers im Vergleich zu Kontrollschnitten von BACE1-reMäusen. Auch die verschiedenen eingesetzten Methoden zur Antigen-Rückgewinnung und -Blockierung ergaben jeweils dasselbe, unspezifische Färbemuster. Die als Kontrolle verwendeten BACE1-ko-Tiere wurden zur Bestätigung erneut genotypisiert. Zusammenfassend ist daher festzuhalten, dass der BACE1-Antikörper 10B8 mit den hier verwendeten Protokollen nicht zur Verwendung in der Immunfluoreszenz geeignet ist. Daher konnte der für die BACE1-Hochregulation verantwortliche Zelltyp durch diese Technik mittels dieses Antikörpers nicht genauer festgelegt werden. 


\subsection{Die Remyelinisierung im ZNS von BACE1-ko-Mäusen nach Cuprizonebehandlung}

\subsubsection{Fragestellung und Studiendesign}

Teile der nun vorzustellenden Cuprizonestudie sind bereits an anderer Stelle durch den Verfasser publiziert worden (Treiber et al. 2012). Dieser Umstand ist jeweils an den Abbildungen kenntlich gemacht. N. Hagemeyer, Max-Planck-Institut für Experimentelle Medizin Göttingen, unterstützte Durchführung und Auswertung dieser Studie. Dies wird in den entsprechenden Abbildungen kenntlich gemacht. Ihr Einverständnis für die Veröffentlichung der Daten liegt vor.

Der Befund, dass mit Cuprizone behandelte Tiere zum Zeitpunkt der Demyelinisierung eine geringere BACE1-Expression im ZNS aufwiesen, führte zur Hypothese, das BACE1 eine Rolle beim Erhalt der Myelinscheiden haben könnte. Zusammen mit seinem Einfluss auf die Myelinisierung ergab sich daraus die Frage, ob auch die Remyelinisierung durch BACE1 vermittelt wird. Um die Remyelinisierung studieren zu können, wurde das bereits beschriebene Cuprizonemodell verwendet. Füttern des Kupferchelators Cuprizone für sechs Wochen löst durch Apoptose der Oligodendrozyten eine nahezu vollständige Demyelinisierung im ZNS aus. Nach weiteren sechs Wochen hat bei Wildtyptieren eine umfangreiche Remyelinisierung stattgefunden. In dieser Studie wurden 51 Tiere untersucht. Davon dienten 20 Tiere als Kontrollgruppe, während 31 Tiere mit Cuprizone behandelt wurden. Jede Gruppe bestand aus zwei Kohorten: Tiere des Wildtyps und BACE1-ko-Mäuse. Nach einer sechswöchigen Behandlungsphase wurden sechs Tiere untersucht, um das Ansprechen der BACE1-ko-Mäuse auf Cuprizone zu überprüfen. Die übrigen Tiere wurden weitere sechs Wochen ohne Cuprizonegabe gehalten. Mit dieser Regenerationsphase soll die Remyelinisierung ermöglicht werden. Das Gewicht der Tiere wurde regelmäßig kontrolliert. Nach Abschluss der Behandlungs- und Regenerationsphasen wurde jeweils zusätzlich als klinischer Parameter der Startleversuch durchgeführt. Dabei wird das Ausmaß der Schreckreaktion auf definierte akustische Reize gemessen. Um die Remyelinisierung bewerten zu können, wurden die Tiere elektronenmikroskopisch untersucht und zur Quantifizierung G-Ratios als Maß der Dicke der Myelinschicht erhoben (vgl. für das Studiendesign Abbildung 4.9). 
Kontrollgruppe (n=20; Wildtyp n=10, BACE1-ko n=10)

\begin{tabular}{|c|c|c|}
\hline \multicolumn{3}{|c|}{ Keine Behandlung } \\
\hline \multicolumn{3}{|c|}{ Cuprizonegruppe (n=31; Wildtyp n=15, BACE1-ko n=16) } \\
\hline & erung & linisierung \\
\hline & sphase & rationsphase \\
\hline 0 Wochen & $\begin{array}{l}\text { Histolo } \\
\text { der De }\end{array}$ & $\begin{array}{r}12 \text { Wochen } \\
\text { Elektronenmikroskopie } \\
\text { G-Ratio }(\mathrm{n}=45), \\
\text { Startleversuch }\end{array}$ \\
\hline
\end{tabular}

Abbildung 4.9: Design der Cuprizonestudie. Modifiziert nach Treiber et al. 2012.

Die vier Gruppen in der Cuprizonestudie wurden durch Tiere mit möglichst gleichem Alter und ähnlicher Verteilung der Geschlechter gebildet. Die Kontrollgruppe bestand aus sechs Weibchen des Wildtyps und sechs BACE1-ko-Weibchen sowie aus vier Männchen des Wildtyps und vier BACE1-ko-Männchen. Das Durchschnittsalter der Wildtypiere bei Perfusion betrug 174,3 Tage, das der BACE1-ko-Tiere 168,5 Tage. In der Cuprizonegruppe befanden sich neun Weibchen des Wildtyps und neun BACE1-ko-Weibchen sowie sechs Männchen des Wildtyps und sieben BACE1-ko-Männchen. Zur Kontrolle der Demyelinisierung wurden drei WildtypWeibchen verwendet, während eine weibliche und zwei männliche BACE1-ko-Mäuse entnommen wurden. Damit befanden sich in der Endauswertung der G-Ratios in der Cuprizonegruppe sechs Wildtyp- und acht BACE1-ko-Weibchen sowie sechs Wildtyp- und fünf BACE1-ko-Männchen. Insgesamt durchliefen also 12 Wildtypund 13 BACE1-ko-Mäuse die Remyelinisierung. Das Durchschnittsalter der Tiere in diesem Studienarm betrug bei Abschluss der Regenerationsphase 168,2 Tage für den Wildtyp und 171,2 Tage für die BACE1-ko-Mäuse. Um diese hohe Anzahl an passenden Versuchstieren zu erreichen, musste die Cuprizonebehandlung in zwei Durchläufen durchgeführt werden, da während des Reviewprozesses für die Publikation in Molecular Psychiatry eine Erhöhung der Stichprobengröße gefordert worden war. Die Kontrollgruppe konnte bereits beim ersten Durchlauf ausreichend besetzt werden, sodass dieser Teil des Experiments nicht wiederholt werden musste. Die ursprünglichen Ergebnisse und die Auswertung der erweiterten Cuprizonegruppe werden hier vorgestellt. 


\subsubsection{Ist das Cuprizonemodell in BACE1-ko-Mäusen anwendbar?}

Die Demyelinisierung nach sechswöchiger Cuprizonebehandlung wurde mittels Immunfluoreszenz gegen das basische Myelinprotein (Myelin Basic Protein, MBP) im Vergleich zu unbehandelten Kontrolltieren beider Genotypen untersucht. Dazu wurden koronare Paraffinschnitte der entnommenen Gehirne erstellt. Untersucht wurde das Corpus callosum als besonders kräftig myelinisierte Struktur. Dabei zeigte sich in den unbehandelten Tieren ein starkes MBP-Signal als Korrelat einer regelrechten, anatomisch korrekten Myelinisierung des Corpus callosum. In den mit Cuprizone behandelten Tieren beider Genotypen war das MBP-Signal sehr schwach und nur in vereinzelten Flecken detektierbar. Es zeigte sich folglich eine nahezu vollständige Demyelinisierung (vgl. Abbildung 4.10). Damit konnte gezeigt werden, dass das Cuprizonemodell zur Untersuchung von Demyelinisierung auch in BACE1-ko-Mäusen verwendbar ist und ein Fehlen von BACE1 die Wirkung von Cuprizone auf Oligodendrozyten nicht behindert. 


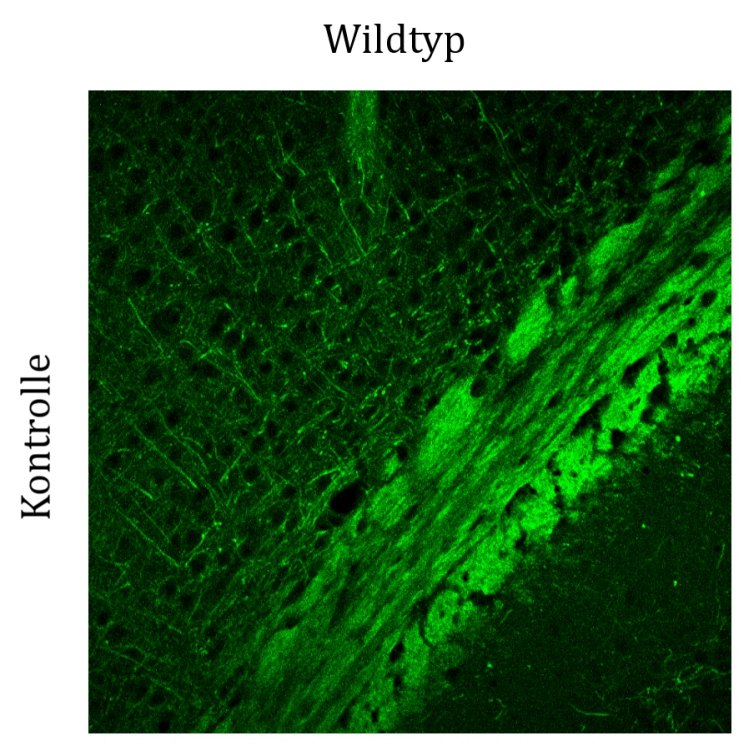

BACE1 -/-
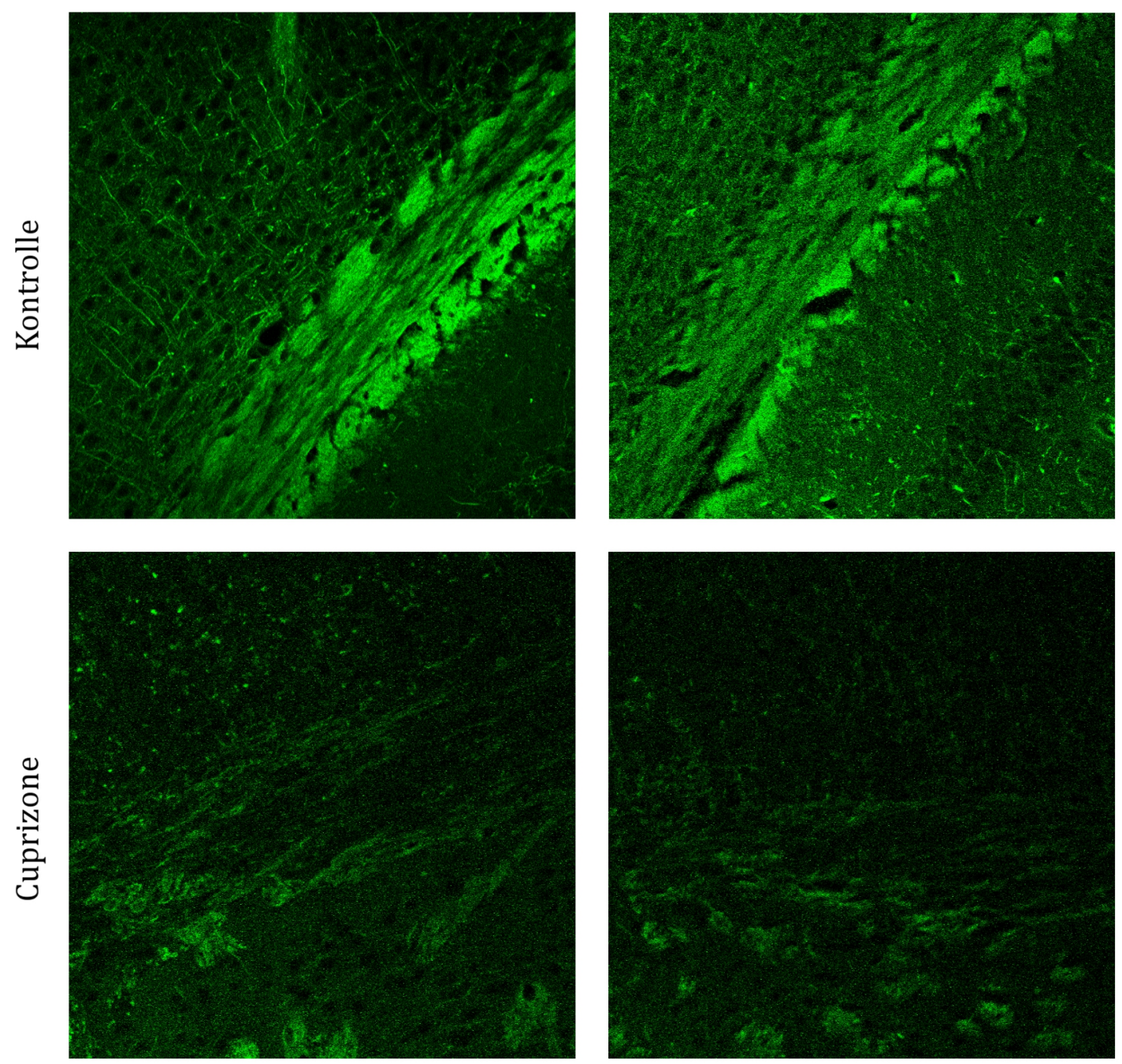

Abbildung 4.10: Immunhistochemische Färbung von Paraffinschnitten gegen das basische Myelinprotein (MBP) in grün zur Kontrolle der erfolgten Demyelinisierung nach sechswöchiger Cuprizonebehandlung. Koronarschnitt durch das Corpus callosum. Während in der Kontrollgruppe ein kräftiges, anatomisch korrektes Signal als Korrelat einer intakten Myelinschicht detektierbar ist, verbleiben in der Cuprizonegruppe nur einzelne, schwach leuchtende Flecken. Es liegt eine ausgeprägte Demyelinisierung vor. 20fache Vergrößerung. 


\subsubsection{Gewicht und Schreckreaktion als biologischer und klinischer Verlaufsparameter in der Cuprizonestudie}

Als biologischer Verlaufsparameter wurde im Verlauf des ersten Durchlaufs der Studie das Gewicht der Tiere ermittelt. In der Cuprizonegruppe wurde es während der Behandlung wöchentlich und nach Abschluss der Remyelinisierung einmalig erfasst, das Gewicht der Kontrolltiere wurde nur nach Abschluss der De- und Remyelinisierungsphasen erhoben. Dabei zeigte sich, dass die Kontrolltiere ein konstantes Gewicht hielten, wobei die Wildtypmäuse durchgehend etwas schwerer als die BACE1-ko-Mäuse waren. In der Cuprizonegruppe hatten die jungen BACE1-ko-
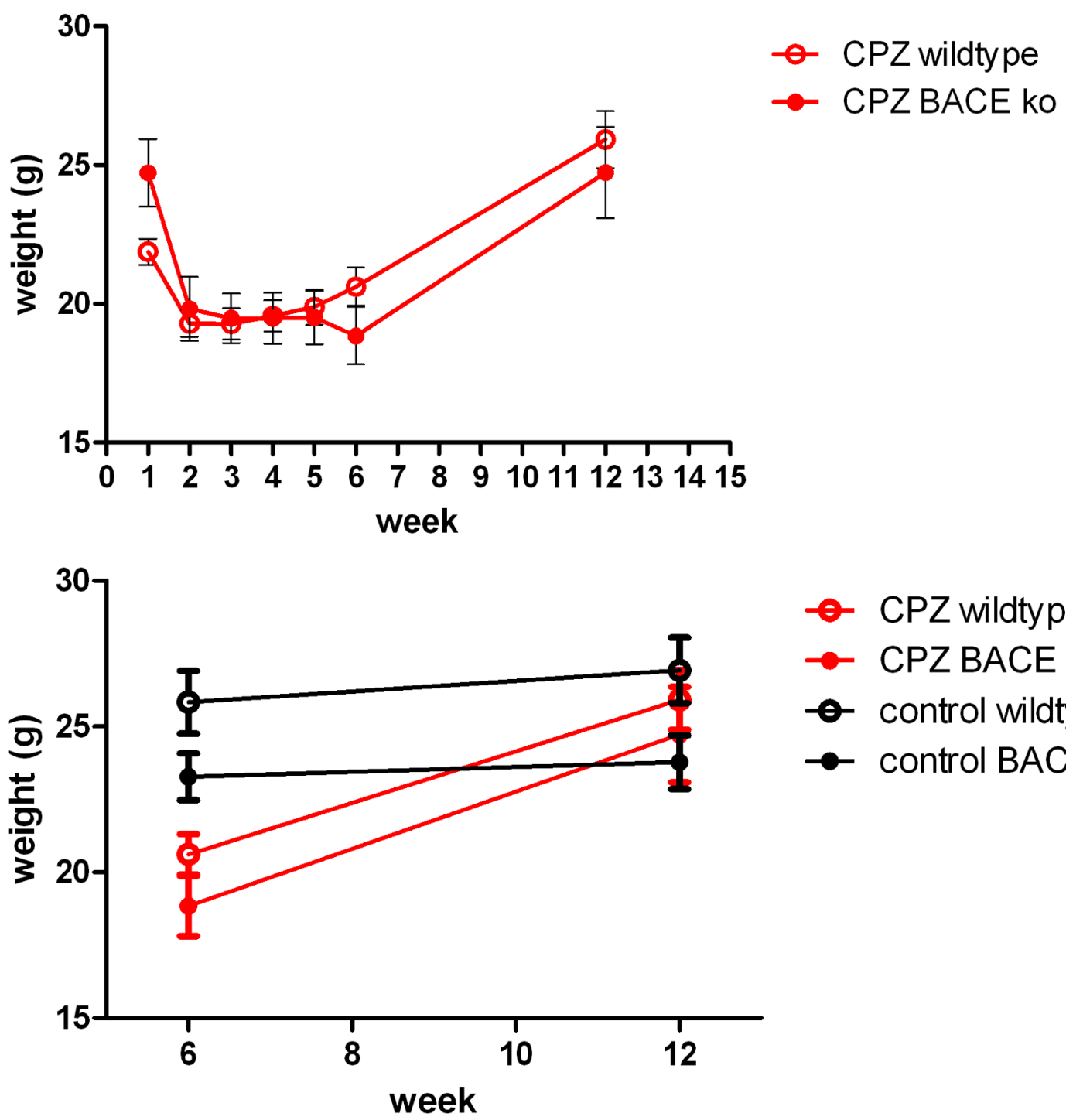

- CPZ wildtype

$\rightarrow$ CPZ BACE ko

- control wildtype

$\rightarrow$ control BACE ko

Abbildung 4.11: Gewichtsverlauf der Mäuse in der Cuprizonestudie. Daten erhoben und ausgewertet von N. Hagemeyer. Fehlerbalken zeigt SEM. 
Mäuse zunächst ein etwas höheres Gewicht als die Wildtymäuse. Beide Genotypen verloren während der Behandlung Gewicht bis auf ein ähnliches Niveau, während sie nach Abschluss der Behandlung deutlich an Gewicht zulegen konnten und die Gewichtsverhältnisse nach Abschluss der Remyelinisierung wieder denen in der Kontrollgruppe entsprachen (vgl. Abbildung 4.11). Zusammenfassend lässt sich feststellen, dass junge BACE1-ko-Mäuse ein höheres Gewicht als ihre Artgenossen mit Wildtyp-Genotyp besaßen, jedoch nicht das Gewicht ausgewachsener Wildtymäuse erreichten. Die Cuprizonebehandlung ging unabhängig vom Genotyp mit einem deutlichen Gewichtsverlust einher, der nach Absetzen von Cuprizone jedoch bis zum Niveau der Kontrollgruppe ausgeglichen werden konnte.

Um ein klinisches Korrelat der Veränderung der Myelinisierung zu erfassen, wurde als Verlaufsparameter mittels des Startleversuchs das Ausmaß der Schreckreaktion der Mäuse auf definierte akustische Reize erhoben. Der Versuch wurde nach Abschluss der De- und Remyelinisierungsphasen in der Cuprizonegruppe sowie je zeitgleich in der Kontrollgruppe durchgeführt. Dabei zeigten sich in der Kontrollgruppe zu beiden Untersuchungszeitpunkten signifikante bis hoch signifikante Unterschiede zwischen beiden Genotypen: Die Wildtymäuse reagierten mit zunehmender Intensität des Stimulus immer stärker, während sich die Schreckreaktion der BACE1-ko-Mäuse nur wenig steigerte (vgl. Abbildung 4.12). Demgegenüber reagierten die Wildtypmäuse in der Cuprizonegruppe nach der Demyelinisierung im Vergleich zu den unbehandelten Tieren deutlich schwächer auf den dargebotenen Reiz. Statistisch war kein signifikanter Unterschied zur weiterhin schwachen Reaktion der BACE1-ko-Mäuse festzustellen. Die Schreckreaktion der BACE1-koMäuse blieb auch nach erfolgter Remyelinisierung schwach, während die Wildtypmäuse sich erholten und wieder signifikant bis hoch signifikant stärker auf laute Stimuli reagierten. Ihre Reaktion erreichte dabei das Ausmaß der unbehandelten Tiere. Auch die Reaktionen der BACE1-ko-Mäuse aus Kontroll- und Cuprizonegrup pe entsprachen sich zum zweiten Untersuchungszeitpunkt wieder (vgl. Abbildung 4.13). Festzuhalten ist also, dass der Startleversuch als klinischer Verlaufsparameter einer Cuprizonebehandlung und der danach einsetzenden Regeneration geeignet ist. Bei Wildtypmäusen zeigte sich dabei nach der Demyelinisierung eine deutliche Abnahme der Schreckreaktion und nach der Remyelinisierung eine Erholung. BACE1-ko-Mäuse dagegen zeigten zu keinem Zeitpunkt starke Schreckreaktionen. Ein Fehlen von BACE1 geht also mit einem deutlich reduzierten Ausmaß der Schreckreaktion auf akustische Stimuli einher. Damit konnte gezeigt werden, dass der Startleversuch bei diesem Genotyp nicht als Verlaufsparameter einer Cuprizo- 
nebehandlung geeignet ist. Daher wurde beim zweiten Durchlauf der Studie auf diesen Versuch verzichtet.

\section{BACE 6weeks NO CPZ}

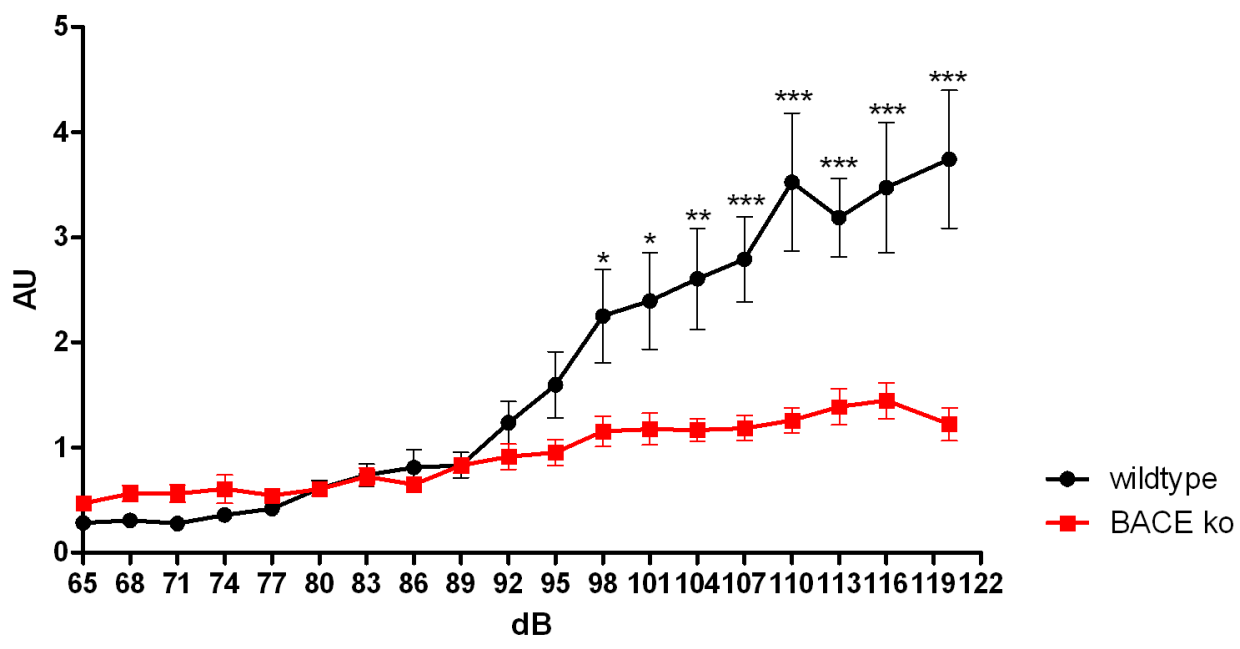

Bace 12 weeks NO CPZ

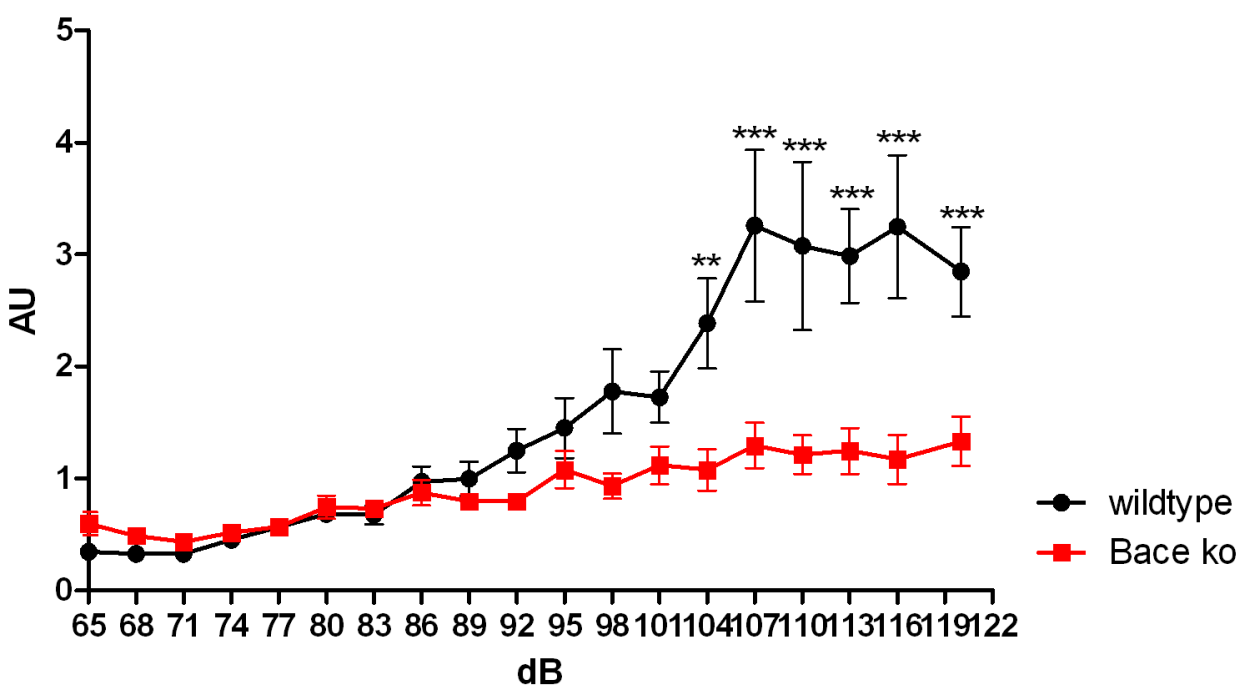

Abbildung 4.12: Cuprizonestudie. Kontrollgruppe. Startleversuch durchgeführt und ausgewertet von N. Hagemeyer. Fehlerbalken zeigt SEM. ${ }^{*}=\mathrm{P}<0,05,{ }^{* *}=\mathrm{P}<0,01,{ }^{* * *}=\mathrm{P}<0,001$ 
BACE 6weeksCPZ

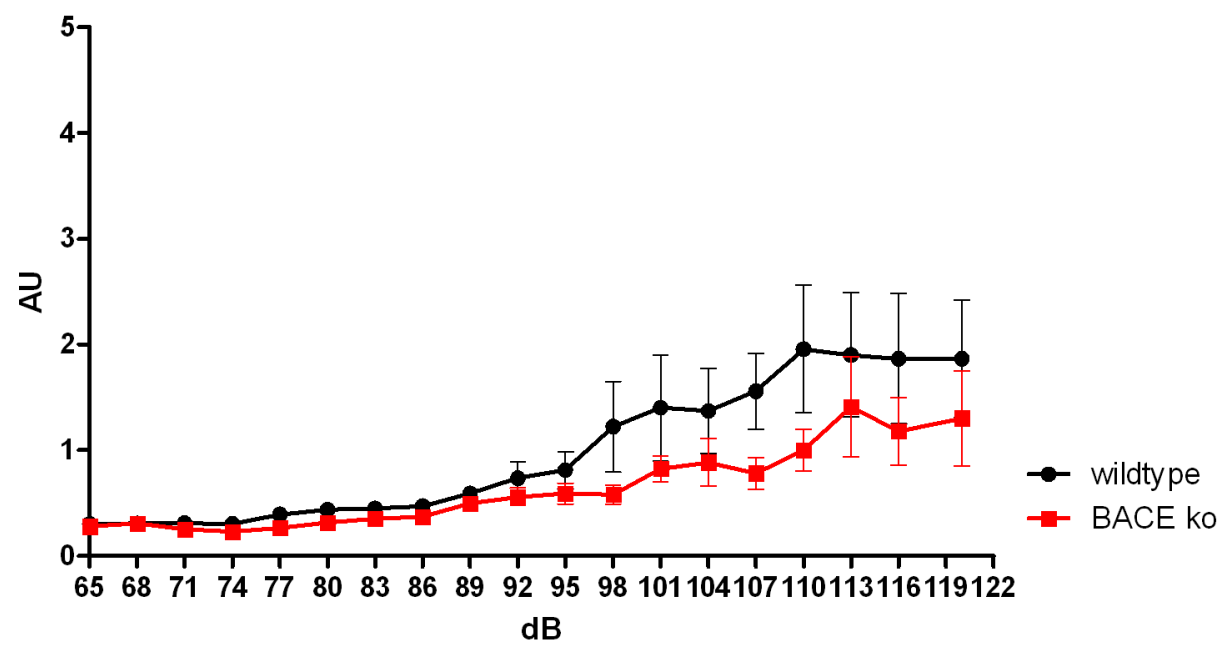

BACE 12 weeks CPZ

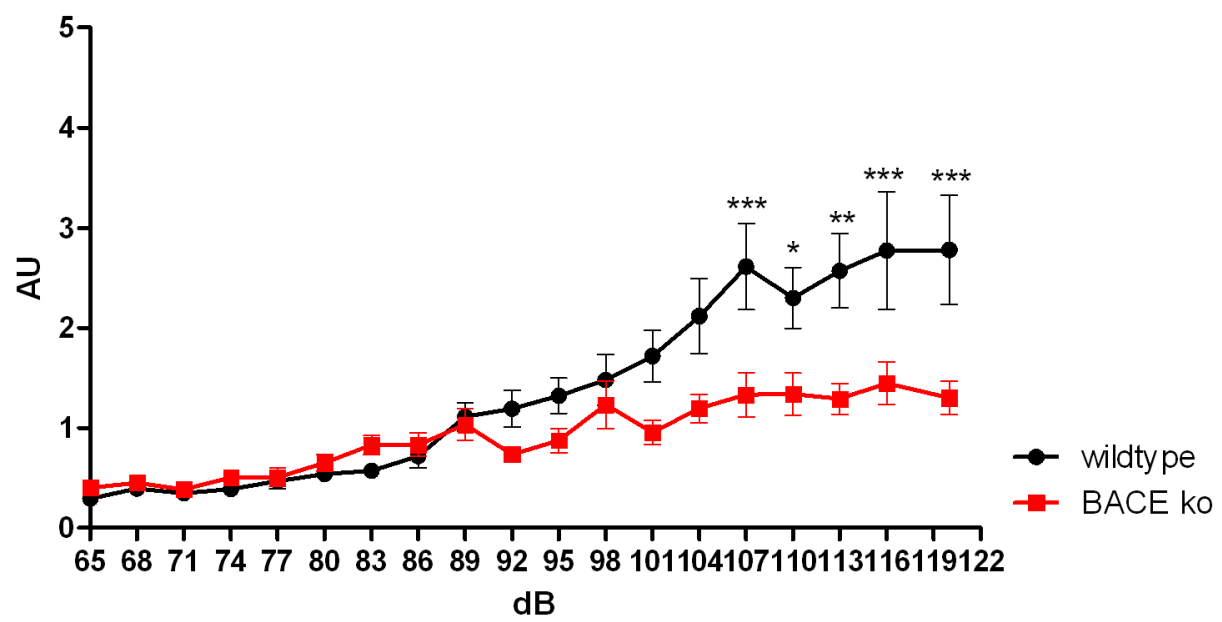

Abbildung 4.13: Cuprizonestudie. Cuprizonegruppe. Startleversuch durchgeführt und ausgewertet von N. Hagemeyer. Fehlerbalken zeigt SEM. ${ }^{*}=\mathrm{P}<0,05,{ }^{* *}=\mathrm{P}<0,01,{ }^{* * *}=\mathrm{P}<0,001$

\subsubsection{Elektronenmikroskopische Auswertung der Cuprizonestudie}

Zur histologischen Bewertung der Remyelinisierung wurden die Tiere elektronenmikroskopisch untersucht. Dabei wurde als besonders kräftig myelinisierte Struktur das Corpus callosum gewählt. Analysiert wurden Sagittalschnitte des kaudalen Corpus callosum über der CA3-Region des Hippokampus. Gemessen wurde die Fläche der Axone sowie der zugehörigen Myelinscheiden. Aus diesen Daten wurde jeweils der Durchmesser berechnet. Die G-Ratio als dimensionslose Kenngröße der Relation des Axondurchmessers zum Gesamtdurchmesser wurde durch Bildung 
des Quotienten der Durchmesser berechnet. In diese Auswertung gingen die Tiere beider Durchläufe der Cuprizonestudie sowie die Kontrolltiere ein. Aus der Kontrollgruppe konnte ein BACE1-ko-Tier aufgrund einer ungenügenden Fixierung nicht elektronenmikroskopisch ausgewertet werden.

In der Elektronenmikroskopie zeigten sich in der Übersichtsvergrößerung keine Unterschiede in der Myelinisierung zwischen beiden Genotypen in der Kontrollgruppe und in der Cuprizonegruppe.
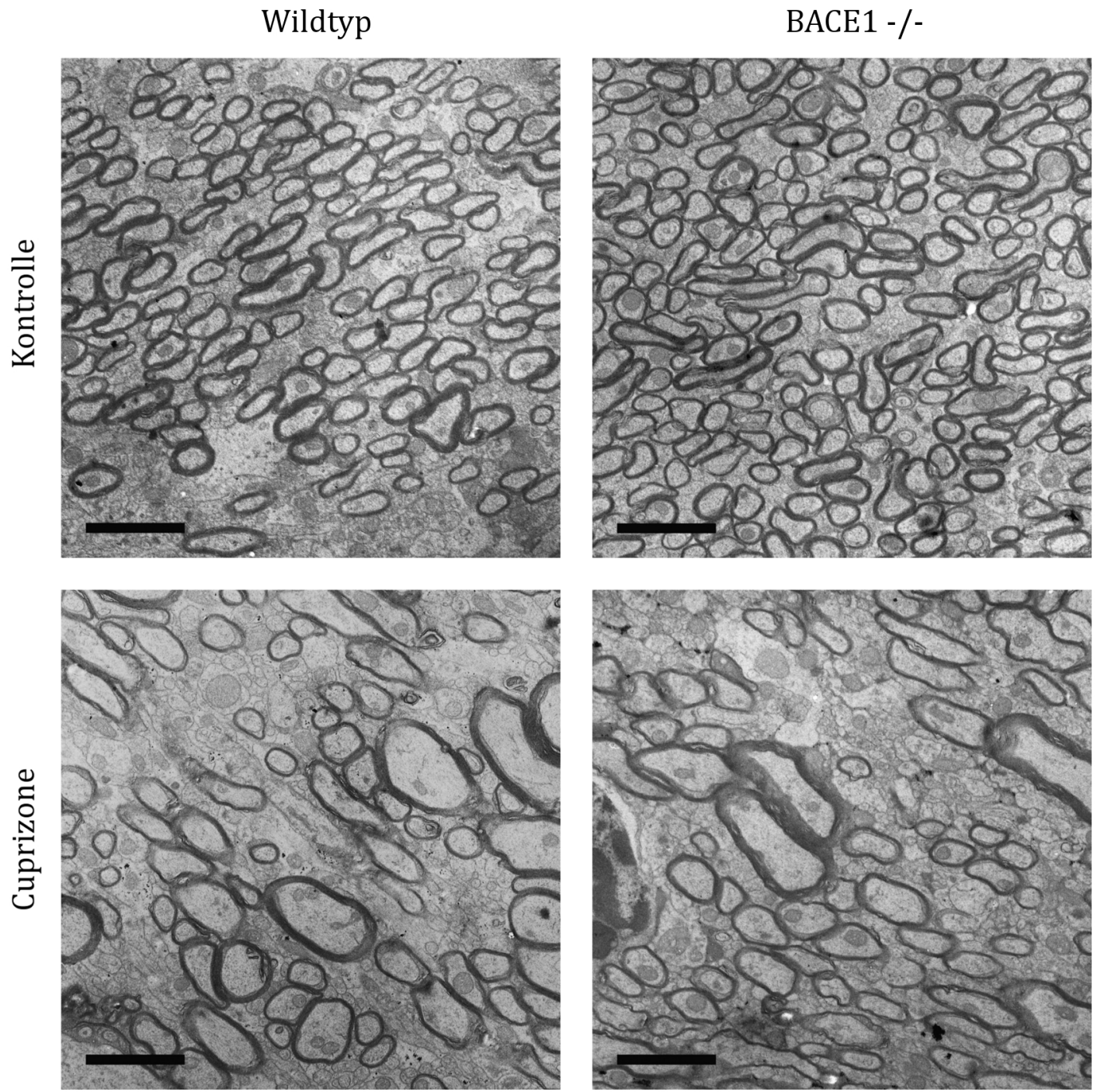

Abbildung 4.14: Elektronenmikroskopische Aufnahmen des Corpus callosum. Man erkennt die deutlich vergrößerten Axone nach der Cuprizonebehandlung in Wildtyp- und Bace1-ko-Mäusen. Modifiziert nach Treiber et al. 2012. Maßstabsbalken entsprechen 2,5 $\mu \mathrm{M}$. 
Im Vergleich zwischen mit Cuprizone behandelten Tieren und unbehandelten Tieren zeigte sich jedoch ein häufiges Auftreten sehr großer Axone in der Cuprizonegruppe. Während die Kontrolltiere viele dicht gepackte, verhältnismäßig kleine Axone aufwiesen, waren in der Cuprizonegruppe mehr unmyelinisierte Axone sichtbar, zwischen denen sich Riesenaxone befanden. Dieser Sachverhalt lässt sich an den in Abbildung 4.14 gezeigten Ausschnitten exemplarisch nachvollziehen. In höheren Vergrößerungen zeigte sich ultrastrukturell soweit beurteilbar kein Unterschied im Aufbau der Myelinscheide zwischen den einzelnen Gruppen.

Für die statistische Auswertung der G-Ratios wurden pro Tier in der ersten Kohorte 159-162 Axone gemessen, in der zweiten Kohorte jeweils 150. Daraus wurde die durchschnittliche G-Ratio des Tieres berechnet. Somit ergibt sich eine umfangreiche Datenlage mit insgesamt annähernd 7000 ausgewerteten Axonen von 44 Tieren. Die durchschnittlichen G-Ratios der Gruppen wurden mittels zweiseitiger Varianzanalyse (two-way ANOVA) miteinander verglichen. Vor der Analyse wurden alle Datensätze auf ihre Normalverteilung und gleiche Varianz untersucht. Sie bestanden diese Tests ausnahmslos. Eine Gesamtübersicht über die erhobenen Daten und die genauen Gruppenzusammensetzungen findet sich in Abbildung 4.21.

In der Gesamtpopulation zeigte sich, dass die Wildtypmäuse in der Kontrollgruppe minimal dickere Myelinscheiden als ihre BACE1-ko-Artgenossen besaßen (G-Ratio 0,670 vs. 0,681). Dieser Befund war statistisch jedoch nicht signifikant $(\mathrm{P}=0,314)$. In der Cuprizonegruppe war die Myelinscheide der Wildtypmäuse ebenfalls geringfügig dicker (G-Ratio 0,716 vs. 0,749). Dieser Unterschied war statistisch hochsignifikant $(P=0,003)$. Insgesamt war die Myelinscheide der Tiere nach der Behandlung mit Cuprizone für beide Genotypen durchschnittlich dünner als in der Kontrollgruppe. Dies war sowohl für die Genotypen untereinander als auch im reinen Vergleich zwischen behandelt und unbehandelt statistisch hoch signifikant $(\mathrm{P}=<0,001)$. Diese Daten werden in Abbildung 4.15 dargestellt. Anzumerken ist, dass das Verhältnis der Myelinscheidendicken zueinander bereits im ersten Durchlauf der Studie mit deutlich weniger Tieren in der Cuprizonegruppe sehr ähnlich zu diesen Ergebnissen war (G-Ratio 0,712 vs. 0,743). In der statistischen Auswertung zeigten sich die gleichen Merkmale als signifikant unterschiedlich, wobei mutmaßlich aufgrund der kleineren Stichprobengröße zum Teil das Hochsignifikanzniveau von $\mathrm{P}=0,01$ nicht erreicht wurde. Ein statistisch signifikanter Unterschied zwischen der Myelinscheidendicke der Tiere in der Kontrollgruppe ließ sich auch hier nicht nachweisen $(P=0,282)$. Zusammenfassend konnte gezeigt werden, dass die Cuprizonebehandlung unabhängig vom Genotyp zu einer geringe- 
ren Dicke der Myelinscheide nach sechswöchiger Remyelinisierung führte. Ein statistisch signifikanter Unterschied in der Myelinscheidendicke zwischen Wildtypund BACE1-ko-Mäusen ließ sich nur in der Cuprizonegruppe nachweisen. Dieser Unterschied zuungunsten der BACE1-ko-Mäuse ist jedoch nur gering ausgeprägt.

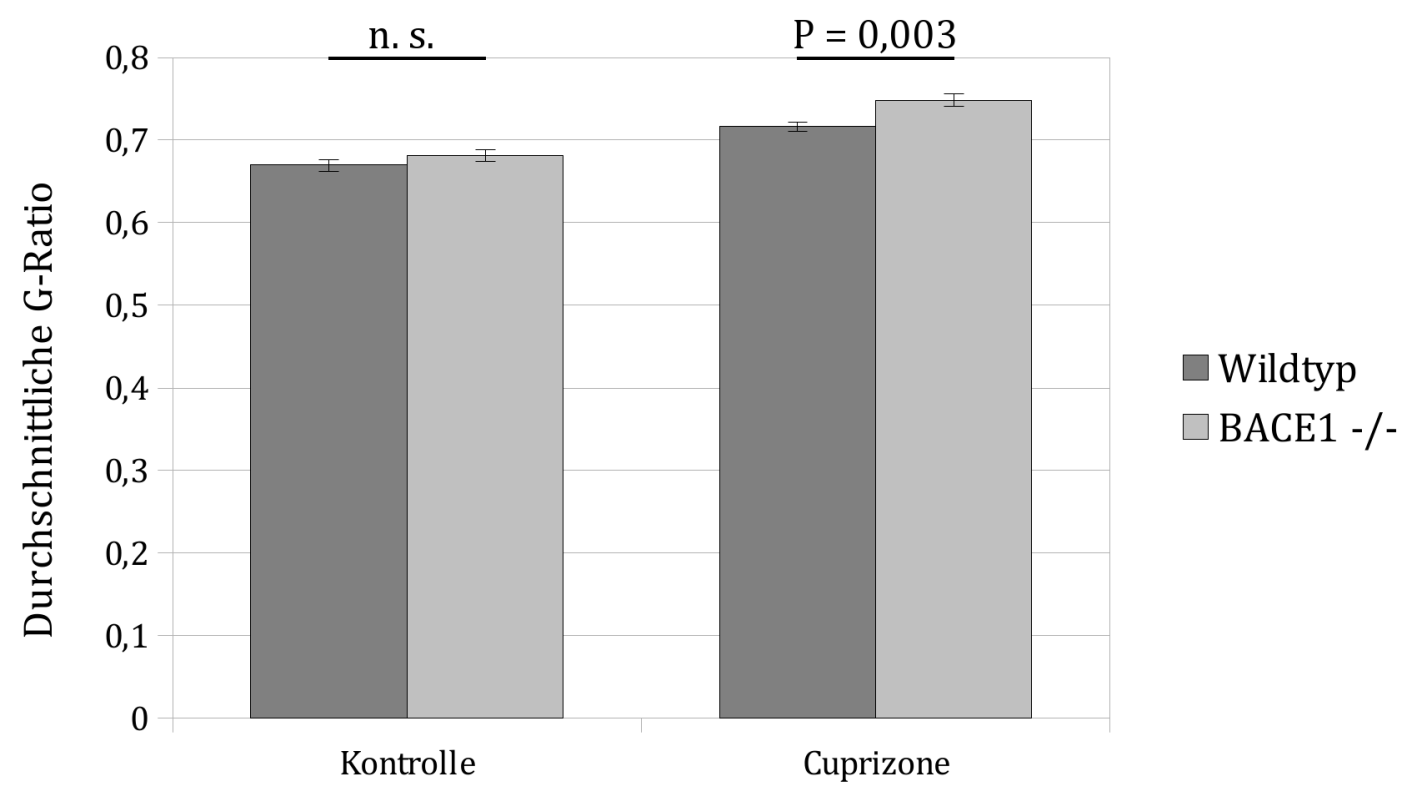

Abbildung 4.15: Vergleich der mittleren G-Ratios in der Cuprizonestudie. In der Kontrollgruppe findet sich kein Unterschied zwischen den Tieren, während in der Cuprizonegruppe BACE1-ko-Tiere eine signifikant dünnere Myelinscheide als die Wildtyptiere aufweisen. Modifiziert nach Treiber et al. 2012. Fehlerbalken zeigt SEM. n. s. $=$ nicht signifikant

Zur genaueren Analyse der Daten wurden Scatterplots aller gemessenen Axone und der zugehörigen G-Ratios erstellt (Abbildung 4.16 bis Abbildung 4.19). Hier bestätigte sich der in der Ansicht der elektronenmikroskopischen Präparate erhaltene Eindruck. Die unbehandelten Tiere wiesen verhältnismäßig kleinere Axone mit einem Durchmesser zwischen etwa 0,25 und 1,75 Mikrometern auf. In der Cuprizonegruppe traten zusätzlich viele Riesenaxone auf, die in den Wildtypmäusen über 2 Mikrometer und in den BACE1-ko-Mäusen sogar vereinzelt über 3 Mikrometer erreichten. Bis auf diesen Unterschied erschienen die Axone in allen Gruppen in einem ähnlichen Muster verteilt. Festzuhalten ist, dass die Cuprizonebehandlung zu einem Auftreten von deutlich vergrößerten Riesenaxonen führte. Die G-Ratios befanden sich in einer vergleichbaren Spannbreite. 


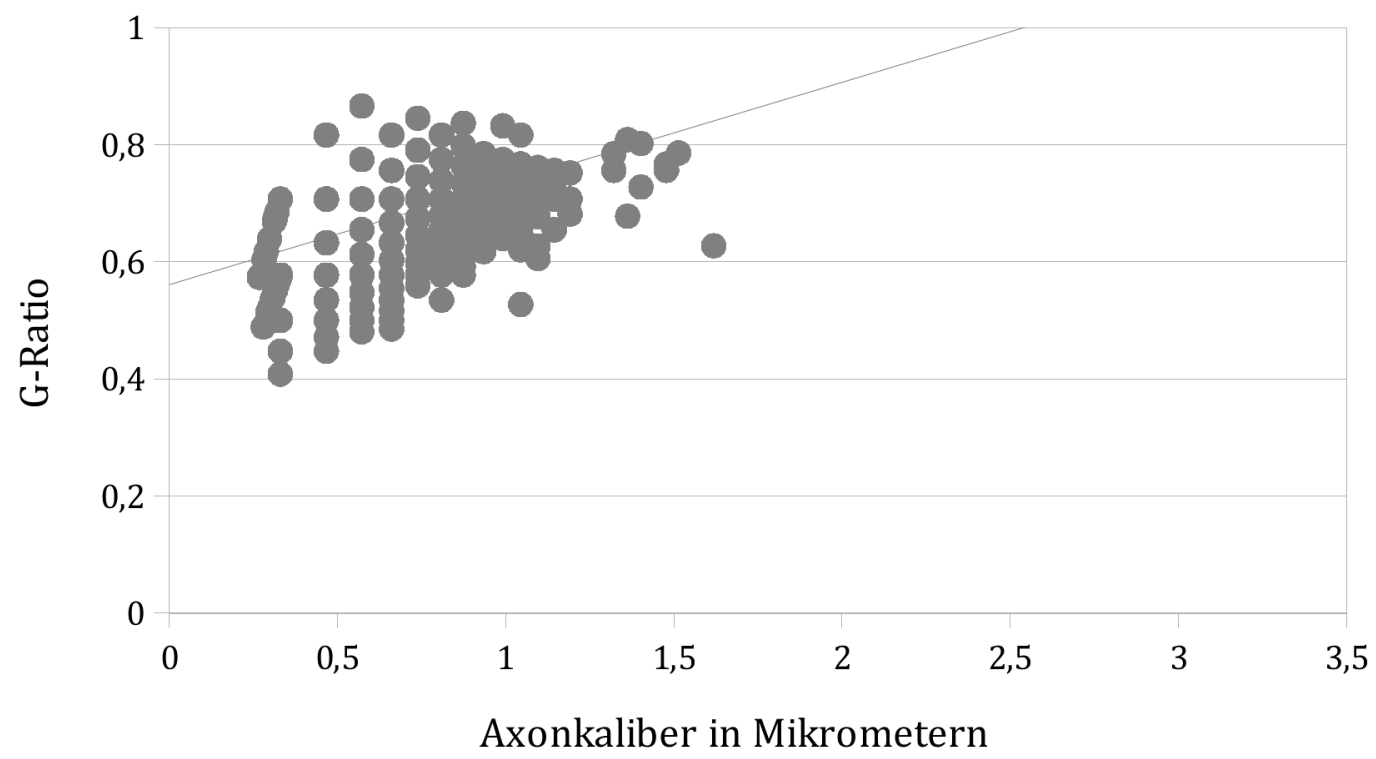

Abbildung 4.16: Scatterplot Kontrollgruppe Wildtyp. Modifiziert nach Treiber et al. 2012.

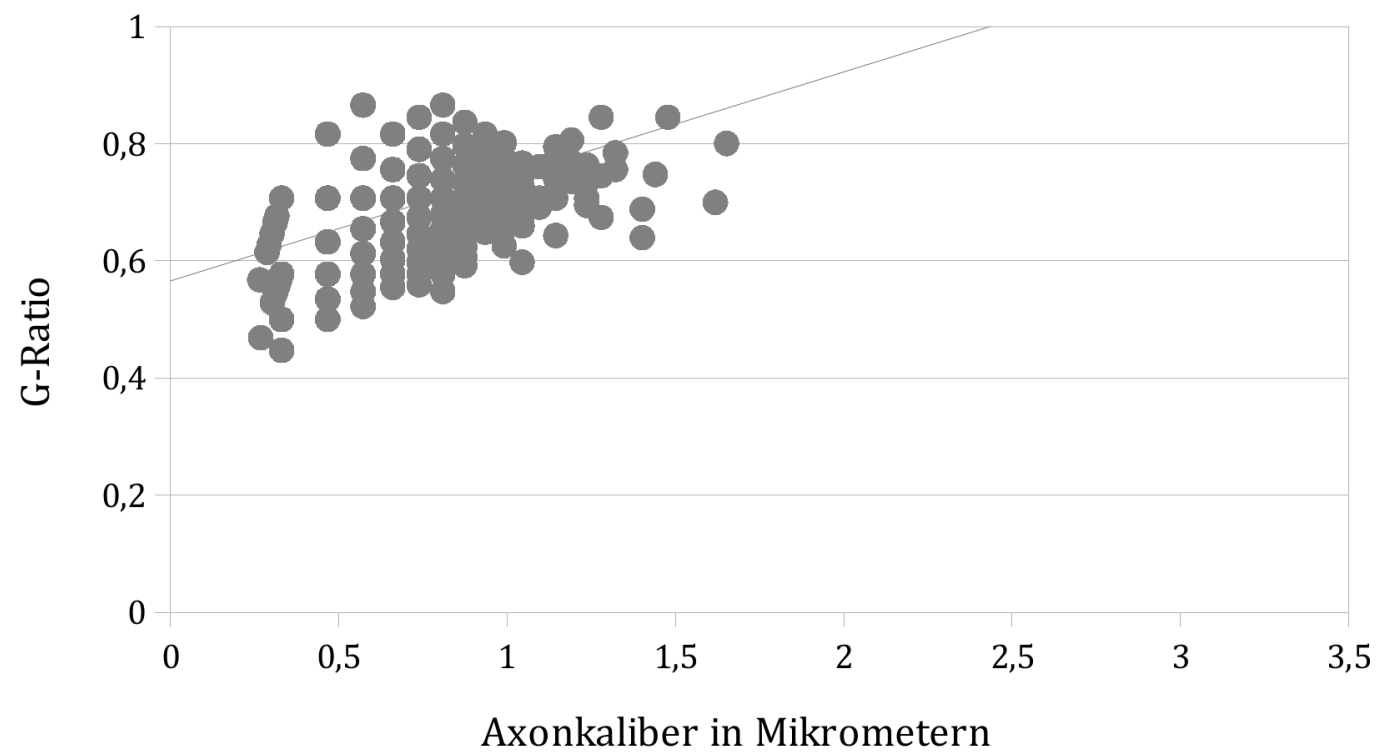

Abbildung 4.17: Scatterplot Kontrollgruppe BACE1 -/-. Modifiziert nach Treiber et al. 2012. 


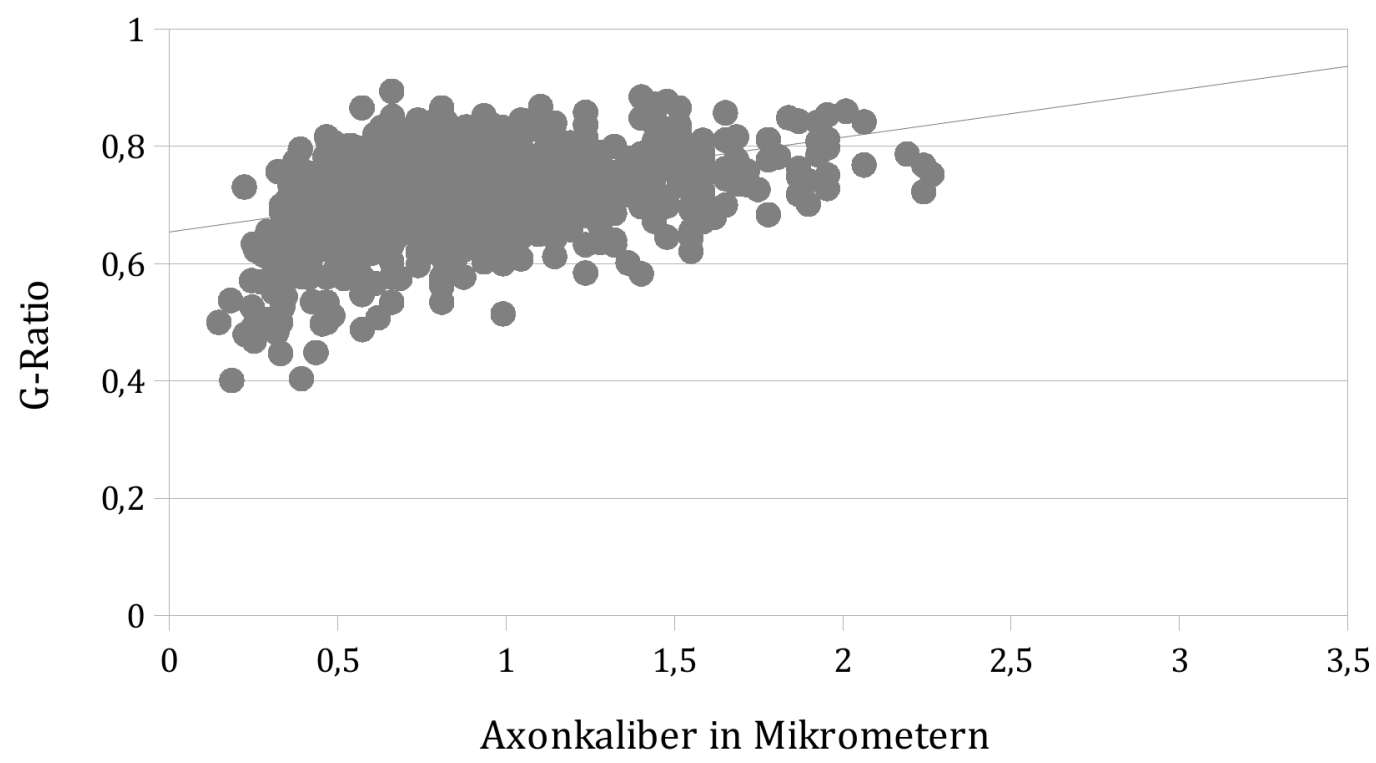

Abbildung 4.18: Scatterplot Cuprizonegruppe Wildtyp. Modifiziert nach Treiber et al. 2012.

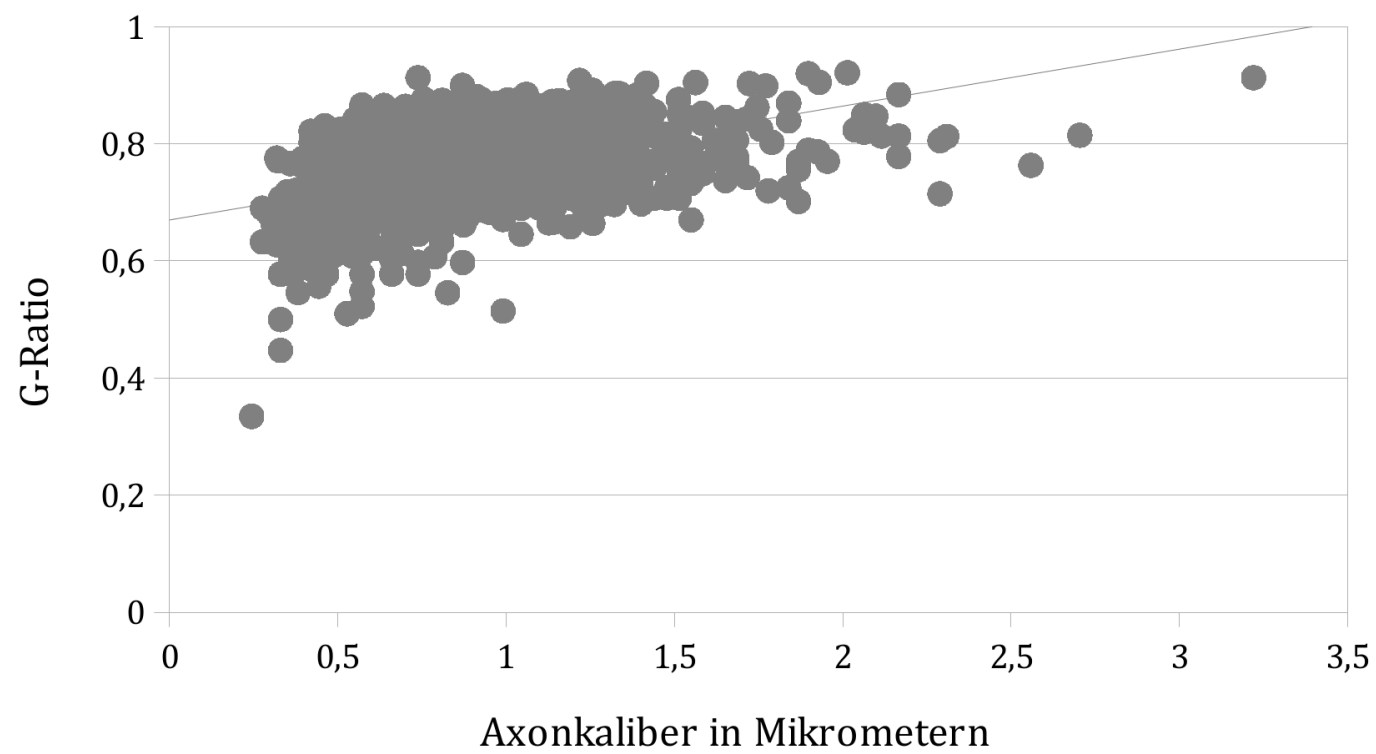

Abbildung 4.19: Scatterplot Cuprizonegruppe BACE1 -/-. Modifiziert nach Treiber et al. 2012. 


\section{$\square$ Wildtyp Kontrolle $\square$ BACE1 -/- Kontrolle \\ $\square$ Wildtyp Cuprizone $\square$ BACE1 -/- Cuprizone}

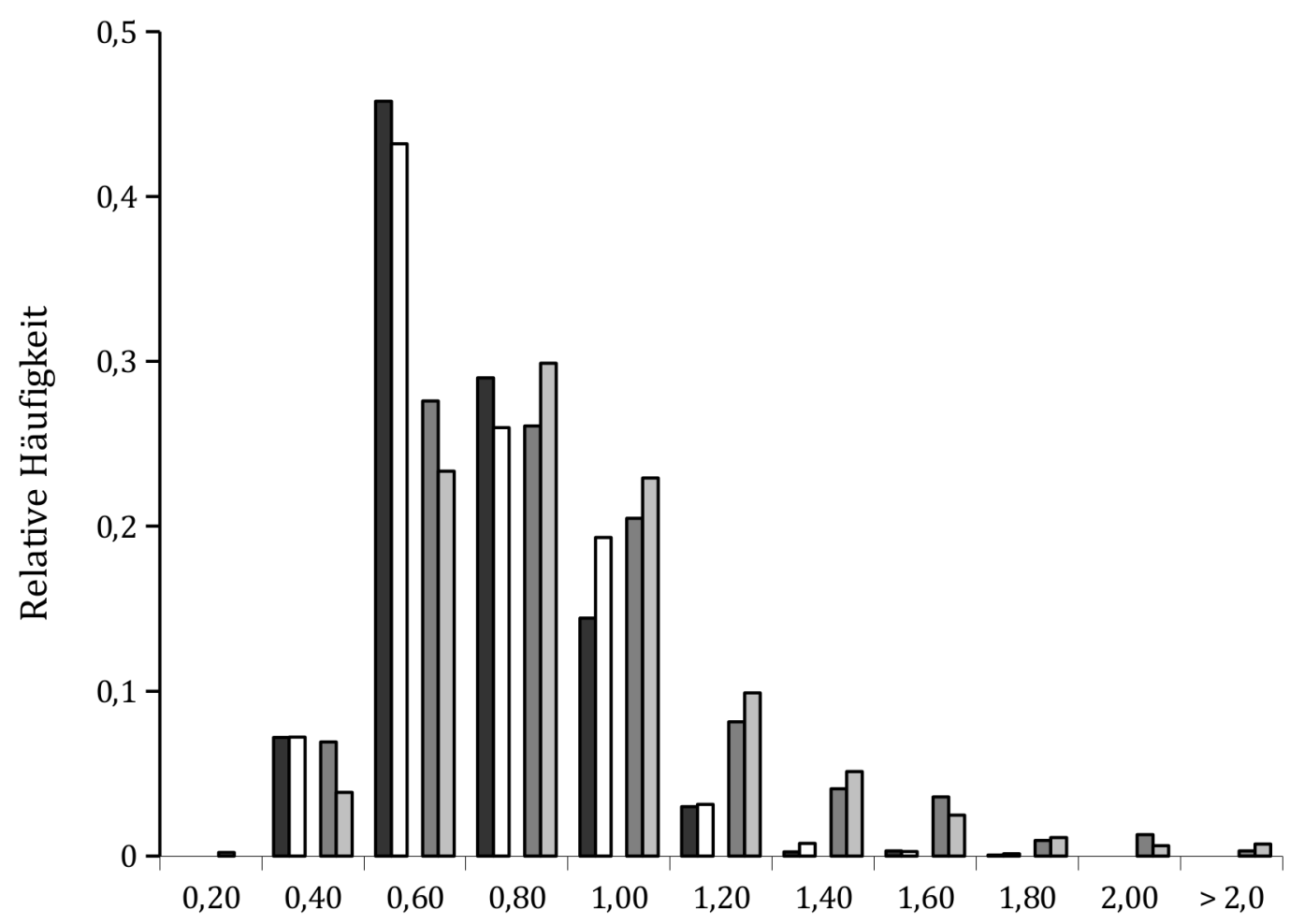

Axonkaliber in Mikrometern

Abbildung 4.20: Relative Häufigkeit der Axonkaliber in der Cuprizonestudie. Modifiziert nach Treiber et al. 2012.

Um ein besseres Verständnis für die Verteilung der Axonkaliber zu erhalten, wurden alle erhobenen Axone der einzelnen Gruppen nach Größe sortiert und ihre relative Häufigkeit in einem Diagramm dargestellt (vgl. Abbildung 4.20). Dabei zeigte sich, dass die Verteilung der Axonkaliber innerhalb der beiden Genotypen relativ uniform war. Doch zwischen behandelten und unbehandelten Tieren trat eine deutliche Rechtsverschiebung der Axondurchmesser innerhalb der Cuprizonegruppe auf, das heißt, sie wiesen verhältnismäßig mehr dickere Axone auf als ihre unbehandelten Artgenossen. Zusätzlich konnten in der Cuprizonegruppe Axone mit einem Durchmesser größer als 1,8 Mikrometer nachgewiesen werden, die in der Kontrollgruppe überhaupt nicht auftraten. Cuprizone führt also nach sechswöchi- 
ger Behandlung unabhängig vom Genotyp zu einer Zunahme der durchschnittlichen Axongröße mit dem Auftreten von Riesenaxonen.

Um sicherzustellen, dass der gemessene Effekt in der Cuprizonegruppe nicht durch Ausreißer bedingt ist, wurden probeweise alle Axone mit einem Durchmesser von mehr als 2,5 Mikrometer aus dem Datensatz entfernt. Mit den neuen Daten wurde die zweiseitige Varianzanalyse wiederholt. Dabei zeigten sich keinerlei Unterschiede in den mittleren G-Ratios und in den multiplen Vergleichen gegen Kontrollgruppe (vgl. Abbildung 4.21). Damit konnte gezeigt werden, dass die gemessenen Daten, mutmaßlich aufgrund der Stichprobengröße, nicht durch Daten, die möglicherweise statistische Ausreißer sind, beeinflusst wurden.

Im letzten Schritt der Auswertung wurde die Frage untersucht, ob das Geschlecht der Tiere eine Rolle für die Dicke der Myelinscheiden spielt. Dafür wurden die Daten nach Geschlechtern getrennt und die entstehenden Datensätze erneut mittels zweiseitiger Varianzanalyse ausgewertet. Bei Weibchen und Männchen zeigten sich durchschnittliche G-Ratios, die denen der Gesamtpopulation sehr ähnlich waren. In der Kontrollgruppe waren die Myelinscheiden der Wildtyptiere ebenfalls minimal dicker als die der BACE1-ko-Tiere, wobei der Unterschied in der dritten Nachkommastelle der Männchen biologisch vermutlich zu vernachlässigen ist (0,669 vs. 0,688 für die Weibchen sowie 0,670 vs. 0,672 für die Männchen). Eine statistische Signifikanz ließ sich ebenfalls nicht nachweisen $(P=0,113$ sowie $P=$ 0,913). In der Cuprizonegruppe zeigte sich ein ähnliches Bild (0,708 vs. 0,729 sowie 0,725 vs. 0,772). Während hier der Unterschied der Männchen als hochsignifikant einzustufen war $(\mathrm{P}=0,005)$, war der Unterschied der Weibchen statistisch nicht signifikant $(\mathrm{P}=0,073)$. Dennoch lässt sich eine deutliche Tendenz feststellen. Die Unterschiede durch die Behandlung waren wie in den übrigen Auswertungen jeweils hoch signifikant unterschiedlich $(P=$ jeweils $<0,001)$. Eine gesamte Aufstellung der Daten dieser Auswertung findet sich in Abbildung 4.21. Insgesamt lässt sich feststellen, dass die gemessenen Unterschiede der Cuprizonestudie auch in den kleineren, nach Geschlecht getrennten Stichproben nachzuweisen waren. Auch hier führte die Cuprizonebehandlung jeweils zu einer durchschnittlich dünneren Myelinscheide. In der Cuprizonegruppe besaßen sowohl weibliche als auch männliche Wildtyptiere statistisch signifikant dickere Myelinscheiden als ihre BACE1-koArtgenossen. 
In der Elektronenmikroskopie ausgewertete Tiere:

\begin{tabular}{lccc}
\hline \multicolumn{1}{c}{ n } & Erster Durchlauf & Pool & Ohne Ausreißer \\
\hline Kontrolle Wildtyp & 10 & 10 & 10 \\
Kontrolle BACE1-ko & 9 & 9 & 9 \\
Cuprizone Wildtyp & 7 & 12 & 12 \\
Cuprizone BACE1-ko & 7 & 13 & 13 \\
\multicolumn{1}{c}{ mittlere G-Ratio } & & \\
\hline Wildtyp x Kontrolle & & & 0,670 \\
Wildtyp x Cuprizone & 0,670 & 0,670 & 0,716 \\
BACE1-ko x Kontrolle & 0,712 & 0,716 & 0,681 \\
BACE1-ko x Cuprizone & 0,681 & 0,681 & 0,748
\end{tabular}

Normalverteilungstest (Shapiro-Wilk) Bestanden $(\mathrm{P}=0,988) \quad$ Bestanden $(\mathrm{P}=0,820)$ Bestanden $(\mathrm{P}=0,809)$ Gleiche-Varianz-Test Bestanden $(\mathrm{P}=0,850) \quad$ Bestanden $(\mathrm{P}=0,585)$ Bestanden $(\mathrm{P}=0,579)$

\begin{tabular}{|c|c|c|c|}
\hline \multicolumn{4}{|c|}{ Multiple Vergleiche gegen Kontrollgruppe (Holm-Sidak-Methode): } \\
\hline Genotyp & $P=0,015$ & $P=0,006$ & $P=0,006$ \\
\hline Behandlung & $P=<0,001$ & $\mathrm{P}=<0,001$ & $P=<0,001$ \\
\hline Behandlung in Wildtyp & $P=<0,001$ & $\mathrm{P}=<0,001$ & $P=<0,001$ \\
\hline Behandlung in BACE1-ko & $P=<0,001$ & $\mathrm{P}=<0,001$ & $P=<0,001$ \\
\hline Genotyp in Kontrolle & $P=0,282$ & $P=0,314$ & $P=0,314$ \\
\hline Genotyp in Cuprizone & $P=0,020$ & $P=0,003$ & $P=0,003$ \\
\hline
\end{tabular}

\begin{tabular}{lcc}
\hline \multicolumn{1}{c}{ n } & Weibchen (Pool) & Männchen (Pool) \\
\hline Kontrolle Wildtyp & 6 & 4 \\
Kontrolle BACE1-ko & 6 & 4 \\
Cuprizone Wildtyp & 6 & 6 \\
Cuprizone BACE1-ko & 8 & 5 \\
\multicolumn{1}{c}{ mittlere G-Ratio } & & \\
\hline \multicolumn{1}{c}{ Wildtyp x Kontrolle } & 0,669 & 0,670 \\
Wildtyp x Cuprizone & 0,708 & 0,725 \\
BACE1-ko x Kontrolle & 0,688 & 0,672 \\
BACE1-ko x Cuprizone & 0,729 & 0,772
\end{tabular}

Normalverteilungstest (Shapiro-Wilk) Bestanden $(\mathrm{P}=0,391) \quad$ Bestanden $(\mathrm{P}=0,316)$

Gleiche-Varianz-Test

Bestanden $(\mathrm{P}=0,401) \quad$ Bestanden $(\mathrm{P}=0,890)$

\begin{tabular}{lcc}
\hline Multiple Vergleiche gegen Kontrollgruppe (Holm-Sidak-Methode): & \\
\hline Genotyp & $\mathrm{P}=0,021$ & $\mathrm{P}=0,046$ \\
Behandlung & $\mathrm{P}=<0,001$ & $\mathrm{P}=<0,001$ \\
Behandlung in Wildtyp & $\mathrm{P}=0,002$ & $\mathrm{P}=0,004$ \\
Behandlung in BACE1-ko & $\mathrm{P}=0,002$ & $\mathrm{P}=<0,001$ \\
Genotyp in Kontrolle & $\mathrm{P}=0,113$ & $\mathrm{P}=0,913$ \\
Genotyp in Cuprizone & $\mathrm{P}=0,073$ & $\mathrm{P}=0,005$ \\
\hline
\end{tabular}

Abbildung 4.21: Gesamtübersicht über die Daten der Cuprizonestudie 


\section{Diskussion}

Die vorliegende Arbeit behandelt die Rolle der $\beta$-Sekretase bei der Remyelinisierung im Zentralen Nervensystem. Die $\beta$-Sekretase ist das geschwindigkeitsbestimmende Enzym bei der Genese von Amyloid, das sich bei der AD in Form von Plaques ablagert. Über weitere physiologische Funktionen der $\beta$-Sekretase war bisher wenig bekannt. Im Jahr 2006 erschienen zwei große Arbeiten, die ihr eine Rolle bei der Myelinisierung zuschrieben (Hu et al. 2006; Willem et al. 2006). Beide Arbeiten untersuchten die Myelinisierung im PNS, die Arbeit von $\mathrm{Hu}$ et al. (2006) auch die Myelinisierung im ZNS. Diese Publikationen wurden bereits in der Einleitung vorgestellt. Zur Zeit des Verfassens dieser Arbeit gab es außer der Publikation des Autors (Treiber et al. 2012) keine weiteren veröffentlichten Studien, die sich mit diesem Thema auseinandersetzen, wie eine Literaturrecherche bei PubMed mit den Suchbegriffen BACE1, beta-secretase und myelination zeigte (Stand: August 2013). Ziel dieser Diskussion ist also zunächst, die erhobenen Ergebnisse in Bezug zur bereits veröffentlichten Literatur zu setzen. Weiterhin sollen die über diese Grundlage heraus reichenden Ergebnisse der Remyelinisierungsuntersuchungen mit dem aktuellen Kenntnisstand abgeglichen werden. Zudem sollen die methodischen Limitierungen dieser Arbeit erörtert werden. Darüber hinaus sollen sich aus den erhobenen Daten ergebende Fragen formuliert und experimentelle Strategien zur Beantwortung dieser diskutiert werden.

\subsection{Die BACE1-Expression in Modellen der Demyelinisierung}

\subsubsection{BACE1 in der Experimentellen Autoimmunen Enzephalomyelitis}

Es ist bekannt, dass der BACE1-Stoffwechsel durch inflammatorische Prozesse beeinflusst wird (Chami und Checler 2012), und BACE1 bei der Myelinisierung eine Rolle spielt (Hu et al. 2006; Willem et al. 2006). Eine Rolle von BACE1 bei demyeli- 
nisierenden Erkrankungen wurde bisher jedoch nur in der Arbeit von HartlageRübsamen et.al (2003) untersucht. Hier fand sich immunhistologisch eine BACE1Expression in reaktiven Astrozyten nach Induktion einer EAE (Hartlage-Rübsamen et al. 2003). In der vorliegenden Arbeit wurden daher Hirnstammlysate von Ratten, bei denen eine EAE induziert worden war, auf ihre BACE1-Expression untersucht und mit Kontrolltieren verglichen. Analysiert wurden jeweils vier Tiere. Dabei zeigte sich eine stark erhöhte BACE1-Expression in den Hirnstammlysaten der behandelten Tiere (BACE1-Calnexin-Quotient von 1,26 nach CpG im Vergleich zu 0,46 ohne Behandlung, vgl. Abbildung 4.5 und Abbildung 4.6). Dieser Unterschied war statistisch jedoch nicht signifikant $(P=0,089)$. Es erscheint jedoch statthaft, von einem robusten Trend zu sprechen. Die erhobenen Daten passen zu den Befunden von Hartlage-Rübsamen et. al. (2003) und der Rolle von BACE1 bei der Myelinisierung im ZNS (Hu et al. 2006). Dass der Effekt statistisch nicht signifikant ist, könnte an der kleinen Stichprobengröße liegen. Zudem besteht bei der EAE eine disseminierte Inflammation mit Inseln von Demyelinisierung in Inseln von intaktem Gewebe. Daher ist der gemessene Anstieg von BACE1 vermutlich lokal höher als die Gehirnlysatanalysen andeuten. Eine genauere Analyse, welche Zellen für den Anstieg verantwortlich sind, wäre wünschenswert. Der von uns verwendete BACE1-Antikörper 10B8 zeigte in der Immunhistochemie jedoch ein unspezifisches Färbemuster. Ein sinnvolles Experiment wäre also die immunhistochemische Untersuchung von ZNS-Präparaten von EAE-Tieren und Kontrollen zu unterschiedlichen Zeitpunkten. Die schnelle Induzierbarkeit von BACE1 in der Mikroglia-Zelllinie EOC macht eine frühe Hochregulation von BACE1 in Mikroglia während der Inflammation plausibel. Dies sollte sich in der Immunhistochemie klären lassen. Zudem könnten so die Befunde von Hartlage-Rübsamen et. al. (2003) bestätigt werden. In einer EAE mit BACE1-ko-Tieren und Kontrollen ließe sich ein möglicher klinischer Effekt der BACE1-Inhibition bei demyelinisierenden Krankheiten nachweisen. Die histopathologische Analyse könnte zudem weitere Hinweise auf die biologische Funktion von BACE1 während der Reymelinisierung liefern.

\subsubsection{BACE1 im Cuprizonemodell}

Im Cuprizonemodell werden spezifisch Oligodendrozyten in die Apoptose getrieben. In diesem Fall betrifft der Effekt das gesamte Gehirn und nicht nur einzelne Läsionen wie bei der EAE. Bisher (Stand: August 2013) gibt es außer der Arbeit des Verfassers (Treiber et al. 2012) keine Daten zu BACE1 im Cuprizonemodell. Daher 
wurden Gehirnlysate von Mäusen, die mit Cuprizone behandelt worden waren, auf die BACE1-Expression untersucht. Analysiert wurden vier Kontrolltiere sowie fünf behandelte Tiere. Es zeigte sich eine Reduktion der BACE1-Expression in den Gehirnlysaten der behandelten Tiere (BACE1-Calnexin-Quotient von 0,25 nach Cuprizone im Vergleich zu 0,52 ohne Behandlung, vgl. Abbildung 4.3 und Abbildung 4.4). Auch hier war der Effekt statistisch nicht signifikant $(P=0,12)$. Eine größere Stichprobengröße würde möglicherweise den Effekt deutlicher herausarbeiten. Es bleibt jedoch unklar, wodurch es zur einer möglichen Verringerung der BACE1Expression nach einer Cuprizonebehandlung kommen könnte. Im gesunden Gehirn wird BACE1 überwiegend in Neuronen exprimiert (Vassar et al. 1999). Bei langandauernder Einwirkung einer Noxe wird es von reaktiven Astrozyten exprimiert (Hartlage-Rübsamen et al. 2003). In der vorliegenden Arbeit wurde BACE1 in EOCZellen durch Inkubation mit einzelnen proinflammatorischen Chemokinen stimuliert. Im Corpus callosum von C57BL/6 kommt es während einer Cuprizonebehandlung zu einer massiven Akkumulation von Mikroglia und Makrophagen (Hiremath et al. 1998). Dies ist jedoch nicht notwendigerweise ein Argument gegen die geringe BACE1-Expression in den hier analysierten Gehirnlysaten, da die Untersuchung der EOC-Zellen nahelegt, dass BACE1 nicht bei jeglicher Stimulation gleichförmig verstärkt exprimiert wird. Dies legen auch die Daten von Hartlage-Rübsamen et. al. (2003) nahe. Es ist also denkbar, dass die im Rahmen der Cuprizonebehandlung rekrutierten Mikroglia nicht vermehrt BACE1 exprimieren.

Die hier analysierten Mäuse waren 5 Wochen mit Cuprizone behandelt worden und ohne Erholungsphase biochemisch ausgewertet worden. Eine Hypothese ist, dass neuronales BACE1 im Sinne eines positiven Feedbacks hochreguliert wird, wenn die Neurone Kontakt mit myelinisierenden Oligodendrozyten haben. Dieser Prozess und die Reifung der Oligodendrozyten beginnt nach vierwöchiger Cuprizonebehandlung allerdings gerade erst (Mason et al. 2000). Das würde dafür sprechen, dass BACE1 nicht zur Initialisierung der Myelinisierung notwendig ist, jedoch sehr wohl zur Ausprägung einer regelrechten Myelinscheide. Dies würde zur beschriebenen Hypomyelinisierung im PNS und ZNS passen (Hu et al. 2006; Willem et al. 2006). Oligodendrozyten-Vorläufer wären also nicht auf BACE1 angewiesen, während reife Oligodendrozyten eine kontinuierliche BACE1-Expression in Neuronen vermitteln könnten. Der hier diskutierte Mechanismus ist weitgehend spekulativ. Im PNS wurde allerdings beschrieben, dass BACE1 nicht für die regelrechte Entwicklung der Schwann-Zell-Vorläufer notwendig ist (Velanac et al. 2012), ein Fehlen von BACE1 jedoch später zu einer Hypomyelinisierung führt (Willem et al. 
2006). Ein Einfluss von BACE1 auf reife myelinisierende Zellen ist daher anzunehmen.

Dies wirft die Frage auf, ob BACE1 auch für den Erhalt der Myelinscheiden adulter Individuen notwendig ist. Gerade im Hinblick auf die mögliche Inhibierung von BACE1 zur Therapie der AD ist dies eine Frage mit wichtigen klinischen Implikationen. Um diese Hypothese zu testen, gibt es unterschiedliche denkbare Ansätze. Zunächst wäre es möglich, mittels eines Liganden-aktivierten Cre/loxP-Systems BACE1 in Schwann-Zellen oder Oligodendrozyten bei adulten Tieren auszuschalten, und so klinische und histopathologische Daten über die Auswirkungen einer späteren vollständigen BACE1-Inhibition zu gewinnen. Sollten ZNS-gängige BACE1Inhibitoren verfügbar sein, wäre diese Analyse deutlich einfacher mittels einer medikamentösen Behandlung der Tiere zu erreichen.

\subsubsection{Resümee der Daten zur BACE1-Expression in Modellen der Demyelinisierung}

Zusammenfassend lässt sich festhalten, dass die BACE1-Expression in Modellen der Demyelinisierung vermutlich verändert ist. Mit größeren Stichprobengruppen ließe sich wahrscheinlich eine statistische Signifikanz der Effekte nachweisen. Der Anstieg der BACE1-Expression im durch Inflammation charakterisierten Modell der EAE passt zu den selbst erhobenen Daten in der Zellkultur sowie zur Literatur (vgl. 5.3 und 5.4). Unklar bleibt dagegen die anzunehmende Abnahme der BACE1Expression während der Demyelinisierung im Cuprizonemodell. Letztendlich können über Ursachen, Mechanismen und Auswirkungen nur spekuliert werden. Hier sind weitere Untersuchungen notwendig.

\subsection{Das Cuprizonemodell in BACE1-ko-Mäusen}

Ausgehend von der hier vorgestellten Hypothese, dass BACE1 für den Erhalt der Myelinscheiden notwendig ist, und der Rolle, die BACE1 bei der Myelinisierung spielt (Hu et al. 2006; Willem et al. 2006), sollte eine mögliche Rolle von BACE1 bei der Remyelinisierung im ZNS untersucht werden. Aufgrund der regelhaften, großflächigen und vergleichbar lokalisierten Demyelinisierung und der daraus resultierenden guten Quantifizierbarkeit mittels G-Ratio wurde dazu das Cuprizonemodell ausgewählt. Zudem war gezeigt worden, dass Cuprizone eine signifikante Ver- 
schlechterung der Schreckreaktion bei behandelten Tieren auslöst (Hagemeyer 2012). Die Ursache dafür ist unbekannt, es handelt sich jedoch um keine Störung des Hörvermögens (Hagemeyer 2012). Dies ermöglichte auch eine klinische Beurteilung der behandelten Tiere. So konnte ein möglicherweise klinisch bedeutender Einfluss der BACE1-Inhibiton untersucht werden. Diese Studie wurden in Kooperation mit H. Ehrenreich und N. Hagemeyer, AG Ehrenreich, Max-Planck-Institut für Experimentelle Medizin Göttingen, durchgeführt. Untersucht wurden insgesamt 51 Tiere. 31 Tiere wurden mit Cuprizone behandelt, 20 Tiere dienten als Kontrollgruppe. Jede Gruppe bestand aus je zwei Kohorten, die von BACE1-ko- und Wildtypmäusen gebildet wurden. Die Kontrollgruppe blieb ohne Behandlung, die Cuprizonegruppe wurde 6 Wochen mit Cuprizone behandelt und danach 6 Wochen zur Remyelinisierung ohne Behandlung gehalten. Vor Beginn der Cuprizonegabe, nach Ende der Behandlungsphase und nach Ende der Regenerationsphase wurde der Startleversuch durchgeführt. Nach der Cuprizonebehandlung wurden sechs Tiere entnommen und immunhistochemisch aufgearbeitet, um die Myelinisierung im Corpus callosum zu untersuchen.

\subsubsection{Das Cuprizonemodell ist bei BACE1-ko-Mäusen anwendbar}

Koronare Schnitte durch das Corpus callosum wurden mittels immunhistochemischer Färbung gegen MBP analysiert. Dabei zeigte sich sowohl in den Wildtyptieren als auch in den BACE1-ko-Tieren eine ausgeprägte Demyelinisierung (vgl. Abbildung 4.10). Dieser Versuch war notwendig, um das Cuprizonemodell abzusichern, denn in der Literatur ist beschrieben, dass Cuprizone bei verschiedenen Spezies und selbst innerhalb dieser bei unterschiedlichen Stämmen differierende Wirkungen entfaltet und die verwendete Cuprizonekonzentration im Futter ein kritischer Punkt ist (Matsushima und Morell 2001). Übereinstimmend mit der Literatur entfaltete die hier gewählte Konzentration von 0,2 \% im Futter die erwartete Wirkung. Zudem ist der genaue Mechanismus, über den Cuprizone wirkt, ist unbekannt (Matsushima und Morell 2001). Daher war es unumgänglich, die BACE1-ko-Tiere zu analysieren, da ein Fehlen von BACE1 möglicherweise die Wirkung von Cuprizone beeinflussen könnte. Gerade, da größere Mengen von BACE1-mRNA im Pankreas nachgewiesen worden konnten (Vassar et al. 1999), war auch eine veränderte intestinale Liberation, Absorption, Distribution oder Elimination denkbar. Die vorliegenden Daten zeigen jedoch, dass Cuprizone in der Immunhistochemie einen vergleichbaren Effekt auf das ZNS hat wie in den Kontrolltieren. Es ist also davon 
auszugehen, dass das Cuprizonemodell in BACE1-ko-Tieren sinnvoll anzuwenden ist. Eine genauere Quantifizierung und Beschreibung des Effektes erfolgte mittels Elektronenmikroskopie.

\subsubsection{Das Gewicht ist ein biologischer Verlaufsparameter im Cuprizonemodell bei BACE1-ko-Tieren}

Als biologischer Verlaufsparameter wurden die Tiere regelmäßig gewogen (vgl. Abbildung 4.11). Dabei ließ sich keine signifikante Gewichtsveränderung im Zeitverlauf der Studie bei den Kontrolltieren feststellen. Auffällig war hier zu beiden untersuchten Zeitpunkten ein geringeres Gewicht der BACE1-ko-Tiere im Vergleich zu ihren Wildtypartgenossen. In einer der ersten Beschreibungen der BACE1-koMaus konnte kein Unterschied im Körpergewicht von BACE1-ko-Tieren und Kontrolltieren festgestellt werden (Roberds et al. 2001). Eine aktuelle Arbeit, die Einfluss von BACE1 auf Körpergewicht sowie Glukose- und Lipidstoffwechsel untersuchte, fand jedoch über den gesamten Beobachtungszeitraum von beinahe einem Jahr regelmäßig ein signifikant niedrigeres Gewicht bei BACE1-ko-Tieren im Vergleich zu Wildtypmäusen (Meakin et al. 2012). In dieser Studie wurde eine verhältnismäßig große Gruppe von insgesamt über 20 Tieren gründlich auf ihr Körpergewicht untersucht (Meakin et al. 2012), während in der Studie von Roberds et al. (2001) der Fokus auf der Untersuchung des Gehirns lag und zudem unklar bleibt, wie oft, zu welchen Zeitpunkten und bei wie vielen Tieren das Gewicht gemessen wurden. Dieser Umstand und die gute Übereinstimmung der Daten von Meakin et al. (2012) mit den hier vorgestellten Ergebnissen spricht für ein signifikant erniedrigtes Körpergewicht bei BACE1-ko-Tieren. Als Mechanismus schlagen Meakin et. al. (2012) eine Rolle von BACE1 im Insulinstoffwechsel vor.

Eine detaillierte Analyse des Verlaufs des Körpergewichts der mit Cuprizone behandelten Tiere zeigt eine deutliche Abnahme des Körpergewichts zu Beginn der Behandlung (vgl. Abbildung 4.11). Sowohl BACE1-ko- als auch Wildtyptiere fallen auf etwas weniger als 20 Gramm Körpergewicht ab und sind nun nicht mehr anhand des Gewichts unterscheidbar. Nach Absetzen von Cuprizone normalisiert sich das Körpergewicht wieder, wobei die BACE1-ko-Tiere nicht das Gewicht der Wildtyptiere erreichten. Interessanterweise wiegen die BACE1-ko-Tiere zu Beginn der Behandlung etwas mehr als die Wildtyptiere. Wie es $\mathrm{zu}$ diesem Unterschied kommt, bleibt unklar. Eine Gewichtsabnahme während der Cuprizonebehandlung 
ist in der Literatur beschrieben und hängt von der verwendeten Dosis ab (Hiremath et al. 1998; Matsushima und Morell 2001).

Zusammenfassend lässt sich festhalten, dass sich das Körpergewicht als biologischer Parameter der Cuprizonebehandlung bei BACE1-ko- und Wildtyptieren gleichsinnig verändert. Zusammen mit der in der Immunhistochemie beobachteten Demyelinisierung ist also anzunehmen, dass ein Fehlen von BACE1 die Wirkung von Cuprizone nicht verhindert oder abschwächt und das Cuprizonemodell daher in BACE1-ko-Tieren ein gutes Modell ist, um De- und Remyelinisierungsvorgänge zu untersuchen.

\subsubsection{Die Schreckreaktion ist als klinischer Verlaufsparameter im Cuprizonemodell für BACE1-ko-Tiere nicht geeignet}

Als klinischer Verlaufsparameter während der Cuprizonebehandlung wurde zur quantitativen Messung der Schreckreaktion der Startleversuch durchgeführt. In der Literatur ist eine Verminderung der Schreckreaktion während der Cuprizonebehandlung beschrieben (Hagemeyer 2012). Daher wurde der Startleversuch in allen vier Gruppen jeweils nach Abschluss der Cuprizonebehandlung und der Regenerationsphase durchgeführt. Der Startleversuch zeigte ein überraschendes Ergebnis. Schon die unbehandelten BACE1-ko-Tiere zeigten eine hochsignifikant erniedrigte Schreckreaktion auf die akustischen Stimuli im Vergleich zu den Wildtyptieren (vgl. Abbildung 4.12). Dieser Unterschied bestand sowohl beim ersten Durchlauf des Startleversuchs als auch bei der Wiederholung nach der sechswöchigen Regenerationsphase. Aus diesem Grund sind die in der Cuprizonegruppe erhobenen Daten weniger aussagekräftig. Wie in der Literatur beschrieben (Hagemeyer 2012) zeigen die Wildtyptiere eine erniedrigte Schreckreaktion nach der Cuprizonebehandlung (vgl. Abbildung 4.13). Diese war nun statistisch nicht mehr von der weiterhin niedrigen Reaktion der BACE1-ko-Tiere zu unterscheiden. Nach der Regenerationsphase erholte sich die Schreckreaktion der Wildtyptiere wieder, während die der BACE1-ko-Tiere auf niedrigem Niveau verblieb. Dieser Unterschied war erneut hochsignifikant. Die zentrale Frage ist also, warum die Schreckreaktion bei den BACE1-ko-Tieren a priori bereits kaum vorhanden ist? In der Arbeit von Roberds et al. (2001) werden die Tiere als gesund beschrieben. Insbesondere öffneten die BACE1-ko-Tiere wie ihre Wildtypartgenossen nach Erregung die Augen vollständig (Roberds et al. 2001). Eine weitere frühe Arbeit beschreibt einen normalen Phänotyp (Luo et al. 2001). Eine Studie, die sich gezielt mit den verhaltens- 
biologischen Auswirkungen beschäftigte, fand bei BACE1-ko-Mäusen reduziertes exploratorisches Verhalten und eine erhöhte Kotproduktion als Merkmale eines ängstlichen Phänotyps (Harrison et al. 2003). Es ist unklar, wodurch dieser Phänotyp entsteht. Es wird eine Veränderung des Serotoninstoffwechsels diskutiert (Harrison et al. 2003). Auch eine veränderte Exzitabilität im ZNS durch eine Beeinflussung der Expression spannungsabhängiger Natriumkanäle ist denkbar (Kim et al. 2011). Da die Befunde von Harrison et. al. (2003) den im Startleversuch erhobenen Daten widersprechen, ist auch ein beeinträchtigtes Hörvermögen zu bedenken. Dieses könnte durch eine Hirnstammaudiometrie bei BACE1-ko-Tieren untersucht werden, wie bereits bei Wildtyptieren geschehen (Hagemeyer 2012).

In der Gesamtschau lässt sich festhalten, dass BACE1-ko-Tiere entgegen früherer Untersuchungen nicht phänotypisch normal sind. Es scheint zumindest eine subtile Veränderung des Verhaltens durch BACE1-Inhibition hervorgerufen zu werden. Diese muss in weiteren Untersuchungen genauer charakterisiert werden. Aufgrund der a priori bestehenden Minderung der Schreckreaktion war der Startleversuch nicht geeignet, eine klinische Veränderung der BACE1-ko-Tiere durch die cuprizoneinduzierte Demyelinisierung und die darauf folgende Regeneration darzustellen.

\subsubsection{Der Einfluss von BACE1 auf die Myelinscheiden im ZNS}

Die folgenden Daten wurden bereits in einer Publikation vorgestellt und diskutiert (Treiber et al. 2012). Um den Einfluss von BACE1 auf die Myelinscheiden im ZNS zu untersuchen, wurden sagittale Schnitte durch das Corpus callosum angefertigt und elektronenmikroskopisch ausgewertet. Dabei zeigte sich ein ultrastrukturell intaktes Myelin (vgl. Abbildung 4.14). Zur Quantifizierung der Myelinscheidendicke in Abhängigkeit vom Axondurchmesser wurde die G-Ratio verwendet. Dabei zeigte sich entgegen der Literatur (Hu et al. 2006) kein Unterschied in der Myelinscheidendicke der unbehandelten Tiere zwischen BACE1-ko- und Kontrolltieren (vgl. Abbildung 4.15). Eine mögliche Erklärung dafür ist die untersuchte anatomische Region: Während Hu et. al. (2006) den N. opticus sowie den Hippokampus untersuchten, wurde hier das Corpus callosum analysiert. Hu et. al. (2006) schlagen einen beeinträchtigten NRG1-Typ-III-Signalweg als Grund für die Hypomyelinisierung im ZNS vor. Andererseits konnte gezeigt werden, dass es auch beim völligen Fehlen von NRG 1 oder dessen Rezeptoren im ZNS zu keiner Dys- oder Demyelinisierung kommt (Brinkmann et al. 2008). Daher bleibt unklar, woher genau der be- 
obachtete Unterschied kommt. Brinkmann et al. (2008) schlagen vor, dass Oligodendrozyten bei Wirbeltiere im Gegensatz zu Schwann-Zellen nicht mehr auf Signale via NRG1 angewiesen sind (Brinkmann et al. 2008). Die vorliegenden Daten stützen diese Hypothese. Aufgrund der verhältnismäßig kleinen Stichprobengröße von Hu et. al (2006) von $n=3$ wäre es anzustreben, die Befunde im N. opticus und Hippokampus mit größeren Kohorten zu replizieren.

Die Analyse der Myelinscheidendicke nach einer sechswöchigen Regenerationsphase, die einer sechswöchigen Cuprizonebehandlung folgte, zeigte überraschenderweise einen kleinen, jedoch statistisch signifikanten Unterschied: BACE1ko-Tieren hatten insgesamt etwas dünnere Myelinscheiden als ihre Wildtypartgenossen. In der Literatur ist beschrieben, dass die Myelinscheiden im Corpus callosum nach cuprizoneinduzierter Demyelinisierung in einer Weise regenerierten, dass sie nach morphometrischen Kriterien nicht von primär gebildeten Myelinscheiden zu unterscheiden waren (Stidworthy et al. 2003). BACE1 scheint also eine Rolle beim Wiedererreichen der ursprünglichen Myelinscheidendicke nach Demyelinisierung zu spielen. Es existieren zu dieser Fragestellung keine weiteren Untersuchungen, sodass ein Vergleich dieser Daten nur unzureichend möglich ist. Daten aus dem PNS legen nahe, dass BACE1 bei der zeitlichen Abfolge der Remyelinisierung nach traumatischer Schädigung im Sinne einer Verzögerung der Regeneration eine Rolle spielt (Hu et al. 2008). Dies ist eine spannende Beobachtung, die die hier vorgestellten Daten nicht erfassen konnten, da nur ein Zeitpunkt untersucht wurde. Eine wichtige Untersuchung wäre also, ob nach einer über sechs Wochen hinaus verlängerten Regenerationsphase eine reguläre Myelinscheidendicke in BACE1-ko-Tieren erreicht wird. Ein sinnvoller Zeitraum wären zum Beispiel zwölf Wochen. Da sich bereits im ersten Durchlauf der Cuprizonestudie mit nur wenigen Tieren $(n=7)$ dieser signifikante Unterschied zeigte (vgl. Abbildung 4.21), sollte eine ähnlich große Kohorte genügen. So könnte die wichtige Frage beantwortet werden, ob BACE1 unabdingbar für die regelrechte Remyelinisierung im ZNS ist, oder ob es die Remyelinisierung nur beschleunigt, der Verlust jedoch mittel- oder langfristig kompensiert werden könnte. Diese Frage hat im Rahmen von pharmakologischer BACE1-Inhibiton eine große klinische Relevanz.

\subsubsection{Cuprizone führt nach der Remyelinisierung zu Riesenaxonen}

Bei der Musterung der elektronenmikroskopischen Bildern fielen deutlich vergrößerte Axone nach Cuprizonebehandlung auf (vgl. Abbildung 4.14). Eine dahinge- 
hende Analyse der elektronenmikroskopischen Daten bestätigte diesen überraschenden Befund in BACE1-ko- und Wildtyptieren (vgl. Abbildung 4.20). In der Literatur sind Veränderungen des Axonkalibers nach Cuprizonebehandlung beschrieben (Mason et al. 2001). Während der Cuprizonebehandlung kam es zu einer Verschiebung hin zu kleineren Axonen im Corpus callosum (Mason et al. 2001). Als Ursache wird das enge Zusammenwirken von Myelin und Axon diskutiert (Mason et al. 2001). Nach sechswöchiger Regeneration wurde eine Zunahme des mittleren Faserdurchmessers und der G-Ratio beobachtet (Mason et al. 2001). Mason et al. (2001) schlagen vor, dass entweder bevorzugt großkalibrige Axone remyelinisiert werden oder die Axone während der Remyelinisierung an Größe zunehmen. Dies ist eine mögliche Erklärung für den beobachteten Effekt, da in der vorliegenden Arbeit nur myelinisierte Axone untersucht wurden, während Mason et. al. (2001) auch unmyelinisierte Axone erfassten. Da der Effekt bei BACE1-ko- und Wildtyptieren gleichermaßen auftrat, ist ein Zusammenhang mit BACE1 unwahrscheinlich.

\subsubsection{Geschlechtsunterschiede bei der Remyelinisierung im ZNS}

Die deutliche Zunahme von BACE1 in der EAE (vgl. Abbildung 4.5 und Abbildung 4.6) lenkte das Augenmerk auf einen weiteren Aspekt. Alle Tiere der EAE waren weiblich. Daher wurde eine weitere, nach Geschlechtern getrennte, statistische Auswertung der Cuprizonestudie vorgenommen (vgl. Abbildung 4.21). Obwohl sich die Stichprobengröße dadurch deutlich reduzierte, konnten die Ergebnisse der Gesamtauswertung weitestgehend bestätigt werden. Ein markanter Unterschied bestand jedoch zwischen weiblichen und männlichen BACE1-ko-Tieren nach Cuprizonebehandlung: Während die Myelinscheiden der behandelten männlichen Tiere hochsignifikant dünner als die der männlichen Kontrollgruppe waren, wurde die statistische Signifikanz bei den Weibchen knapp verfehlt. Zwar zeigte sich auch hier ein deutlicher Trend zur statistischen Signifikanz (P = 0,073), doch in der etwas weniger Tiere umfassenden männlichen Gruppe war der P-Wert um mehr als den Faktor 10 geringer $(P=0,005)$. Zusammen mit den geringfügig dickeren Myelinscheiden der weiblichen Tiere nach der Remyelinisierungsphase (G-Ratio von 0,729 vs. 0,772 ) bei etwas dünneren Myelinscheiden der weiblichen Tiere ohne $\mathrm{Cu}$ prizonebehandlung (G-Ratio von 0,688 vs. 0,672) legt eine effektivere Remyelinisierung bei weiblichen Tieren nahe. Auch die ohne Behandlung nicht anhand der GRatio unterscheidbaren Kontrolltiere deuteten dies an (G-Ratio von 0,708 der Weibchen vs. 0,725 der Männchen nach Remyelinisierung). Eine aktuelle Studie 
fand keinen geschlechtsspezifischen Unterschied im Ausmaß der De- und Remyelinisierung nach Cuprizonebhandlung bei C57BL/6-Mäusen (Taylor et al. 2010). Bei dieser Studie wurde jedoch nicht die qualitative Ausprägung der einzelnen Myelinscheiden mittels G-Ratio untersucht. Eine weitere Studie konnte jedoch bei erwachsenen Ratten eine bessere Remyelinisierung bei weiblichen als bei männlichen Tieren nach fokaler Demyelinisierung im ZNS nachweisen (Li et al. 2006). Dieser Unterschied zeigte sich nicht bei jüngeren Tieren (Li et al. 2006). Diese Arbeit macht jedoch keine Aussagen über die Dicke der Myelinscheiden. Histopathologische Untersuchungen von Patientenmaterial zeigten keine signifikanten Unterschiede in der Remyelinisierung zwischen Frauen und Männern (Kuhlmann et al. 2009). Auch in dieser Studie wurde die Dicke der Myelinscheiden nicht untersucht. Die vorliegende Arbeit weist also zum ersten Mal auf einen qualitativen Unterschied in der Dicke der Myelinscheiden nach Remyelinisierung zwischen den beiden Geschlechtern hin. Dies ist ein überraschendes, aber wichtiges Ergebnis der erneuten statistischen Auswertung der Cuprizonestudie. Inwiefern dieser Unterschied von Geschlechtshormonen abhängt, könnte anhand einer medikamentösen Inhibition oder durch Zugabe von Sexualhormonen untersucht werden.

\subsection{BACE1 wird in allen Zelltypen des Gehirns exprimiert}

Grundlage dieser Arbeit war der in der AG B. De Strooper, Katholieke Universiteit Leuven, Niederlande, generierte monoklonale BACE1-Antikörper 10B8. Dieser war im Westernblot getestet worden (vgl. Abbildung 2.1). In einer der ersten Arbeiten über BACE1 war BACE1-mRNA mittels in-situ-Hybridisierung in Neuronen lokalisiert worden, während Glia fast keine oder keine mRNA enthielten (Vassar et al. 1999). In ruhenden Astrozyten im Gehirn war BACE1 zunächst nicht nachweisbar (Rossner et al. 2005). Auch in Mäusen mit der schwedischen APP-Mutation als Modell der AD konnte kein BACE1 in Astrozyten nachgewiesen werden (Bigl et al. 2000). Später wurde BACE1-mRNA und BACE1-Enzym-Aktivität jedoch in reaktiven Astrozyten nachgewiesen (Rossner et al. 2005). Ebenfalls ließ sich BACE1-Aktivität in Mikroglia und Oligodendrozyten nachweisen, diese war jedoch deutlich geringer als in den untersuchten Astrozyten (Rossner et al. 2005). Daher wurde die Expression von BACE1 in den verschiedenen Zelltypen des ZNS mit dem neuen Antikörper untersucht, um weitere Daten zu gewinnen und mögliche Quellen für BACE1 zu identifizieren. Alle Zelltypen des ZNS exprimierten BACE1. Die höchsten 
BACE1-Werte wiesen erwartungsgemäß Neurone auf. Auch in Oligodendrozyten konnten größere Mengen BACE1 nachgewiesen werden. Astrozyten und Mikroglia wiesen demgegenüber nur äußerst geringe Mengen BACE1 auf (vgl. Abbildung 4.1 und Abbildung 4.2). Im Lichte dieser Ergebnisse sind alle Zelltypen des ZNS als mögliche Quellen von BACE1 in Betracht zu ziehen. Dass auch ohne zusätzliche Stimulation der Nachweis in Astrozyten gelang, könnte daran liegen, dass die Zellen außerhalb ihrer physiologischen Umgebung vermehrt unter Stress stehen und daher wie die reaktiven Zellen im ZNS (Rossner et al. 2005) beginnen, BACE1 zu exprimieren. Zudem könnte der verwendete BACE1-Antikörper eine höhere Sensitivität als die bisherigen aufweisen. Vergleiche mit weiteren BACE1-Antikörpern würden diese Frage klären. Während die erhobenen Daten die Nachweisbarkeit von BACE1 in allen Zelltypen des ZNS bestätigen, unterscheidet sich das Ausmaß der Expression zwischen Rossner et. al. (2005) und den hier vorgestellten Ergebnissen. Während Rossner et. al. (2005) immunzytochemisch BACE1 vor allem in Neuronen und Astrozyten nachwiesen, wiesen wir BACE1 mittels Westernblot vor allem in Neuronen und Oligodendrozyten nach. Dazu ist festzustellen, dass unterschiedliche Spezies verwendet wurden (Rossner: Ratte, hier: Maus). Es gibt nur wenige weitere Arbeiten zu dieser Fragestellung. Eine Studie konnte BACE1 immunhistochemisch in Neuronen von Mäusen lokalisieren (He et al. 2004), für größere Mengen von BACE1 außerhalb dieses Zelltyps finden sich in den dort gezeigten Bildern keine Hinweise. Eine ältere Arbeit (Rossner et al. 2001) konnte immunhistochemisch BACE1 einzig in Neuronen von Wildtypmäusen nachweisen. Nur in transgenen Mäusen mit der schwedischen Mutation von APP zeigte sich in reaktiven Astrozyten um senile Plaques herum eine Expression von BACE1 (Rossner et al. 2001). Später wies diese Arbeitsgruppe in durch andere Ursachen wie EAE, Schlaganfall oder Bornaviruserkrankung aktivierten Astrozyten ebenfalls BACE1 nach (Hartlage-Rübsamen et al. 2003). In Mikroglia ließ sich in dieser Studie kein BACE1 nachweisen (Hartlage-Rübsamen et al. 2003).

Die hier vorgestellten Daten weisen also Unterschiede zur Literatur auf. Zwar könnte diese Diskrepanz durch die verschiedenen betrachteten Spezies erklärt werden, doch der Vergleich des relativen BACE1-Gehalts im Verhältnis zu Calnexin der Mausgehirn- und Rattenhirnstammlysate dieser Arbeit zeigt eine erstaunlich ähnliche Menge von BACE1 in den unbehandelten Kontrollgruppen (Maus: 0,52, Ratte: 0,46, vgl. Abb 4.4 und 4.6). Bei einer hypothetisch angenommen ähnlichen Biologie beider Nagetierspezies ist dies ein plausibles Ergebnis. Eine bessere Erklärung des verhältnismäßig hohen BACE1-Gehalts in Oligodendrozyten und demge- 
genüber niedrigen BACE1-Gehalts in Astrozyten im Vergleich zur Literatur (Hartlage-Rübsamen et al. 2003; Rossner et al. 2005) bietet der physiologische und ontogenetische Status der untersuchten Tiere. In der Arbeit von Willem et. al. (2006) war die Expression des BACE1-Proteins im Verlauf der Ontogenese mittels Westernblot untersucht worden. Man fand hier eine besonders starke BACE1-Expression perinatal, die in der ersten Lebenswoche anhält und dann innerhalb von zehn Tagen rapide abfällt (Willem et al. 2006). Bei adulten Tieren waren nur Bruchteile der BACE1-Menge von Jungtieren nachzuweisen (Willem et al. 2006). Im Rahmen dieser Betrachtung wären Primärzellen in der Kultur den Jungtieren gleichzusetzen und eine hohe BACE1-Expression wäre zu erwarten. Die Arbeit von $\mathrm{Hu}$ et al. (2006) zeigt die unterschiedliche Expression von Myelinproteinen bei Wildtypund BACE1-ko-Tieren im Verlauf der Ontogenese. Insbesondere MBP, PLP und MOG werden von BACE1-ko-Tieren deutlich geringer exprimiert (Hu et al. 2006). Da diese Proteine von Oligodendrozyten gebildet werden und ein Fehlen von BACE1 nach $\mathrm{Hu}$ et. al (2006) mit einer reduzierten Myelinbildung im ZNS einhergeht, erscheinen hohe BACE1-Spiegel bei Oligodendrozyten-Primärzellkulturen realistisch. Die Differenz zwischen den teilweise hohen BACE1-Werten von Astrozyten in der Literatur und den geringen BACE1-Werten, die hier gemessen worden waren, lässt sich anhand der vorhandenen Daten erklären. Zunächst ist positiv festzuhalten, dass BACE1-Protein in Astrozyten-Primärzellkulturen überhaupt nachzuweisen war. Dieser Umstand spricht für einen besonders sensitiven Antikörper, der schon kleinste Mengen von BACE1 nachweisen kann. Eine neuere Arbeit konnte ebenfalls geringere Mengen von BACE1 in Astrozyten-Primärzellkulturen nachweisen (Zhao et al. 2011). In den hier vorgestellten älteren Arbeiten war BACE1 jeweils nur nach zellulärem Stress nachweisbar. Es scheint sich allerdings nicht um eine Akutreaktion zu handeln, sondern nur bei länger andauernden, chronischen Zuständen aufzutreten, wie die Autoren schreiben (Hartlage-Rübsamen et al. 2003). In der Zellkultur von primären Astrozyten lässt sich jedoch schon nach einem Tag ein signifikanter Anstieg der BACE1-Expression nachweisen (Zhao et al. 2011). Um diesen Befund zu bestätigen, wäre eine weitere, möglichst noch länger andauernde Stimulation von Astrozyten in Zellkultur durch alternative Modalitäten und die regelmäßige Messung der BACE1-Expression notwendig. Auch die Oligodendrozytendaten könnten so weiter bestätigt und die Interpretation validiert werden, indem der Verlauf der BACE1-Expression zu verschiedenen Zeitpunkten in Einzel- und Kokultivierung von Primärzellen gemessen werden würde. 


\subsection{Der Einfluss von Inflammation auf die BACE1-Expression}

In dieser Arbeit findet sich eine erste Annäherung an die Fragestellung, inwiefern sich zellulärer Stress wie zum Beispiel durch Inflammation auf die BACE1-Expression auswirkt. Dazu wurde eine murine Zelllinie von Mikroglia, EOC-Zellen, mit unterschiedlichen Stimulanzien inkubiert und die BACE1-Expression nach 24 Stunden gemessen. Dabei zeigte sich eine deutliche Zunahme der BACE1-Expression nach Stimulation mit dem TLR-9-Liganden CpG, während das bakterielle Endotoxin LPS keine nennenswerte Steigerung der BACE1-Expression nach sich zog. Ebenso blieb die Zugabe von Rantes ohne Effekt. MIP-1 $\alpha$, ein Chemokin, führte ebenfalls zu einer deutlichen Zunahme der BACE1-Expression (vgl. Abbildung 4.7 und Abbildung 4.8). Ein Zusammenhang zwischen der Aktivität von BACE1 und zellulärem Stress ist bereits in der Literatur beschrieben. Eine Übersicht geben Chami und Checler 2012. Im Rahmen der AD-Forschung stand dabei vor allem der durch A $\beta$ ausgelöste oxidative Stress im Vordergrund. Eine aktuelle Studie, die unter diesem Aspekt die Auswirkungen proinflammatorischer Zytokine auf BACE1 in Astrozyten-Primärzellkulturen untersuchte, fand eine massive Induktion der BACE1Expression insbesondere unter Stimulation mit Kombinationen von LPS, Tumornekrosefaktor- $\alpha$ (TNF- $\alpha$ ) und Interferon- $\gamma$ (IFN- $\gamma$; Zhao et al. 2011). Demgegenüber veränderte sich die BACE1-Expression nach LPS allein zwar signifikant, fiel jedoch nach 24h Stunden zunächst leicht ab, um nach 96 Stunden deutlich anzusteigen (Zhao et al. 2011). Die hier vorgestellten Daten zeigen keine nennenswerte Veränderung der BACE1-Expression nach 24stündiger Stimulation mit LPS als Ligand des TLR 4 (BACE1-Aktin-Quotient 0,23 nach LPS im Vergleich zu 0,22 ohne Behandlung). Dies stimmt mit den für Astrozyten in der Literatur beschriebenen Daten gut überein. Doch Stimulation mit CpG als Ligand des TLR 9 führt bereits nach 24 Stunden zu einer deutlichen Zunahme der BACE1-Expression in EOC-Zellen (BACE1-Aktin-Quotient 0,45 nach CpG im Vergleich zu 0,22 ohne Behandlung). Dies passt deutlich besser zur Vorstellung von Mikroglia als „Sensor pathologischer Ereignisse des ZNS“ (Kreutzberg 1996). Auch die Stimulation mit MIP-1 $\alpha$ führt schnell zu einer deutlichen Zunahme der BACE1-Expression (BACE1-Aktin-Quotient 0,33 nach MIP-1 $\alpha$ im Vergleich zu 0,22 ohne Behandlung). Überraschenderweise bleibt die Stimulation mit Rantes ohne Auswirkung (BACE1-Aktin-Quotient 0,21 nach Rantes im Vergleich zu 0,22 ohne Behandlung).

Am eindeutigsten fällt die Stimulation mittels CpG via TLR 9 aus. Dies passt zur in der Literatur beschriebenen Hochregulation von BACE1 bei Inflammation. Über- 
raschend ist, dass LPS in der Zellkultur keinen Effekt auf die BACE1-Expression hat. Zwar ist dies bei Astrozyten in akuten Modellen ebenfalls beschrieben (HartlageRübsamen et al. 2003; Zhao et al. 2011), doch der auffällige Unterschied zwischen TLR-4- und TLR-9-induzierter Reaktion bei Mikroglia erstaunt. Eine mögliche Erklärung findet sich in der Biologie des zur Generierung der EOC-Zellen verwendeten Mausstammes C3H/HeJ. Dieser besitzt eine Mutation, die die LPS-vermittelte Immunantwort verhindert (Wong et al. 1999). Somit ist die ausbleibende Stimulation vermutlich durch einen defekten TLR 4 bedingt. Die fehlende Zunahme der BACE1-Expression nach Stimulation von EOC-Zellen mittels LPS war also zu erwarten und ist ein Beleg für die Freiheit des Versuchsaufbaus von äußere Störfaktoren. Unklar bleibt die unterschiedliche Auswirkung der Stimulation mit Rantes und MIP-1 $\alpha$ auf die BACE1-Expression, da diese einen gemeinsamen Rezeptor, CCR5, besitzen (Rock et al. 2004). In der Literatur ist jedoch beschrieben, dass unterschiedliche Chemokine zu einem differierenden Ausmaß der Phosphorylierung von CCR5 führen (Olbrich et al. 1999). Zudem beeinflusst die Chemokinkonzentration das Ausmaß der Phosphorylierung (Olbrich et al. 1999). Im Versuchsaufbau war eine höhere Konzentration von Rantes als von MIP-1 $\alpha$ gewählt worden. Rantes führt zudem zu einer stärkeren Phosphorylierung von CCR5 als MIP-1 $\alpha$ (Olbrich et al. 1999). Möglich ist also, dass BACE1 nur bei unvollständiger Phosphorylierung von CCR5 vermehrt exprimiert wird, während eine vollständige Phosphorylierung die Expression von BACE1 inhibiert. Um diese Frage beantworten zu können, wäre eine Stimulationsreihe mit verschiedenen Konzentrationen beider Chemokine notwendig. Dieser Versuch würde auch die Biologie von CCR5 im Rahmen von inflammatorischen Prozessen weiter aufklären. Wichtig in diesem Zusammenhang ist die Beobachtung von Zhao et. al (2011), dass BACE1 als Protein durch proinflammatorische Zytokine vermehrt exprimiert wird, jedoch die BACE1-mRNA unverändert oder nach Stimulation durch mehrere Zytokine sogar signifikant vermindert exprimiert wird. Dies lässt auf einen posttranskriptionellen Mechanismus der vermehrten BACE1-Synthese im Rahmen akuter Inflammation schließen (Zhao et al. 2011). 


\section{Zusammenfassung}

Ziel dieser Arbeit war die Untersuchung der Rolle der $\beta$-Sekretase, BACE1, bei der Remyelinisierung im Zentralen Nervensystem. Die $\beta$-Sekretase ist das Schlüsselenzym bei der Genese von Abeta. $A \beta$ lagert sich bei der Alzheimer-Demenz als herausragendes histopathologisches Merkmal in Form von Amyloid-Plaques ab. Jüngst untersuchten zwei Studien die bisher nur wenig verstandene physiologische Funktion von BACE1 und fanden eine Rolle bei der Myelinisierung im Peripheren und Zentralen Nervensystem. Das Fehlen von BACE1 ging mit einer Hypomyelinisierung einher. Dies ist die Grundlage dieser Arbeit.

Untersucht wurde zunächst die Expression von BACE1 in Modellen der Demyelinisierung. Dabei deutete sich eine erniedrigte BACE1-Expression in Gehirnlysaten von mit dem Kupferchelator Cuprizone behandelten Mäusen an. Im Gegensatz dazu wiesen Hirnstammlysate von Ratten, bei denen eine EAE induziert worden war, erhöhte BACE1-Level auf. Beide Analysen kleiner Stichproben verfehlten die statistische Signifikanz. Daraufhin wurde eine groß angelegte Cuprizonestudie an BACE1ko- und Wildtypmäusen mit klinischer und histopathologischer Analyse durchgeführt. Dabei zeigte sich überraschend als klinischer Parameter eine signifikant erniedrigte Schreckreaktion von unbehandelten BACE1-ko-Tieren im Vergleich zu Wildtypartgenossen. Elektronenmikroskopisch konnte anhand der G-Ratio die in der Literatur im Hippokampus sowie im N. opticus von BACE1-ko-Tieren beschriebene Hypomyelinisierung nicht im Corpus callosum nachgewiesen werden. Dieses Ergebnis ist im Rahmen der sich in klinischer Erprobung befindenden BACE1-Inhibitoren zur Behandlung der Alzheimer-Demenz von großer Wichtigkeit. Es zeigte sich jedoch ein kleiner, aber signifikanter Unterschied in der Dicke der Myelinscheiden von BACE1-ko-Tieren und Wildtypartgenossen nach Cuprizonebehandlung im Sinne einer Hypomyelinisierung von BACE1-ko-Tieren. Auch wenn das Cuprizonemodell ein extremes Beispiel von Demyelinisierung ist, können bereits klei- 
ne Unterschiede große klinische Auswirkungen haben und dürfen nicht vernachlässigt werden.

Zusammenfassend zeigt die Studie keinen Einfluss einer BACE1-Inhibiton auf die primäre Ausprägung der Myelinscheiden im Corpus callosum. Sie widerspricht damit der Hypothese, dass BACE1 via Neuregulin-1-Prozessierung notwendig für die Myelinisierung im ZNS ist. Ob es sich dabei um lokale Differenzen einzelner anatomischer Regionen handelt, muss in weiteren Studien untersucht werden. Zudem zeigt diese Arbeit einen kleinen, aber signifikanten Einfluss von BACE1 bei der Remyelinisierung im Corpus callosum nach Cuprizonebehandlung auf. Dies spricht dafür, dass die Remyelinisierung nicht nur eine Rekapitulation der primären Myelinisierung ist. Der mechanistische Zusammenhang bleibt ebenso wie die klinische Auswirkung unklar. Hier sind weitere Forschungen notwendig. 


\section{Anhang}

\subsection{Originalarbeiten}

Teile dieser Dissertation wurden bereits veröffentlicht:

Treiber H, Hagemeyer N, Ehrenreich H, Simons M (2012): BACE1 in central nervous system myelination revisited. Mol Psychiatry 17, 237-239.

\subsection{Abbildungsverzeichnis}

Abbildung 1.1: Auguste Deter, der erste berichtete Fall einer Alzheimer-Demenz....3

Abbildung 1.2: AD-Pathologie in Gehirnschnitten des Neokortex................................... 7

Abbildung 1.3: Stoffwechsel des Amyloid-Precursor-Proteins....................................... 10

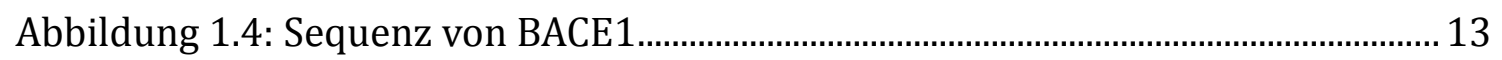

Abbildung 1.5: Schematische Darstellung eines Oligodendrozyten................................15

Abbildung 2.1: Westernblot des BACE1-Antikörpers 10B8..............................................29

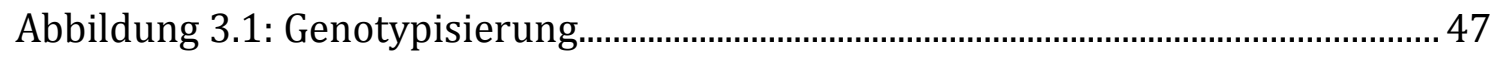

Abbildung 4.1: BACE1-Verteilung in Zellpopulationen des ZNS......................................51

Abbildung 4.2: BACE1-Verteilung in Zellpopulationen des ZNS. Quantifizierung....51

Abbildung 4.3: BACE1-Expression in Gehirnlysaten von Mäusen nach Cuprizonebehandlung.

Abbildung 4.4: BACE1-Expression in Gehirnlysaten von Mäusen nach Cuprizonebe-

handlung. Quantifizierung. 53 
Abbildung 4.5: BACE1-Expression in Hirnstammlysaten von Ratten nach Induktion einer EAE. 54

Abbildung 4.6: BACE1-Expression in Hirnstammlysaten von Ratten nach Induktion einer EAE. Quantifizierung. 54

Abbildung 4.7: BACE1-Expression in EOC-Zellen nach Stimulation durch Liganden von toll-like-Rezeptoren und Chemokinen 55

Abbildung 4.8: BACE1-Expression in EOC-Zellen nach Stimulation durch Liganden von toll-like-Rezeptoren und Chemokinen. Quantifizierung............................................56

Abbildung 4.9: Design der Cuprizonestudie..................................................................... 58

Abbildung 4.10: Immunhistochemische Färbung von Paraffinschnitten gegen das basische Myelinprotein. 60

Abbildung 4.11: Gewichtsverlauf der Mäuse in der Cuprizonestudie. 61

Abbildung 4.12: Cuprizonestudie. Kontrollgruppe. Startleversuch 63

Abbildung 4.13: Cuprizonestudie. Cuprizonegruppe. Startleversuch 64

Abbildung 4.14: Elektronenmikroskopische Aufnahmen des Corpus callosum........65

Abbildung 4.15: Vergleich der mittleren G-Ratios in der Cuprizonestudie. 67

Abbildung 4.16: Scatterplot Kontrollgruppe Wildtyp. 68

Abbildung 4.17: Scatterplot Kontrollgruppe BACE1 -/-. 68

Abbildung 4.18: Scatterplot Cuprizonegruppe Wildtyp. 69

Abbildung 4.19: Scatterplot Cuprizonegruppe BACE1 -/-. 69

Abbildung 4.20: Relative Häufigkeit der Axonkaliber in der Cuprizonestudie..........70

Abbildung 4.21: Gesamtübersicht über die Daten der Cuprizonestudie. 72 


\subsection{Bildquellen}

Die Bildquellen sind, soweit nicht vom Verfasser erstellt, jeweils unter den Abbildungen angegeben. Bei den nicht vom Verfasser erstellten Abbildungen wurde, soweit nötig, die Genehmigung zur Verwendung in dieser Dissertation eingeholt.

Die Fotografie von Auguste Deter (Abbildung 1.1) stammt von Wikimedia commons: http://commons.wikimedia.org/wiki/File:Auguste_D_aus_Marktbreit.jpg, abgerufen am 02.11.2012.

Die Abbildung zur AD-Pathologie in Gehirnschnitten des Neokortex (Abbildung 1.2) wurde mit freundlicher Genehmigung von IOS Press verwendet.

\subsection{Abkürzungsverzeichnis}

$\mathrm{AD}$

AG

AICD

ApoE

APP

APS

BACE

BCA

BSA

DNA

DSM-IV

EAE

EDTA

$\mathrm{EGF}$

EGTA
Alzheimer-Demenz

Arbeitsgruppe

Amyloid-Precursor-Protein intracellular domain

Apolipoprotein E

Amyloid-Precursor-Protein

Ammoniumperoxodisulfat

$\beta$-site Amyloid-Precursor-Protein-cleaving enzyme

bicinchonic acid, Bicinchonsäure

bovine serum albumin

deoxyribonucleic acid

Diagnostic and Statistical Manual of Mental Disorders

Experimentelle autoimmune Enzephalomyelitis

Ethylendiamintetraacetat

epidermal growth factor

Ethylenglykol-bis(aminoethylether)-N,N,N'N'-Tetraessigsäure 
Epon $\quad$ Epoxidharz

FAD

Familiäre Alzheimer-Demenz

FTDP-17 erbliche frontotemporale Demenz mit Parkinsonismus des Chromosoms 17

HRP

horseradish peroxidase, Meerrettichperoxidase

ICD-10

Internationale statistische Klassifikation der Krankheiten und verwandter Gesundheitsprobleme

IFN- $\gamma \quad$ Interferon- $\gamma$

LPS Lipopolysaccharide

MAG Myelin-assoziiertes Glykoprotein

MAP Mikrotubuli-assoziiertes Protein

MAP-T Mikrotubuli-assoziiertes Protein-Tau

MBP myelin basic protein

MIP-1 $\quad$ Macrophage Inflammatory Protein-1 $1 \alpha$

MMST Mini Mental Status Test

MOG Myelin-Oligodendrozyten-Glykoprotein

mRNA messenger ribonucleic acid

NINCDS-ADRDA National Institute of Neurological Disorders and Stroke - Alzheimer's Disease and Related Disorders Association

NRG1 Neuregulin 1

PAGE polyacrylamide gel electrophoresis

PBS phosphate buffered saline

PBS-T phosphate buffered saline - tween

PCR polymerase chain reaction

PHF paired helical filament

PKN Proteinkinase N 
PLP Proteolipid-Protein

PNS Peripheres Nervensystem

PSEN Presenilin

PSP progressive supranuclear palsy

RT Raumtemperatur

SAPP- $\alpha \quad$ soluble Amyloid-Precursor-Protein- $\alpha$

sAPP- $\beta \quad$ soluble Amyloid-Precursor-Protein- $\beta$

SAD Sporadische Alzheimer-Demenz

SDS sodium dodecyl sulfate, Natriumlaurylsulfat

SEM Standard Error of the Mean

TAE TRIS-Acetat-EDTA

TEMED Tetramethylethylendiamin

TLR toll-like-Rezeptor

TNF- $\alpha \quad$ Tumornekrosefaktor- $\alpha$

TRIS TRIS(hydroxymethyl)-aminomethan

ZNS Zentrales Nervensystem 


\section{Literaturverzeichnis}

Acquati F, Accarino M, Nucci C, Fumagalli P, Jovine L, Ottolenghi S, Taramelli R (2000): The gene encoding DRAP (BACE2), a glycosylated transmembrane protein of the aspartic protease family, maps to the down critical region. FEBS Lett $\underline{468}$ : 59-64

Alzheimer A (1907): Über eine eigenartige Erkrankung der Hirnrinde. Allg Zeitschr Psychiat Psych Gerichtl Med 64: 146-148

Baumann N, Pham-Dinh D (2001): Biology of oligodendrocyte and myelin in the mammalian central nervous system. Physiol Rev 81: 871-927

Baxter AG (2007): The origin and application of experimental autoimmune encephalomyelitis. Nat Rev Immunol 7: 904-912

Ben-Nun A, Wekerle H, Cohen IR (1981): The rapid isolation of clonable antigenspecific T lymphocyte lines capable of mediating autoimmune encephalomyelitis. Eur J Immunol 11: 195-199

Bennett BD, Babu-Khan S, Loeloff R, Louis JC, Curran E, Citron M, Vassar R (2000a): Expression analysis of BACE2 in brain and peripheral tissues. J Biol Chem $\underline{275}$ : 20647-20651

Bennett BD, Denis P, Haniu M, Teplow DB, Kahn S, Louis JC, Citron M, Vassar R (2000b): A furin-like convertase mediates propeptide cleavage of BACE, the Alzheimer's beta -secretase. J Biol Chem 275: 37712-37717

Bielschowsky M (1902): Die Silberimprägnation der Achsencylinder. Neurol Centralbl 21: 579-584 
Bigl M, Apelt J, Luschekina EA, Lange-Dohna C, Rossner S, Schliebs R (2000): Expression of beta-secretase mRNA in transgenic Tg2576 mouse brain with Alzheimer plaque pathology. Neurosci Lett 292: 107-110

Billingsley ML, Kincaid RL (1997): Regulated phosphorylation and dephosphorylation of tau protein: effects on microtubule interaction, intracellular trafficking and neurodegeneration. Biochem J 323 (Pt 3): 577-591

Blennow K, Leon MJ de, Zetterberg H (2006): Alzheimer's disease. Lancet $\underline{368}$ : 387-403

Blessed G, Tomlinson BE, Roth M (1968): The association between quantitative measures of dementia and of senile change in the cerebral grey matter of elderly subjects. Br J Psychiatry 114: 797-811

Blocq P, Marinesco G (1892): Sur les lésions et la pathogénie de l'épilepsie dite essentielle. Sem méd (Paris) 12: 445-446

Blomqvist ME-L, Reynolds C, Katzov H, Feuk L, Andreasen N, Bogdanovic N, Blennow K, Brookes AJ, Prince JA (2006): Towards compendia of negative genetic association studies: an example for Alzheimer disease. Hum Genet $\underline{119}$ : 29-37

Bloom GS, Schoenfeld TA, Vallee RB (1984): Widespread distribution of the major polypeptide component of MAP 1 (microtubule-associated protein 1) in the nervous system. J Cell Biol 98: 320-330

Borisy GG, Marcum JM, Olmsted JB, Murphy DB, Johnson KA (1975): Purification of tubulin and associated high molecular weight proteins from porcine brain and characterization of microtubule assembly in vitro. Ann N Y Acad Sci 253: 107132

Braak H, Braak E (1991): Neuropathological stageing of Alzheimer-related changes. Acta Neuropathol 82: 239-259

Brinkmann BG, Agarwal A, Sereda MW, Garratt AN, Müller T, Wende H, Stassart RM, Nawaz S, Humml C, Velanac V, et al. (2008): Neuregulin-1/ErbB signaling serves distinct functions in myelination of the peripheral and central nervous system. Neuron 59: 581-595 
Butt AM, Ransom BR (1989): Visualization of oligodendrocytes and astrocytes in the intact rat optic nerve by intracellular injection of lucifer yellow and horseradish peroxidase. Glia 2: 470-475

Calaora V, Rogister B, Bismuth K, Murray K, Brandt H, Leprince P, Marchionni M, Dubois-Dalcq M (2001): Neuregulin signaling regulates neural precursor growth and the generation of oligodendrocytes in vitro. J Neurosci 21: 47404751

Cellerino A, Carroll P, Thoenen H, Barde YA (1997): Reduced size of retinal ganglion cell axons and hypomyelination in mice lacking brain-derived neurotrophic factor. Mol Cell Neurosci 9. 397-408

Chami L, Checler F (2012): BACE1 is at the crossroad of a toxic vicious cycle involving cellular stress and $\beta$-amyloid production in Alzheimer's disease. Mol Neurodegener 7: 52

Chang A, Nishiyama A, Peterson J, Prineas J, Trapp BD (2000): NG2-positive oligodendrocyte progenitor cells in adult human brain and multiple sclerosis lesions. J Neurosci 20: 6404-6412

Chang A, Tourtellotte WW, Rudick R, Trapp BD (2002): Premyelinating oligodendrocytes in chronic lesions of multiple sclerosis. N Engl J Med $\underline{346}$ : 165-173

Chen S, Velardez MO, Warot X, Yu Z-X, Miller SJ, Cros D, Corfas G (2006): Neuregulin 1-erbB signaling is necessary for normal myelination and sensory function. J Neurosci 26: 3079-3086

Chien A, Edgar DB, Trela JM (1976): Deoxyribonucleic acid polymerase from the extreme thermophile Thermus aquaticus. J Bacteriol 127: 1550-1557

Cipriani G, Dolciotti C, Picchi L, Bonuccelli U (2011): Alzheimer and his disease: a brief history. Neurol Sci 32: 275-279

Citron M, Oltersdorf T, Haass C, McConlogue L, Hung AY, Seubert P, Vigo-Pelfrey C, Lieberburg I, Selkoe DJ (1992): Mutation of the beta-amyloid precursor protein in familial Alzheimer's disease increases beta-protein production. Nature $\underline{360}$ : $672-674$ 
Citron M, Teplow DB, Selkoe DJ (1995): Generation of amyloid beta protein from its precursor is sequence specific. Neuron $\underline{14}$ : 661-670

Cole SL, Vassar R (2008): The role of amyloid precursor protein processing by BACE1, the beta-secretase, in Alzheimer disease pathophysiology. J Biol Chem 283: 29621-29625

Comas-Herrera A, Northey S, Wittenberg R, Knapp M, Bhattacharyya S, Burns A (2011): Future costs of dementia-related long-term care: exploring future scenarios. Int Psychogeriatr 23: 20-30

Compston A, Coles A (2002): Multiple sclerosis. The Lancet 359: 1221-1231

ffrench-Constant C, Colognato H, Franklin RJM (2004): Neuroscience. The mysteries of myelin unwrapped. Science 304: 688-689

Corder EH, Saunders AM, Strittmatter WJ, Schmechel DE, Gaskell PC, Small GW, Roses AD, Haines JL, Pericak-Vance MA (1993): Gene dose of apolipoprotein E type 4 allele and the risk of Alzheimer's disease in late onset families. Science 261: 921-923

Creemers JW, Ines Dominguez D, Plets E, Serneels L, Taylor NA, Multhaup G, Craessaerts K, Annaert W, De Strooper B (2001): Processing of beta-secretase by furin and other members of the proprotein convertase family. J Biol Chem 276: 4211-4217

Cruts M, Duijn CM van, Backhovens H, Broeck M Van den, Wehnert A, Serneels S, Sherrington R, Hutton M, Hardy J, St George-Hyslop PH, et al. (1998): Estimation of the genetic contribution of presenilin-1 and -2 mutations in a populationbased study of presenile Alzheimer disease. Hum Mol Genet 7: 43-51

De Strooper B, Annaert W, Cupers P, Saftig P, Craessaerts K, Mumm JS, Schroeter EH, Schrijvers V, Wolfe MS, Ray WJ, et al. (1999): A presenilin-1-dependent gammasecretase-like protease mediates release of Notch intracellular domain. Nature 398: 518-522

De Strooper B, Saftig P, Craessaerts K, Vanderstichele H, Guhde G, Annaert W, Figura K Von, Leuven F Van (1998): Deficiency of presenilin-1 inhibits the normal cleavage of amyloid precursor protein. Nature $\underline{391}$ : 387-390 
Diener H-C (2012): Leitlinien für Diagnostik und Therapie in der Neurologie: Herausgegeben von der Kommission „Leitlinien“ der DGN. Georg Thieme Verlag, Stuttgart 2012

Dilling H, Freyberger HJ (2012): Taschenführer zur ICD-10-Klassifikation psychischer Störungen: Mit Glossar und Diagnostischen Kriterien sowie Referenztabellen ICD-10 vs. ICD-9 und ICD-10 vs. DSM-IV-TR. Verlag Hans Huber, Bern 2012

Edgar JM, McLaughlin M, Werner HB, McCulloch MC, Barrie JA, Brown A, Faichney AB, Snaidero N, Nave K-A, Griffiths IR (2009): Early ultrastructural defects of axons and axon-glia junctions in mice lacking expression of Cnp1. Glia 57: 1815-1824

Esler WP, Das C, Campbell WA, Kimberly WT, Kornilova AY, Diehl TS, Ye W, Ostaszewski BL, Xia W, Selkoe DJ, et al. (2002): Amyloid-lowering isocoumarins are not direct inhibitors of $\gamma$-secretase. Nature Cell Biology 4 : E110-E111

Falls DL (2003): Neuregulins and the neuromuscular system: 10 years of answers and questions. J Neurocytol 32: 619-647

Farrer LA, Cupples LA, Haines JL, Hyman B, Kukull WA, Mayeux R, Myers RH, Pericak-Vance MA, Risch N, Duijn CM van (1997): Effects of age, sex, and ethnicity on the association between apolipoprotein E genotype and Alzheimer disease. A meta-analysis. APOE and Alzheimer Disease Meta Analysis Consortium. JAMA 278: 1349-1356

Ferri CP, Prince M, Brayne C, Brodaty H, Fratiglioni L, Ganguli M, Hall K, Hasegawa K, Hendrie H, Huang Y, et al. (2005): Global prevalence of dementia: a Delphi consensus study. Lancet 366: 2112-2117

Fields RD (2008): White matter in learning, cognition and psychiatric disorders. Trends Neurosci 31: 361-370

Folstein MF, Folstein SE, McHugh PR (1975): „Mini-mental state“. A practical method for grading the cognitive state of patients for the clinician. J Psychiatr Res 12: 189-198 
Frances A, Ross R (2001): DSM-IV-TR Case Studies: A Clinical Guide to Differential Diagnosis. American Psychiatric Publishing, Arlington 2001

Franklin RJM (2002): Why does remyelination fail in multiple sclerosis? Nat Rev Neurosci $\underline{3}$ : 705-714

Franklin RJM, ffrench-Constant C (2008): Remyelination in the CNS: from biology to therapy. Nat Rev Neurosci 9: 839-855

Garratt AN, Britsch S, Birchmeier C (2000a): Neuregulin, a factor with many functions in the life of a schwann cell. Bioessays 22: 987-996

Garratt AN, Voiculescu O, Topilko P, Charnay P, Birchmeier C (2000b): A dual role of erbB2 in myelination and in expansion of the schwann cell precursor pool. J Cell Biol 148: 1035-1046

Gasser HS (1941): The Classification of Nerve Fibers. Ohio J Sci 41: 145-159

Gatz M, Reynolds CA, Fratiglioni L, Johansson B, Mortimer JA, Berg S, Fiske A, Pedersen NL (2006): Role of genes and environments for explaining Alzheimer disease. Arch Gen Psychiatry $\underline{63}$ : 168-174

Glenner GG, Wong CW (1984): Alzheimer's disease: initial report of the purification and characterization of a novel cerebrovascular amyloid protein. Biochem Biophys Res Commun 120: 885-890

Goate A, Chartier-Harlin MC, Mullan M, Brown J, Crawford F, Fidani L, Giuffra L, Haynes A, Irving N, James L (1991): Segregation of a missense mutation in the amyloid precursor protein gene with familial Alzheimer's disease. Nature $\underline{349}$ : 704-706

Goedert M, Spillantini MG, Jakes R, Rutherford D, Crowther RA (1989): Multiple isoforms of human microtubule-associated protein tau: sequences and localization in neurofibrillary tangles of Alzheimer's disease. Neuron $\underline{3}$ : 519526

Goedert M, Wischik CM, Crowther RA, Walker JE, Klug A (1988): Cloning and sequencing of the cDNA encoding a core protein of the paired helical filament of Alzheimer disease: identification as the microtubule-associated protein tau. Proc Natl Acad Sci U S A 85: 4051-4055 
Gold R, Linington C, Lassmann H (2006): Understanding pathogenesis and therapy of multiple sclerosis via animal models: 70 years of merits and culprits in experimental autoimmune encephalomyelitis research. Brain 129: 1953-1971

Graeber MB, Mehraein P (1999): Reanalysis of the first case of Alzheimer's disease. Eur Arch Psychiatry Clin Neurosci 249 Suppl 3: 10-13

Griffiths I, Klugmann M, Anderson T, Yool D, Thomson C, Schwab MH, Schneider A, Zimmermann F, McCulloch M, Nadon N, et al. (1998): Axonal swellings and degeneration in mice lacking the major proteolipid of myelin. Science $\underline{280}$ : 1610-1613

Grundke-Iqbal I, Iqbal K, Tung YC, Quinlan M, Wisniewski HM, Binder LI (1986): Abnormal phosphorylation of the microtubule-associated protein tau (tau) in Alzheimer cytoskeletal pathology. Proc Natl Acad Sci USA 모: 4913-4917

Haass C, Schlossmacher MG, Hung AY, Vigo-Pelfrey C, Mellon A, Ostaszewski BL, Lieberburg I, Koo EH, Schenk D, Teplow DB (1992): Amyloid beta-peptide is produced by cultured cells during normal metabolism. Nature 359: 322-325

Hagemeyer N (2012): Effects of recombinant human erythropoietin in the cuprizone mouse model of de- and remyelination. Biol.-Diss. Göttingen 2012

Harada A, Oguchi K, Okabe S, Kuno J, Terada S, Ohshima T, Sato-Yoshitake R, Takei Y, Noda T, Hirokawa N (1994): Altered microtubule organization in small-calibre axons of mice lacking tau protein. Nature $\underline{369}$ : 488-491

Hardy J, Allsop D (1991): Amyloid deposition as the central event in the aetiology of Alzheimer's disease. Trends Pharmacol Sci 12: 383-388

Hardy J, Selkoe DJ (2002): The amyloid hypothesis of Alzheimer's disease: progress and problems on the road to therapeutics. Science 297: 353-356

Harrison SM, Harper AJ, Hawkins J, Duddy G, Grau E, Pugh PL, Winter PH, Shilliam CS, Hughes ZA, Dawson LA, et al. (2003): BACE1 (beta-secretase) transgenic and knockout mice: identification of neurochemical deficits and behavioral changes. Mol Cell Neurosci 24: 646-655 
Hartlage-Rübsamen M, Zeitschel U, Apelt J, Gärtner U, Franke H, Stahl T, Günther A, Schliebs R, Penkowa M, Bigl V, et al. (2003): Astrocytic expression of the Alzheimer's disease beta-secretase (BACE1) is stimulus-dependent. Glia $\underline{41}$ : 169-179

Harvey R, Skelton-Robinson M, Rossor M (2003): The prevalence and causes of dementia in people under the age of 65 years. J Neurol Neurosurg Psychiatry 74: 1206-1209

He W, Lu Y, Qahwash I, Hu X-Y, Chang A, Yan R (2004): Reticulon family members modulate BACE1 activity and amyloid-beta peptide generation. Nat Med $\underline{10}$ : 959-965

Hiremath MM, Saito Y, Knapp GW, Ting JP, Suzuki K, Matsushima GK (1998): Microglial/macrophage accumulation during cuprizone-induced demyelination in C57BL/6 mice. J Neuroimmunol 92: 38-49

Hobson GM, Garbern JY (2012): Pelizaeus-Merzbacher disease, PelizaeusMerzbacher-like disease 1, and related hypomyelinating disorders. Semin Neurol 32: 62-67

Hu X, He W, Diaconu C, Tang X, Kidd GJ, Macklin WB, Trapp BD, Yan R (2008): Genetic deletion of BACE1 in mice affects remyelination of sciatic nerves. FASEB J 22: 2970-2980

Hu X, Hicks CW, He W, Wong P, Macklin WB, Trapp BD, Yan R (2006): Bace1 modulates myelination in the central and peripheral nervous system. Nat Neurosci 9: 1520-1525

Hussain I, Powell D, Howlett DR, Tew DG, Meek TD, Chapman C, Gloger IS, Murphy KE, Southan CD, Ryan DM, et al. (1999): Identification of a novel aspartic protease (Asp 2) as beta-secretase. Mol Cell Neurosci 14: 419-427

Hussain I, Powell DJ, Howlett DR, Chapman GA, Gilmour L, Murdock PR, Tew DG, Meek TD, Chapman C, Schneider K, et al. (2000): ASP1 (BACE2) cleaves the amyloid precursor protein at the beta-secretase site. Mol Cell Neurosci 16: 609619 
Iqbal K, Liu F, Gong C-X, Grundke-Iqbal I (2010): Tau in Alzheimer disease and related tauopathies. Curr Alzheimer Res 7: 656-664

Jahn O, Tenzer S, Werner HB (2009): Myelin proteomics: molecular anatomy of an insulating sheath. Mol Neurobiol 40: 55-72

Janssen JC, Beck JA, Campbell TA, Dickinson A, Fox NC, Harvey RJ, Houlden H, Rossor MN, Collinge J (2003): Early onset familial Alzheimer's disease: Mutation frequency in 31 families. Neurology $\underline{60}$ : 235-239

Kandalepas PC, Vassar R (2012): Identification and biology of $\beta$-secretase. J Neurochem 120 Suppl 1: 55-61

Kanemaru K, Takio K, Miura R, Titani K, Ihara Y (1992): Fetal-type phosphorylation of the tau in paired helical filaments. J Neurochem $\underline{58}$ : 1667-1675

Kang J, Lemaire HG, Unterbeck A, Salbaum JM, Masters CL, Grzeschik KH, Multhaup G, Beyreuther K, Müller-Hill B (1987): The precursor of Alzheimer's disease amyloid A4 protein resembles a cell-surface receptor. Nature $\underline{325}$ : 733-736

Karlsson U, Schultz RL (1965): Fixation of the Central Nervous System for Electron Microscopy by Aldehyde Perfusion. !. Preservation with Aldehyde Perfusotes versus Direct Perfusion with Osmium Tetroxide with Special Reference to Membranes and the Extracellular Space. J Ultrastruct Res 12: 160-186

Kawamata T, Taniguchi T, Mukai H, Kitagawa M, Hashimoto T, Maeda K, Ono Y, Tanaka C (1998): A protein kinase, PKN, accumulates in Alzheimer neurofibrillary tangles and associated endoplasmic reticulum-derived vesicles and phosphorylates tau protein. J Neurosci 18: 7402-7410

Kim DY, Gersbacher MT, Inquimbert P, Kovacs DM (2011): Reduced sodium channel $\mathrm{Na}(v) 1.1$ levels in BACE1-null mice. J Biol Chem 286: 8106-8116

Kitazume S, Tachida Y, Oka R, Kotani N, Ogawa K, Suzuki M, Dohmae N, Takio K, Saido TC, Hashimoto Y (2003): Characterization of alpha 2,6-sialyltransferase cleavage by Alzheimer's beta -secretase (BACE1). J Biol Chem 278: 1486514871 
Kitazume S, Tachida Y, Oka R, Shirotani K, Saido TC, Hashimoto Y (2001):

Alzheimer's beta-secretase, beta-site amyloid precursor protein-cleaving enzyme, is responsible for cleavage secretion of a Golgi-resident sialyltransferase. Proc Natl Acad Sci USA 98: 13554-13559

Kreutzberg GW (1996): Microglia: a sensor for pathological events in the CNS. Trends Neurosci 19: 312-318

Kuhlmann T, Goldschmidt T, Antel J, Wegner C, König F, Metz I, Brück W (2009): Gender differences in the histopathology of MS? Journal of the Neurological Sciences 286: 86-91

Laemmli UK (1970): Cleavage of structural proteins during the assembly of the head of bacteriophage T4. Nature 227: 680-685

Lee VM, Goedert M, Trojanowski JQ (2001): Neurodegenerative tauopathies. Annu Rev Neurosci 24: 1121-1159

Lemke G (2006): Neuregulin-1 and myelination. Sci STKE 2006: pe11

Levy-Lahad E, Wasco W, Poorkaj P, Romano DM, Oshima J, Pettingell WH, Yu CE, Jondro PD, Schmidt SD, Wang K (1995): Candidate gene for the chromosome 1 familial Alzheimer's disease locus. Science 269: 973-977

Li Q Südhof TC (2004): Cleavage of amyloid-beta precursor protein and amyloidbeta precursor-like protein by BACE 1. J Biol Chem 279: 10542-10550

Li W-W, Penderis J, Zhao C, Schumacher M, Franklin RJM (2006): Females remyelinate more efficiently than males following demyelination in the aged but not young adult CNS. Exp Neurol 202: 250-254

Lichtenthaler SF, Dominguez D-I, Westmeyer GG, Reiss K, Haass C, Saftig P, De Strooper B, Seed B (2003): The cell adhesion protein P-selectin glycoprotein ligand-1 is a substrate for the aspartyl protease BACE1. J Biol Chem $\underline{278}$ : 48713-48719

Lin X, Koelsch G, Wu S, Downs D, Dashti A, Tang J (2000): Human aspartic protease memapsin 2 cleaves the beta-secretase site of beta-amyloid precursor protein. Proc Natl Acad Sci USA 97: 1456-1460 
Lleó A, Blesa R, Queralt R, Ezquerra M, Molinuevo JL, Peña-Casanova J, Rojo A, Oliva $R$ (2002): Frequency of mutations in the presenilin and amyloid precursor protein genes in early-onset Alzheimer disease in Spain. Arch Neurol 59: 17591763

Logue SF, Owen EH, Rasmussen DL, Wehner JM (1997): Assessment of locomotor activity, acoustic and tactile startle, and prepulse inhibition of startle in inbred mouse strains and F1 hybrids: implications of genetic background for single gene and quantitative trait loci analyses. Neuroscience $\underline{80}$ : 1075-1086

Luo Y, Bolon B, Kahn S, Bennett BD, Babu-Khan S, Denis P, Fan W, Kha H, Zhang J, Gong Y, et al. (2001): Mice deficient in BACE1, the Alzheimer's beta-secretase, have normal phenotype and abolished beta-amyloid generation. Nat Neurosci $\underline{4}$ : 231-232

Mason JL, Jones JJ, Taniike M, Morell P, Suzuki K, Matsushima GK (2000): Mature oligodendrocyte apoptosis precedes IGF-1 production and oligodendrocyte progenitor accumulation and differentiation during demyelination/remyelination. Journal of Neuroscience Research 61: 251-262

Mason JL, Langaman C, Morell P, Suzuki K, Matsushima GK (2001): Episodic demyelination and subsequent remyelination within the murine central nervous system: changes in axonal calibre. Neuropathol Appl Neurobiol 27: 5058

Masters CL, Simms G, Weinman NA, Multhaup G, McDonald BL, Beyreuther K (1985): Amyloid plaque core protein in Alzheimer disease and Down syndrome. Proc Natl Acad Sci USA 82: 4245-4249

Matsushima GK, Morell P (2001): The neurotoxicant, cuprizone, as a model to study demyelination and remyelination in the central nervous system. Brain Pathol 11: 107-116

Mawal-Dewan M, Henley J, Voorde A Van de, Trojanowski JQ Lee VM (1994): The phosphorylation state of tau in the developing rat brain is regulated by phosphoprotein phosphatases. J Biol Chem 269: 30981-30987 
McKhann G, Drachman D, Folstein M, Katzman R, Price D, Stadlan EM (1984): Clinical diagnosis of Alzheimer's disease: report of the NINCDS-ADRDA Work Group under the auspices of Department of Health and Human Services Task Force on Alzheimer's Disease. Neurology 34: 939-944

McKhann GM, Knopman DS, Chertkow H, Hyman BT, Jack CR Jr, Kawas CH, Klunk WE, Koroshetz WJ, Manly JJ, Mayeux R, et al. (2011): The diagnosis of dementia due to Alzheimer's disease: recommendations from the National Institute on Aging-Alzheimer's Association workgroups on diagnostic guidelines for Alzheimer's disease. Alzheimers Dement 7: 263-269

Meakin PJ, Harper AJ, Hamilton DL, Gallagher J, McNeilly AD, Burgess LA, Vaanholt LM, Bannon KA, Latcham J, Hussain I, et al. (2012): Reduction in BACE1 decreases body weight, protects against diet-induced obesity and enhances insulin sensitivity in mice. Biochem J 441: 285-296

Merkler D, Ernsting T, Kerschensteiner M, Brück W, Stadelmann C (2006): A new focal EAE model of cortical demyelination: multiple sclerosis-like lesions with rapid resolution of inflammation and extensive remyelination. Brain 129: 19721983

Michailov GV, Sereda MW, Brinkmann BG, Fischer TM, Haug B, Birchmeier C, Role L, Lai C, Schwab MH, Nave K-A (2004): Axonal neuregulin-1 regulates myelin sheath thickness. Science $\underline{304:}$ 700-703

Mu Y, Gage FH (2011): Adult hippocampal neurogenesis and its role in Alzheimer's disease. Mol Neurodegener $\underline{6}: 85$

Mukai H, Kitagawa M, Shibata H, Takanaga H, Mori K, Shimakawa M, Miyahara M, Hirao K, Ono Y (1994): Activation of PKN, a novel 120-kDa protein kinase with leucine zipper-like sequences, by unsaturated fatty acids and by limited proteolysis. Biochem Biophys Res Commun 204: 348-356

Mukai H, Ono Y (1994): A novel protein kinase with leucine zipper-like sequences: its catalytic domain is highly homologous to that of protein kinase C. Biochem Biophys Res Commun 199: 897-904

Mullan M, Crawford F, Axelman K, Houlden H, Lilius L, Winblad B, Lannfelt L (1992): A pathogenic mutation for probable Alzheimer's disease in the APP gene at the N-terminus of beta-amyloid. Nat Genet 1: 345-347 
Nukina N, Ihara Y (1986): One of the antigenic determinants of paired helical filaments is related to tau protein. J Biochem 99: 1541-1544

Ogata T, Iijima S, Hoshikawa S, Miura T, Yamamoto S, Oda H, Nakamura K, Tanaka S (2004): Opposing extracellular signal-regulated kinase and Akt pathways control Schwann cell myelination. J Neurosci 24: 6724-6732

Olbrich H, Proudfoot AE, Oppermann M (1999): Chemokine-induced phosphorylation of CC chemokine receptor 5 (CCR5). J Leukoc Biol 65: 281-285

Patrikios P, Stadelmann C, Kutzelnigg A, Rauschka H, Schmidbauer M, Laursen H, Sorensen PS, Brück W, Lucchinetti C, Lassmann H (2006): Remyelination is extensive in a subset of multiple sclerosis patients. Brain 129: 3165-3172

Patzig J, Jahn O, Tenzer S, Wichert SP, Monasterio-Schrader P de, Rosfa S, Kuharev J, Yan K, Bormuth I, Bremer J, et al. (2011): Quantitative and integrative proteome analysis of peripheral nerve myelin identifies novel myelin proteins and candidate neuropathy loci. J Neurosci 31: 16369-16386

Petit A, Bihel F, Alvès da Costa C, Pourquié O, Checler F, Kraus JL (2001): New protease inhibitors prevent gamma-secretase-mediated production of Abeta40/42 without affecting Notch cleavage. Nat Cell Biol $\underline{3}$ : 507-511

Pinnix I, Council JE, Roseberry B, Onstead L, Mallender W, Sucic J, Sambamurti K (2001): Convertases other than furin cleave beta-secretase to its mature form. FASEB J 15: 1810-1812

Podlisny MB, Lee G, Selkoe DJ (1987): Gene dosage of the amyloid beta precursor protein in Alzheimer's disease. Science 238: 669-671

Poirier J, Davignon J, Bouthillier D, Kogan S, Bertrand P, Gauthier S (1993):

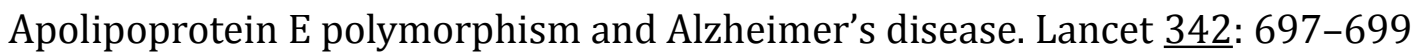

Prasher VP, Farrer MJ, Kessling AM, Fisher EM, West RJ, Barber PC, Butler AC (1998): Molecular mapping of Alzheimer-type dementia in Down's syndrome. Ann Neurol 43: 380-383 
Purohit DP, Batheja NO, Sano M, Jashnani KD, Kalaria RN, Karunamurthy A, Kaur S, Shenoy AS, Dyk K Van, Schmeidler J, et al. (2011): Profiles of Alzheimer's Disease-Related Pathology in an Aging Urban Population Sample. J Alzheimers Dis 24: 187-196

Raber J, Huang Y, Ashford JW (2004): ApoE genotype accounts for the vast majority of AD risk and AD pathology. Neurobiol Aging 25: 641-650

Reynolds ES (1963): The use of lead citrate at high $\mathrm{pH}$ as an electron-opaque stain in electron microscopy. J Cell Biol 17: 208-212

Rivers TM, Sprunt DH, Berry GP (1933): Obersations on Attempts to produce Acute Disseminated Encephalomyelitis in Monkeys. J Exp Med 58: 39-53

Roberds SL, Anderson J, Basi G, Bienkowski MJ, Branstetter DG, Chen KS, Freedman SB, Frigon NL, Games D, Hu K, et al. (2001): BACE knockout mice are healthy despite lacking the primary beta-secretase activity in brain: implications for Alzheimer's disease therapeutics. Hum Mol Genet 10: 1317-1324

Robles A (2009): [The complexes of degenerative dementias: an evolution from disease to spectrum]. Neurologia 24: 399-418

Rock RB, Gekker G, Hu S, Sheng WS, Cheeran M, Lokensgard JR, Peterson PK (2004): Role of Microglia in Central Nervous System Infections. Clin Microbiol Rev 17: 942-964

Rossner S, Apelt J, Schliebs R, Perez-Polo JR, Bigl V (2001): Neuronal and glial betasecretase (BACE) protein expression in transgenic Tg2576 mice with amyloid plaque pathology. J Neurosci Res $\underline{64}$ : 437-446

Rossner S, Lange-Dohna C, Zeitschel U, Perez-Polo JR (2005): Alzheimer's disease beta-secretase BACE1 is not a neuron-specific enzyme. J Neurochem 92: 226234

Saiki RK, Scharf S, Faloona F, Mullis KB, Horn GT, Erlich HA, Arnheim N (1985): Enzymatic amplification of beta-globin genomic sequences and restriction site analysis for diagnosis of sickle cell anemia. Science 230: 1350-1354 
Sandbrink R, Masters CL, Beyreuther K (1994): Beta A4-amyloid protein precursor mRNA isoforms without exon 15 are ubiquitously expressed in rat tissues including brain, but not in neurons. J Biol Chem 269: 1510-1517

Sannerud R, Declerck I, Peric A, Raemaekers T, Menendez G, Zhou L, Veerle B, Coen K, Munck S, De Strooper B, et al. (2011): ADP ribosylation factor 6 (ARF6) controls amyloid precursor protein (APP) processing by mediating the endosomal sorting of BACE1. Proc Natl Acad Sci USA 108: E559-568

Saunders AJ, Kim T-W, Tanzi RE (1999): BACE Maps to Chromosome 11 and a BACE Homolog, BACE2, Reside in the Obligate Down Syndrome Region of Chromosome 21. Science 286: 1255a-1255

Schneider A, Araújo GW, Trajkovic K, Herrmann MM, Merkler D, Mandelkow E-M, Weissert R, Simons M (2004): Hyperphosphorylation and aggregation of tau in experimental autoimmune encephalomyelitis. J Biol Chem 279: 55833-55839

Sherrington R, Rogaev EI, Liang Y, Rogaeva EA, Levesque G, Ikeda M, Chi H, Lin C, Li G, Holman K, et al. (1995): Cloning of a gene bearing missense mutations in early-onset familial Alzheimer's disease. Nature 375: 754-760

Simons M, De Strooper B, Multhaup G, Tienari PJ, Dotti CG, Beyreuther K (1996): Amyloidogenic processing of the human amyloid precursor protein in primary cultures of rat hippocampal neurons. J Neurosci 16: 899-908

Simons M, Trotter J (2007): Wrapping it up: the cell biology of myelination. Curr Opin Neurobiol 17: 533-540

Sinha S, Anderson JP, Barbour R, Basi GS, Caccavello R, Davis D, Doan M, Dovey HF, Frigon N, Hong J, et al. (1999): Purification and cloning of amyloid precursor protein beta-secretase from human brain. Nature 402: 537-540

Skripuletz T, Lindner M, Kotsiari A, Garde N, Fokuhl J, Linsmeier F, Trebst C, Stangel $M$ (2008): Cortical demyelination is prominent in the murine cuprizone model and is strain-dependent. Am J Pathol 172: 1053-1061

Smith KJ, Blakemore WF, McDonald WI (1979): Central remyelination restores secure conduction. Nature 280: 395-396 
Solans A, Estivill X, La Luna S de (2000): A new aspartyl protease on 21q22.3, BACE2, is highly similar to Alzheimer's amyloid precursor protein betasecretase. Cytogenet Cell Genet 89: 177-184

Stachel SJ, Coburn CA, Steele TG, Jones KG, Loutzenhiser EF, Gregro AR, Rajapakse HA, Lai M-T, Crouthamel M-C, Xu M, et al. (2004): Structure-based design of potent and selective cell-permeable inhibitors of human beta-secretase (BACE1). J Med Chem 47: 6447-6450

Stidworthy MF, Genoud S, Suter U, Mantei N, Franklin RJM (2003): Quantifying the early stages of remyelination following cuprizone-induced demyelination. Brain Pathol 13: 329-339

Sussman CR, Vartanian T, Miller RH (2005): The ErbB4 neuregulin receptor mediates suppression of oligodendrocyte maturation. J Neurosci $\underline{25}$ : 57575762

Taniguchi T, Kawamata T, Mukai H, Hasegawa H, Isagawa T, Yasuda M, Hashimoto T, Terashima A, Nakai M, Mori H, et al. (2001): Phosphorylation of tau is regulated by PKN. J Biol Chem 276: 10025-10031

Tanzi RE, Gusella JF, Watkins PC, Bruns GA, St George-Hyslop P, Keuren ML Van, Patterson D, Pagan S, Kurnit DM, Neve RL (1987): Amyloid beta protein gene: cDNA, mRNA distribution, and genetic linkage near the Alzheimer locus. Science 235: 880-884

Taveggia C, Zanazzi G, Petrylak A, Yano H, Rosenbluth J, Einheber S, Xu X, Esper RM, Loeb JA, Shrager P, et al. (2005): Neuregulin-1 type III determines the ensheathment fate of axons. Neuron 47: 681-694

Taylor LC, Gilmore W, Ting JP-Y, Matsushima GK (2010): Cuprizone induces similar demyelination in male and female C57BL/6 mice and results in disruption of the estrous cycle. J Neurosci Res 88: 391-402

Treiber H, Hagemeyer N, Ehrenreich H, Simons M (2012): BACE1 in central nervous system myelination revisited. Mol Psychiatry 17: 237-239 
Vassar R, Bennett BD, Babu-Khan S, Kahn S, Mendiaz EA, Denis P, Teplow DB, Ross S, Amarante P, Loeloff R, et al. (1999): Beta-secretase cleavage of Alzheimer's amyloid precursor protein by the transmembrane aspartic protease BACE. Science 286: 735-741

Velanac V, Unterbarnscheidt T, Hinrichs W, Gummert MN, Fischer TM, Rossner MJ, Trimarco A, Brivio V, Taveggia C, Willem M, et al. (2012): Bace1 processing of NRG1 type III produces a myelin-inducing signal but is not essential for the stimulation of myelination. Glia $\underline{60}$ : 203-217

Virchow R (1854): Ueber das ausgebreitete Vorkommen einer dem Nervenmark analogen Substanz in den thierischen Geweben. Archiv f pathol Anat $\underline{6}$ : 562572

Weingarten MD, Lockwood AH, Hwo SY, Kirschner MW (1975): A protein factor essential for microtubule assembly. Proc Natl Acad Sci USA 72: 1858-1862

Willem M, Garratt AN, Novak B, Citron M, Kaufmann S, Rittger A, De Strooper B, Saftig P, Birchmeier C, Haass C (2006): Control of peripheral nerve myelination by the beta-secretase BACE1. Science $\underline{314}$ : 664-666

Wolfe MS (2012): $\gamma$-Secretase inhibitors and modulators for Alzheimer's disease. J Neurochem 120 Suppl 1: 89-98

Wong H-K, Sakurai T, Oyama F, Kaneko K, Wada K, Miyazaki H, Kurosawa M, De Strooper B, Saftig P, Nukina N (2005): beta Subunits of voltage-gated sodium channels are novel substrates of beta-site amyloid precursor protein-cleaving enzyme (BACE1) and gamma-secretase. J Biol Chem 280: 23009-23017

Wong PMC, Kang A, Chen H, Yuan Q, Fan P, Sultzer BM, Kan YW, Chung S-W (1999): Lpsd/Ran of endotoxin-resistant $\mathrm{C} 3 \mathrm{H} / \mathrm{HeJ}$ mice is defective in mediating lipopolysaccharide endotoxin responses. PNAS 96: 11543-11548

Yan R, Bienkowski MJ, Shuck ME, Miao H, Tory MC, Pauley AM, Brashier JR, Stratman NC, Mathews WR, Buhl AE, et al. (1999): Membrane-anchored aspartyl protease with Alzheimer's disease beta-secretase activity. Nature $\underline{402}$ : 533-537 
Yin X, Baek RC, Kirschner DA, Peterson A, Fujii Y, Nave K-A, Macklin WB, Trapp BD (2006): Evolution of a neuroprotective function of central nervous system myelin. J Cell Biol 172: 469-478

Zhang H, Ma Q Zhang Y, Xu H (2012): Proteolytic processing of Alzheimer's $\beta$ amyloid precursor protein. J Neurochem 120 Suppl 1: 9-21

Zhao J, O'Connor T, Vassar R (2011): The contribution of activated astrocytes to A $\beta$ production: implications for Alzheimer's disease pathogenesis. J Neuroinflammation $\underline{8}: 150$

Zhou L, Chávez-Gutiérrez L, Bockstael K, Sannerud R, Annaert W, May PC, Karran E, De Strooper B (2011): Inhibition of beta-secretase in vivo via antibody binding to unique loops (D and F) of BACE1. J Biol Chem 286: 8677-8687 


\section{Danksagung}

Wir sind Zwerge auf den Schultern von Riesen - dieses Gleichnis gilt wohl insbesondere für Doktoranden. So haben zum Gelingen dieser Dissertation viele Menschen beigetragen. Bedanken möchte ich mich daher zunächst und vor allem bei meinem Doktorvater Prof. Dr. M. Simons, Max-Planck-Institut für Experimentelle Medizin Göttingen, der mir dieses Thema überlassen und mich während aller Höhen und Tiefen begleitet hat. Bedanken möchte ich mich auch bei allen Mitgliedern der AG Simons, ohne die diese Arbeit nicht möglich gewesen wäre. Ausdrücklich erwähnen möchte ich hier vor allem Dr. L. Yurlova und S. Schmitt, von denen ich die grundlegenden Labortechniken erlernte. G. Schulz danke ich für ihre unermüdliche Hilfe in der Zellkultur. Die Cuprizonestudie war nur durch die fruchtbare Kooperation mit Prof. Dr. Dr. H. Ehrenreich, Max-Planck-Institut für Experimentelle Medizin Göttingen, sowie Dr. N. Hagemeyer möglich. Ihnen gebührt mein besonderer Dank. S. Sperling möchte ich für die große Hilfe, die sie mir beim Erlernen von Histologietechniken war, danken. Die Elektronenmikroskopie war ein wesentlicher Teil meiner Arbeit. Diese komplexe Methode konnte ich nur durch die hervorragende Unterstützung von Dr. W. Möbius und T. Ruhwedel erlernen. Sie waren stets mein Fels in der Brandung. Neben diesen gab es unzählige kleine und größere Begegnungen am Max-Planck-Institut, die diese Arbeit und mich bereichert haben. Ich möchte mich daher ausdrücklich bei allen Mitarbeitern des Max-Planck-Instituts für Experimentelle Medizin Göttingen bedanken. Auch möchte ich mich herzlich bei Prof. Dr. H. J. Steinfelder und Dr. K. Kusch bedanken, die weite Teile des Manuskriptes durchgesehen und mich vor so mancher Eselei bewahrt haben. Ihre selbstlose Unterstützung wird mir immer ein Vorbild bleiben. Zuletzt gilt mein Dank auch der Medizinischen Fakultät der Universität Göttingen, die diese Promotion durch ein Stipendium im Rahmen von Gö4med unterstützte. 